Improving oocyte competence in dairy cows exposed to heat stress

Hansen, P.J. University of Florida Board of Trustees FL

Roth, Z. The Hebrew University of Jerusalem

Block, J.J. University of Florida Board of Trustees FL

Project award year: 2014

Three year research project 


\begin{abstract}
Original Objectives. The overall goal is to develop methods to increase pregnancy rate in lactating dairy cows exposed to heat stress through methods that minimize damage to the oocyte and embryo caused by heat stress. Objectives were as follows: (1) examine the protective effects of melatonin on developmental competence of oocytes exposed to elevated temperature in vitro; (2) test whether melatonin feeding can improve developmental competence of oocytes in vivo and, if so, whether effects are limited to the summer or also occur in the absence of heat stress; and (3) evaluate the effectiveness of improving fertility by facilitating follicular turnover in the summer and winter.
\end{abstract}

Revised Objectives. (1) Examine protective effects of melatonin and follicular fluid on developmental competence of oocytes exposed to elevated temperature in vitro; (2) examine the protective effects of melatonin on developmental competence of embryos exposed to elevated temperature in vitro; (3) evaluate effectiveness of improving fertility by administering human chorionic gonadotropin (hCG) to increase circulating concentrations of progesterone and evaluate whether response to hCG depends upon genotype for four mutations reported to be related to cow fertility; and (4) identify genes with allelic variants that increase resistance of embryos to heat shock.

Background. The overall hypothesis is that pregnancy success is reduced by heat stress because of damage to the oocyte and cleavage-stage embryo mediated by reactive oxygen species (ROS), and that fertility can be improved by provision of antioxidants or by removing follicles containing oocytes damaged by heat stress. During the study, additional evidence from the literature indicated the potential importance of treatment with chorionic gonadotropin to increase fertility of heatstressed cows and results from other studies in our laboratories implicated genotype as an important determinant of cow fertility. Thus, the project was expanded to evaluate hCG treatment and to identify whether fertility response to hCG depended upon single nucleotide polymorphisms (SNP) in genes implicated as important for cow fertility. We also evaluated whether a SNP in a gene important for cellular resistance to heat stress (HSPA1L, a member of the heat shock protein 70 family) is important for embryonic resistance to elevated temperature.

Major conclusions, solutions \& achievements. Results confirmed that elevated temperature increases ROS production by the oocyte and embryo and that melatonin decreases ROS. Melatonin reduced, but did not completely block, damaging effects of heat shock on the oocyte and had no effect on development of the embryo. Melatonin was protective to the oocyte at $0.1-1 \mu \mathrm{M}$, a concentration too high to be achieved in cows. It was concluded that melatonin is unlikely to be a useful molecule for increasing fertility of heat-stressed cows. Treatment with hCG at day 5 after breeding increased first-service pregnancy rate for primiparous cows but not for multiparous cows. Thus, hCG could be useful for increasing fertility in first-parity cows. The effectiveness of hCG depended upon genotype for a SNP in $\mathrm{COQ}^{9}$, a gene encoding for a mitochondrial-function protein. This result points the way to future efforts to use genetic information to identify populations of cows for which hormone treatments will be effective or ineffective. The SNP in HSPA1L was related to embryonic survival after heat shock. Perhaps, genetic selection for mutations that increase cellular resistance to heat shock could be employed to reduce effects of heat stress on fertility.

Implications, both scientific and agricultural. This project has resulted in abandonment of one possible approach to improve fertility of the heat-stressed cow (melatonin therapy) while also leading to a method for improving fertility of primiparous cows exposed to heat stress (hCG treatment) that can be implemented on farms today. Genetic studies have pointed the way to using genetic information to 1) tailor hormonal treatments to cow populations likely to respond favorably and 2) select animals whose embryos have superior resistance to elevated body temperatures. 


\section{Summary Sheet}

\section{Publication Summary}

\begin{tabular}{|c|c|c|c|}
\hline PubType & IS only & Joint & US only \\
\hline Book Chapter & 0 & 0 & 1 \\
\hline Reviewed & 0 & 1 & 1 \\
\hline Submitted & 0 & 1 & 1 \\
\hline
\end{tabular}

\section{Training Summary}

\begin{tabular}{|c|c|c|c|c|}
\hline Trainee Type & Last Name & First Name & Institution & Country \\
\hline M.Sc. Student & Shik-Lang & Yael & Hebrew University & Israel \\
\hline Ph.D. Student & Ortega & Sofia & University of Florida & USA \\
\hline Ph.D. Student & Nathalia & Rocha & University of Florida & USA \\
\hline M.Sc. Student & Grosman & Sofia & Hebrew University of Jerusalem & Israel \\
\hline M.Sc. Student & Ortiz & William & University of Florida & USA \\
\hline Ph.D. Student & Estrada-Cortes & Eliab & University of Florida & USA \\
\hline Ph.D. Student & Sosa & Froylan & Cornell University & USA \\
\hline Ph.D. Student & Rodriques & Thais & University of Florida & USA \\
\hline Postdoctoral Fellow & Tuna & Kubra & University of Florida & USA \\
\hline M.Sc. Student & Sacchenco & Ilya & Hebrew University & Israel \\
\hline Ph.D. Student & Cavallari de Castro & Fernanda & University of Florida & USA \\
\hline M.Sc. Student & Simoni & Chen & Hebrew University & Israel \\
\hline
\end{tabular}




\section{Contribution of Collaboration}

This project represents a synergistic collaboration between two research groups who each bring unique resources to bear on an agricultural problem of importance to both Israel and the United States. Drs. Hansen and Roth have jointly been performing research on improving fertility in heatstressed cows since 2002. Their collaboration has been based on shared interests, friendship, and perceived opportunities for doing joint research that allows both to benefit from the unique resources available to each separately. Dr. Hansen has an excellent relationship with the dairy industry in Florida and south Georgia and has the capability of using commercial dairies for performing large-scale embryo transfer studies. Dr. Roth is skilled in the transvaginal, ultrasoundguided aspiration of follicles. The experiments involved a course of research that is integrated between both research laboratories. For example, experiments for Objective 1 were performed in both laboratories. There has been frequent communication between laboratories. 


\section{ACHIEVEMENTS}

\section{Effectiveness of melatonin for protecting the oocyte and embryo (Revised Obj. 1 and 2)}

Experiments in both Israel and the USA evaluated thermoprotective effects of melatonin. For both the oocyte and zygote, culture at elevated temperature $\left(41.0\right.$ or $41.5^{\circ} \mathrm{C}$ for oocytes and $40^{\circ} \mathrm{C}$ for zygotes) increased ROS production and 0.1-1.0 $\mu \mathrm{M}$ melatonin blocked this effect (see Figure 1 for

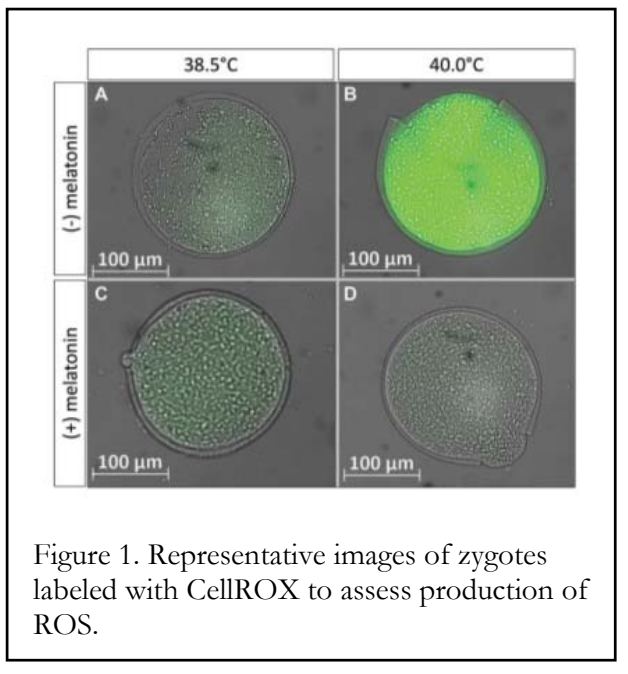
representative effects). Melatonin $(1.0 \mu \mathrm{M})$ improved developmental competence of oocytes that were either matured at $41^{\circ} \mathrm{C}$ for $14 \mathrm{~h}$ or exposed to the pro-oxidant menadione. In particular, melatonin prevented negative effects of heat shock or menadione on the proportion of oocytes that cleaved after fertilization and the proportion of cleaved embryos that developed to the blastocyst stage. When the incubation temperature was raised to $41.5^{\circ} \mathrm{C}$ and duration of heat shock was increased to $22 \mathrm{~h}, 0.1 \mu \mathrm{M}$ melatonin was less able to maintain developmental competence. Melatonin increased the proportion of heat-shocked oocytes that completed nuclear maturation (as measured by the proportion of oocytes at meiosis II) but did not block the effect of

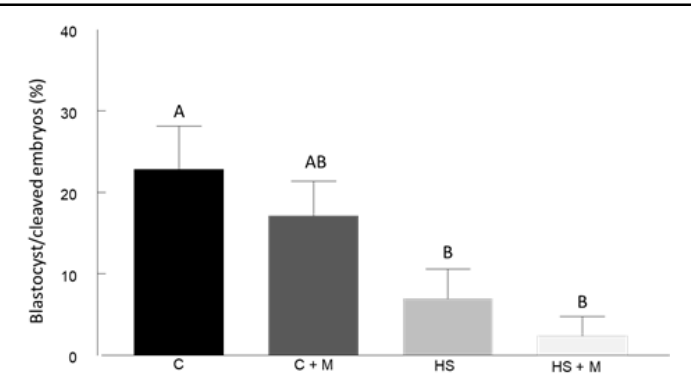

Figure 2. Effect of $0.1 \mu \mathrm{M}$ melatonin (M) during oocyte maturation on competence of embryos derived from control (C) or heat-shocked (HS) oocytes to develop to the blastocyst stage. The HS was $41.5^{\circ} \mathrm{C}$ for $22 \mathrm{~h}$. Data are means $\pm \mathrm{SEM}$.

Different letters indicate significant differences at $\mathrm{P}<0.05$. heat shock on proportion of matured oocytes that cleaved after fertilization or that subsequently developed to the blastocyst stage (see Figure 2).

The 1-cell embryo (zygote) is very sensitive to heat shock - exposure to temperatures as low as $40^{\circ} \mathrm{C}$ are sufficient to arrest development. We found that addition of $1.0 \mu \mathrm{M}$ melatonin to culture medium of zygotes exposed to $40.0^{\circ} \mathrm{C}$ for $12 \mathrm{~h}$ did not block the negative effect of heat shock on development (not shown).

It should be noted that the concentrations of melatonin that were effective in reducing effects of $41.0^{\circ} \mathrm{C}$ on developmental competence of oocytes $(1.0 \mu \mathrm{M})$ were much higher than could reasonably be achieved through melatonin administration by injection, implants, or feeding. Indeed, concentrations of melatonin in the blood of cows treated with 12 melatonin implants was in the 
picomolar range (Garcia-Ispierto et al., Reprod Domest Anim 2013;48:577-583). Additional experiments from our laboratories indicated that treatment of oocytes with melatonin at

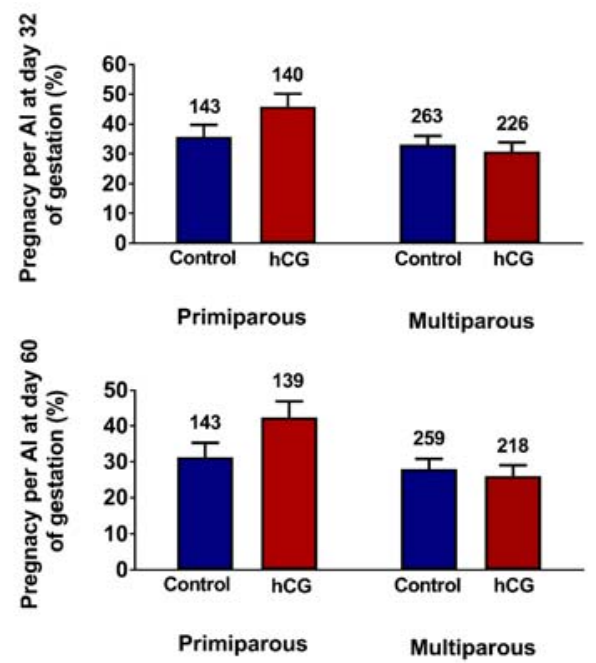

Figure 3. Effect of hCG on fertility. Values are leastsquares means \pm SEM of pregnancy per AI after TAI. Effect of hCG treatment on pregnancy per AI of primiparous (top) and multiparous cows (bottom). There was a tendency for a treatment $\mathrm{x}$ parity interaction on $\mathrm{d} 32(\mathrm{P}=0.098)$ and $\mathrm{d} 60(\mathrm{P}=0.063)$ of gestation, with hCG increasing pregnancy per $\mathrm{AI}$ in primiparous cows but not in multiparous cows. concentrations less than $1.0 \mu \mathrm{M}$ were without effect on oocyte developmental competence. Based on these results, the decision was made to abandon efforts to use melatonin to improve fertility.

We have also initiated experiments to determine whether follicular fluid contains molecules that can protect the oocyte from heat shock. Results indicate that exosomes in follicular fluid can reduce effects of heat shock on the maturing oocyte. This work may lead to new methods for protecting oocytes from heat shock.

Interactions between $h C G$ and genotype on fertility during heat stress (Rev. Obj. 3)

Treatment with hCG at day 5 after artificial insemination (AI) has been reported to improve pregnancy per AI in lactating cows but there is much variation in treatment effectiveness (Nascimento et al., J. Dairy Sci. 2013; 96:2873-2882.). Season of the year may be an important determinant of effectiveness of hCG because heat stress can decrease circulating concentrations of progesterone (Howell et al., J. Dairy Sci. 1994; 77:735-739) and treatment with the related molecule, equine chorionic gonadotropin, at day 5 after AI improved pregnancy per AI in lactating cows exposed to heat stress (Garcia-Ispierto et al., Reprod Domest Anim 2013;48:577-83). For Objective 3 , we tested whether fertility response to hCG in lactating Holsteins cows interacts with genotype and parity. Primiparous $(n=538)$ and multiparous $(n=613)$ cows were treated with hCG $(3,300 \mathrm{IU})$ or vehicle $5 \mathrm{~d}$ after AI. Pregnancy was diagnosed on days 32 and 60 after artificial insemination (AI). A subset of cows ( $n=593-701)$ were genotyped for four SNP previously associated with fertility. Treatment with hCG increased progesterone concentration on day 12 after AI regardless of genotype or parity. Treatment with hCG tended to increase pregnancy per AI in primiparous cows but not in multiparous cows (Figure 3).

Moreover, hCG treatment interacted with a SNP in COQ9 to affect fertility (Figure 4). Treatment with hCG increased pregnancy rate in AG cows (heterozygotes), decreased pregnancy rate in AA 
cows and had no effect in GG cows. Stated differently, among cows treated with vehicle, AA cows had the highest pregnancy per AI at d 32 and 60 of gestation wherease, among hCG-treated cows, pregnancy per AI was lowest in AA cows. Pregnancy per AI was also affected by genotype for HSPA1L and PGR, but there were no interactions with treatment. Genotype for a SNP in PARM1 was not associated with fertility. Overall, results show that variation in response to hCG treatment on fertility depends on parity and interacts with a SNP in COQ9.

\section{Identify genes that increase resistance of embryos to heat shock (Revised Objective 4).}

As illustrated in results from the previous experiment, the SNP in HSPA1L is important for dairy cow fertility. This SNP, located in the promoter, controls the expression level of the gene, which encodes for a heat shock protein important for cell survival to stress. To test whether this SNP affects embryonic resistance to heat shock, we genotyped blastocysts derived from zygotes exposed to $40^{\circ} \mathrm{C}$ for $12 \mathrm{~h}$ and compared the frequency of HSPA1L alleles to that of blastocysts derived from
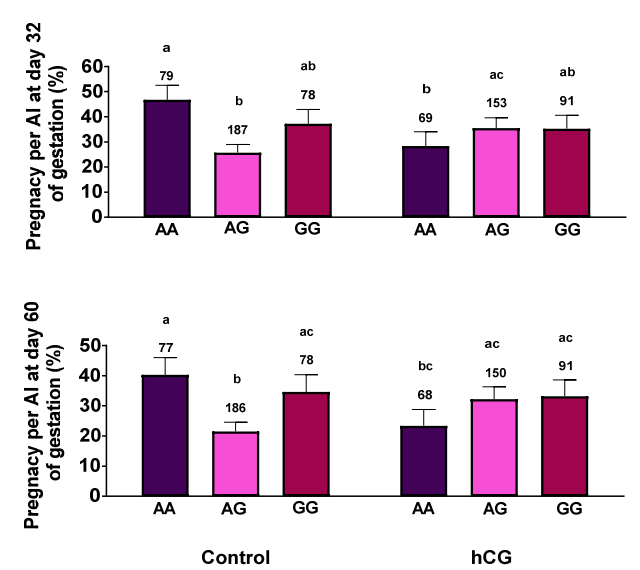

Figure 4. Effect of COQ9 genotype on the response to hCG treatment on pregnancy per AI. Values are leastsquares means \pm SEM of pregnancy per AI after TAI. There was a significant interaction between treatment with hCG and genotype for COQ9 on d $32[\mathrm{P}=0.016$ (top)] and d $60[\mathrm{P}=0.012$ (bottom)] of gestation. Bars with different superscripts differ $(\mathrm{P}<0.05)$. embryos not exposed to heat shock. Embryos were cultured in either low oxygen or high oxygen environments (high oxygen increases ROS production). The distribution of blastocysts according to the three genotypes (CC, CD (deletion), and DD) was affected by genotype $\mathrm{x}$ temperature $x$ oxygen $(\mathrm{P}=0.0054)$. Frequency of the $\mathrm{D}$ allele (associated with higher expression of HSPA1L) was lower for blastocysts cultured at $38.5^{\circ} \mathrm{C}$ in low oxygen than for blastocysts produced under other conditions (not shown). This result suggests that inheritance of the $\mathrm{D}$ allele makes embryos better able to survive stressful conditions such as heat shock and a high oxygen environment.

\section{Agricultural and Economic Impacts}

This project has resulted in a method for improving fertility of primiparous cows exposed to heat stress (hCG treatment) that can be implemented on farms today. Genetic studies have pointed the way to using genetic information to 1) tailor hormonal treatments to cow populations likely to respond favorably and 2) select animals whose embryos have superior resistance to elevated body temperatures. 


\section{Changes to Original Research Plan}

The overall goal is to develop methods to increase pregnancy rate in lactating dairy cows exposed to heat stress through methods that minimize damage to the oocyte and embryo caused by heat stress.

Original Objectives. (1) examine the protective effects of melatonin on developmental competence of oocytes exposed to elevated temperature in vitro; (2) test whether melatonin feeding can improve developmental competence of oocytes in vivo and, if so, whether effects are limited to the summer or also occur in the absence of heat stress; and (3) evaluate the effectiveness of improving fertility by facilitating follicular turnover in the summer and winter.

Revised Objectives. (1) Examine the protective effects of melatonin and follicular fluid on developmental competence of oocytes exposed to elevated temperature in vitro; (2) examine the protective effects of melatonin on developmental competence of embryos exposed to elevated temperature in vitro; (3) evaluate the effectiveness of improving fertility by administering human chorionic gonadotropin (hCG) to increase circulating concentrations of progesterone and evaluate whether response to hCG depends upon genotype for four mutations previously reported to be related to cow fertility; and (4) identify genes with allelic variants that increase resistance of embryos to heat shock.

Rationale. The overall hypothesis is that pregnancy success is reduced by heat stress because of damage to the oocyte and cleavage-stage embryo mediated by reactive oxygen species (ROS), and that fertility can be improved by provision of antioxidants or by removing follicles containing oocytes damaged by heat stress. During the study, additional evidence from the literature indicated the potential importance of treatment with chorionic gonadotropin to increase fertility of heatstressed cows and results from other studies in our laboratories implicated genotype as an important determinant of cow fertility. Thus, the project was expanded to evaluate hCG treatment and to identify whether fertility response to hCG depended upon single nucleotide polymorphisms (SNP) in genes implicated as important for cow fertility. We also evaluated whether a SNP in a gene important for cellular resistance to heat stress (HSPA1L, a member of the heat shock protein 70 family) is important for embryonic resistance to elevated temperature. Finally, we conducted an experiment suggesting the existence of thermoprotective molecules in exosomes located in follicular fluid. 
Publications for Project US-4709-14

\begin{tabular}{|c|c|c|c|c|c|c|}
\hline $\begin{array}{l}\text { Stat } \\
\text { us }\end{array}$ & Type & Authors & Title & Journal & $\begin{array}{l}\text { Vol:pg } \\
\text { Year }\end{array}$ & $\begin{array}{c}\text { Cou } \\
\text { n }\end{array}$ \\
\hline Published & Reviewed & $\begin{array}{l}\text { Ortega, M.S., } \\
\text { Rocha-Frigoni, } \\
\text { N.A.S., Mingoti, } \\
\text { G.Z., Roth, Z., and } \\
\text { Hansen, P.J. }\end{array}$ & $\begin{array}{l}\text { Modification of embryonic } \\
\text { resistance to heat shock in cattle } \\
\text { by melatonin and genetic } \\
\text { variation in HSPA1L }\end{array}$ & $\begin{array}{c}\text { Journal of Dairy } \\
\text { Science }\end{array}$ & $\begin{array}{l}99: 9152- \\
91642016\end{array}$ & Joint \\
\hline Published & $\begin{array}{c}\text { Book } \\
\text { Chapter }\end{array}$ & Hansen, P.J. & $\begin{array}{l}\text { Physiological approaches to } \\
\text { improving fertility during heat } \\
\text { stress. }\end{array}$ & $\begin{array}{c}\text { Large Herd Dairy } \\
\text { Management, 3rd } \\
\text { Ed. }\end{array}$ & $\begin{array}{l}\text { : in press } \\
2016\end{array}$ & US only \\
\hline Accepted & Reviewed & $\begin{array}{l}\text { Zolini, A.M., Ortiz, } \\
\text { W.G., Estrada- } \\
\text { Cortes, A., Ortega, } \\
\text { M.S., Dikmen, S., } \\
\text { Sosa, F., Giordano, } \\
\text { J.O., and Hansen, } \\
\text { P.J. }\end{array}$ & $\begin{array}{l}\text { Interactions of human chorionic } \\
\text { gonadotropin with genotype and } \\
\text { parity on fertility responses of } \\
\text { lactating dairy cows. }\end{array}$ & $\begin{array}{l}\text { Journal of Dairy } \\
\text { Science }\end{array}$ & : & US only \\
\hline Submitted & Reviewed & $\begin{array}{l}\text { Cavallari de Castro, } \\
\text { F., Lima Verde } \\
\text { Leal, C., Roth, Z., } \\
\text { and Hansen, P.J. }\end{array}$ & $\begin{array}{l}\text { Effects of melatonin on } \\
\text { production of reactive oxygen } \\
\text { species and developmental } \\
\text { competence of bovine oocytes } \\
\text { exposed to heat shock and } \\
\text { oxidative stress during in vitro } \\
\text { maturation. }\end{array}$ & $\begin{array}{l}\text { Molecular } \\
\text { Reproduction and } \\
\text { Development }\end{array}$ & : & Joint \\
\hline Submitted & Reviewed & $\begin{array}{l}\text { Rodriques, T.A., } \\
\text { Tuna, K.M., Alli, } \\
\text { A.A., Tribulo, P., } \\
\text { Hansen, P.J., Koh, } \\
\text { J., and Paul-Lopes, } \\
\text { F.F. }\end{array}$ & $\begin{array}{l}\text { Follicular fluid exosomes act on } \\
\text { the bovine oocyte to improve } \\
\text { oocyte competence to support } \\
\text { development and survive heat } \\
\text { shock. }\end{array}$ & $\begin{array}{l}\text { Reproduction } \\
\text { Fertility and } \\
\text { Development }\end{array}$ & : & US only \\
\hline
\end{tabular}




\title{
Modification of embryonic resistance to heat shock in cattle by melatonin and genetic variation in HSPA1L
}

\author{
M. Sofia Ortega, ${ }^{*}$ Nathália A. S. Rocha-Frigoni,†‡ Gisele Zoccal Mingoti,†‡ Zvi Roth,§ and Peter J. Hansen*1 \\ ${ }^{*}$ Department of Animal Sciences, D.H. Barron Reproductive and Perinatal Biology Research Program and Genetics Institute, University of Florida, \\ Gainesville 32611-0910 \\ †School of Veterinary Medicine, Laboratory of Reproductive Physiology, Universidade Estadual Paulista, Araçatuba, SP 16050-680, Brazil \\ ¥ Graduate Program in Veterinary Medicine, School of Agrarian and Veterinary Sciences, Department of Animal Reproduction, \\ Universidade Estadual Paulista, Jaboticabal, SP 16050-680, Brazil \\ §Department of Animal Sciences, Robert H. Smith Faculty of Agriculture, Food and Environment, The Hebrew University, Rehovot 76100, Israel
}

\begin{abstract}
The objectives were to test whether (1) melatonin blocks inhibition of embryonic development caused by heat shock at the zygote stage, and (2) the frequency of a thermoprotective allele for HSPA1L is increased in blastocysts formed from heat-shocked zygotes as compared with blastocysts from control zygotes. It was hypothesized that melatonin prevents effects of heat shock on development by reducing accumulation of reactive oxygen species (ROS) and that embryos inheriting the thermoprotective allele of $H S P A 1 L$ would be more likely to survive heat shock. Effects of $1 \mu M$ melatonin on ROS were determined in experiments 1 and 2. Zygotes were cultured at 38.5 or $40^{\circ} \mathrm{C}$ for $3 \mathrm{~h}$ in the presence of CellROX reagent (ThermoFisher Scientific, Waltham, MA). Culture was in a low $[5 \%$ (vol/ vol)] oxygen (experiment 1) or low or high [21\% (vol/ vol)] oxygen environment (experiment 2). Heat shock and high oxygen increased ROS; melatonin decreased ROS. Development was assessed in experiments 3 and 4. In experiment 3 , zygotes were cultured in low oxygen $\pm 1 \mu M$ melatonin and exposed to 38.5 or $40^{\circ} \mathrm{C}$ for $12 \mathrm{~h}$ (experiment 1 ) beginning $8 \mathrm{~h}$ after fertilization. Melatonin did not protect the embryo from heat shock. Experiment 4 was performed similarly except that temperature treatments $\left(38.5\right.$ or $\left.40^{\circ} \mathrm{C}, 24 \mathrm{~h}\right)$ were performed in a low or high oxygen environment $(2 \times 2$ $\times 2$ factorial design with temperature, melatonin, and oxygen concentration as main effects), and blastocysts were genotyped for a deletion $(\mathrm{D})$ mutation $(\mathrm{C} \rightarrow \mathrm{D})$ in the promoter region of $H S P A 1 L$ associated with thermotolerance. Heat shock decreased percent of zygotes developing to the blastocyst stage independent of mela-
\end{abstract}

Received May 24, 2016.

Accepted August 2, 2016.

${ }^{1}$ Corresponding author: pjhansen@ufl.edu tonin or oxygen concentration. Frequency of genotypes for $H S P A 1 L$ was affected by oxygen concentration and temperature, with an increase in the $\mathrm{D}$ allele for blastocysts that developed in high oxygen and following heat shock. It was concluded that (1) lack of effect of melatonin or oxygen concentration on embryonic development means that the negative effects of heat shock on the zygote are not mediated by ROS, (2) previously reported effect of melatonin on fertility of heat-stressed cows might involve actions independent of the antioxidant properties of melatonin, and (3) the deletion mutation in the promoter of HSPA1L confers protection to the zygote from heat shock and high oxygen. Perhaps, embryonic survival during heat stress could be improved by selecting for thermotolerant genotypes. Key words: heat shock, melatonin, reactive oxygen species, HSPA1L

\section{INTRODUCTION}

In lactating dairy cattle, environmental temperatures as low as 23 to $29^{\circ} \mathrm{C}$ can lead to hyperthermia (Sartori et al., 2002; Dikmen and Hansen, 2009). Increases in body temperature to around $39^{\circ} \mathrm{C}$ are associated with reduced pregnancy rates (Gwazdauskas et al., 1973) and therefore pregnancy rates per AI decline during period of heat stress (Hansen and Aréchiga, 1999; Flamenbaum and Galon, 2010). One of the actions of heat stress responsible for lower fertility are actions on oocyte maturation (Putney et al., 1989), fertilization (Sartori et al., 2002), and early embryonic development (Ealy et al., 1993). Embryos are particularly susceptible to the effects of heat stress in vivo and exposure to elevated temperature in vitro during early stages of development, from the 1-cell through 4-cell stages of development (Ealy et al., 1995; Edwards and Hansen, 1997; Sakatani et al., 2012).

One of the proposed mechanisms by which heat stress can damage the oocyte and the embryo is through pro- 
duction of reactive oxygen species (ROS). Exposure of the oocyte and embryo to elevated temperatures can increase ROS production (Sakatani et al., 2004; Nabenishi et al., 2012b). Some antioxidants have been reported to reduce effects of heat shock in cultured embryos including anthocyanin (Sakatani et al., 2007) and dithiothreitol (de Castro e Paula and Hansen, 2008), whereas others such as glutathione (Ealy et al., 1995) and vitamin E (Paula-Lopes et al., 2003a) had little effect on embryo susceptibility to heat shock. Recently, it has been reported that supplementation of melatonin to oocytes exposed to heat shock during the maturation period reduced negative effects of heat shock (CebrianSerrano et al., 2013). Moreover, administration of slowrelease implants of melatonin to lactating cows exposed to heat stress improved fertility (Garcia-Ispierto et al., 2013b).

Genetic effects also occur on resistance of the embryo to heat shock, as is evidenced by the observation that heat shock reduced development of bovine embryos from thermotolerant breeds less than for less adapted breeds (Paula-Lopes et al., 2003b; Eberhardt et al., 2009; Silva et al., 2013). One family of genes involved in cellular thermoprotection is the heat shock protein 70 (HSP70) family (Christians et al., 2003). In the cow, 2 HSP70 genes exist: HSPA1A and HSPA1L. Reversetranscription PCR using primers that do not distinguish between the 2 genes indicated that heat shock can increase transcription of $H S P A 1 A / A 1 L$ as early as the 2-cell stage (Chandolia et al., 1999; Sakatani et al., 2012). A mutation in the promoter region of $H S P A 1 L$ (Rosenkrans et al., 2010; Ortega et al., 2016) that results in a deletion of a cytosine $(\mathbf{C})$ has been associated with thermotolerance in peripheral blood mononuclear cells exposed to heat stress (Basiricò et al., 2011). The same mutation has been associated with superior embryonic development to the blastocyst stage in cultured embryos (Cochran et al., 2013). It is possible, therefore, that inheritance of this allele can increase embryonic resistance to heat shock.

The objective of this study was to determine if the deleterious effects of exposure of bovine embryos to heat shock at the zygote stage of development is modified by melatonin or inheritance of the deletion (D) allele of $H S P A 1 L$. The effect of melatonin was tested by evaluating whether its addition to culture medium would reduce effects of heat shock on production of ROS and inhibition of embryonic development. The effect of $H S P A 1 L$ genotype was determined indirectly by testing whether the allele frequency of the D allele (the putative thermotolerant allele) would be greater in blastocysts developing after exposure to heat shock than for blastocysts not exposed to heat shock.

\section{MATERIALS AND METHODS}

\section{In Vitro Production of Embryos}

Ovaries were obtained from Central Packing Co. (Center Hill, FL) from cattle of Bos taurus and various admixtures of B. taurus and Bos indicus breeds. The surface of each ovary was cut with a scalpel to harvest immature cumulus-oocyte complexes (COC) from follicles 2 to $8 \mathrm{~mm}$ in diameter into oocyte washing medium (BoviPRO), which contained salts, bicarbonate, HEPES, DL-lactic acid, and BSA and was purchased from MOFA Global (Verona, WI). The COC were washed and those having uniform cytoplasm and at least 3 layers of cumulus cells were matured in groups of 10 in $50-\mu \mathrm{L}$ droplets of oocyte maturation medium (composition of all media is presented in Supplemental Table S1; http://dx.doi.org/10.3168/jds.2016-11501) covered with mineral oil for $21 \mathrm{~h}$ at $38.5^{\circ} \mathrm{C}$ in a humidified atmosphere of $5 \%$ (vol/vol) $\mathrm{CO}_{2}$. For each replicate, up to $300 \mathrm{COC}$ were matured. After maturation, COC were washed 3 times in HEPES-TALP (Tyrode's albumen lactate pyruvate) medium and placed in a $35-\mathrm{mm}$ dish containing $1.7 \mathrm{~mL}$ of fertilization medium (IVFTALP). Insemination of each replicate of fertilization was performed with semen pooled from 3 individual bulls of various taurine breeds (the total number of bulls were 29). Sperm were purified from frozen-thawed straws of extended semen using an Isolate gradient [Irvine Scientific, Santa Ana, CA; 50\% (vol/vol) and 90\% (vol/vol) isolate] and diluted in IVF-TALP to achieve a final concentration of $1 \times 10^{6} / \mathrm{mL}$ in the fertilization dish. In addition, $80 \mu \mathrm{L}$ of penicillamine-hypotaurineepinephrine solution was added to each fertilization well to improve sperm motility and promote fertilization. Fertilization proceeded for 8 to $9 \mathrm{~h}$ at $38.5^{\circ} \mathrm{C}$ in a humidified atmosphere of $5 \%$ (vol/vol) $\mathrm{CO}_{2}$.

Putative zygotes (i.e., oocytes exposed to sperm) were denuded from the surrounding cumulus cells at the end of fertilization by vortexing groups of 200 to 300 putative zygotes for $5 \mathrm{~min}$ in $600 \mu \mathrm{L}$ of HEPESTALP containing $10,000 \mathrm{U} / \mathrm{mL}$ of hyaluronidase. Unless otherwise stated, embryos were cultured in groups of $25-30 / 50 \mu \mathrm{L}$ microdrops of culture medium (SOF$\mathrm{BE} 2$ ) prepared with or without $1 \mu M$ melatonin (Santa Cruz Biotechnologies, Dallas, TX), which was dissolved directly in SOF-BE2. The microdrops were covered with mineral oil at $38.5^{\circ} \mathrm{C}$ in a humidified atmosphere of $5 \%(\mathrm{vol} / \mathrm{vol}) \mathrm{O}_{2}$ and $5 \%$ (vol/vol) $\mathrm{CO}_{2}$ with the balance $\mathrm{N}_{2}$. When embryos were heat shocked, culture was performed under either high oxygen conditions $\left[40.0^{\circ} \mathrm{C}\right.$ in a humidified atmosphere of $6 \%$ (vol/vol) $\mathrm{CO}_{2}$ and atmospheric oxygen] or low oxygen conditions $\left[40.0^{\circ} \mathrm{C}\right.$ 
in a humidified atmosphere of $5 \%$ (vol/vol) $\mathrm{O}_{2}$ and $6 \%$ (vol/vol) $\mathrm{CO}_{2}$ with the balance as $\mathrm{N}_{2}$ ]. The increase in $\mathrm{CO}_{2}$ for heat shock was to account for its reduced solubility at a higher temperature. Heat shock was initiated $8 \mathrm{~h}$ after insemination (at the end of fertilization) and proceeded for 3,12 , or $24 \mathrm{~h}$. Afterward, heat-shocked embryos were examined for ROS production $(3 \mathrm{~h})$ or were returned to the same environment as the embryos not exposed to heat shock [38.5, 5\% (vol/vol) $\mathrm{O}_{2}$ and $5 \%$ (vol/vol) $\mathrm{CO}_{2}$ in a humidified incubator with the balance $\mathrm{N}_{2}$.

Percentage of putative zygotes that cleaved was determined at Day 3 of development (Day $0=$ day of fertilization) and the percentage of putative zygotes and cleaved embryos that became blastocysts was determined at Day 7 of development.

\section{Detection of Reactive Oxygen Species}

Production of ROS by embryos was determined by incubating putative zygotes for $3 \mathrm{~h}$ in SOF-BE2 containing $5 \mu M$ CellROX green reagent (ThermoFisher Scientific, Waltham, MA). This reagent is a cellpermeant dye that exhibits bright green photostable fluorescence upon oxidation and subsequent binding to DNA. After incubation with CellROX, embryos were washed 3 times in $50-\mu \mathrm{L}$ droplets of Dulbecco's phosphate-buffered saline (DPBS) containing 1\% (wt/ vol) polyvinylpyrrolidone (PVP), fixed in $4 \%$ (wt/vol) paraformaldehyde in DPBS, washed 3 additional times in DPBS-PVP and mounted in groups of 10 embryos on microscope slides using Prolong Gold anti-fade reagent (Invitrogen, Carlsbad, CA). Embryos were examined for fluorescence within $10 \mathrm{~h}$ after labeling by fluorescence microscopy using a green emission filter with a Zeiss Axioplan 2 epifluorescence microscope (Zeiss, Göttingen, Germany). Digital images of each embryo were acquired using AxioVision software (v. 4.8.2, Zeiss, Peabody, MA) and a high-resolution black and white Zeiss Axiocam MRM digital camera. Analysis of the images was performed using ImageJ V. 1.48 (National Institutes of Health, Bethesda, MD). Net fluorescent intensity was calculated by obtaining the average pixel intensity of each embryo (obtained after manually drawing a boundary around the embryo) and subtracting the background intensity obtained from a region of the image not containing the embryo.

\section{Genotype Determination and Frequency}

Day 7 blastocysts were genotyped for a SNP in the promoter region of HSPA1L (UMD3.1.1 chr 23:27334005) in which a $\mathrm{C}$ is replaced by a deletion $(\mathrm{C} / \mathrm{D}$ mutation; Rosenkrans et al., 2010; Supplemental Figure S1; http://dx.doi.org/10.3168/jds.2016-11501). Blastocysts were washed 3 times in PBS-PVP and the zona pellucida denuded using $0.1 \%$ (wt/vol) protease from Streptococcus griseus. After further washing, embryos were placed individually in wells of 96-well plates with $5 \mu \mathrm{L}$ of molecular biology-grade water for subsequent genotyping by PCR using an anchored KASP by design assay (LGC Genomics, Middlesex, UK). The assay is a PCR-based technique involving a common reverse primer and 2 allele-specific forward primers, with one bound to fluorescein amidite (FAM) and the second to hexachlorofluorescein (HEX) to produce genotypespecific PCR products. The primer sequences $\left(5^{\prime} \rightarrow 3^{\prime}\right)$ to target each allele were CAAGTCCTGCCCCCTGCFAM for the deletion allele and CTCAAGTCCTGCCCCCTGG-HEX for the $\mathrm{C}$ allele. The common reverse primer was GCATCCAGGGCGCTGATTGGTT. Each PCR reaction included $5 \mu \mathrm{L}$ of embryo resuspended in molecular biology-grade water, $5 \mu \mathrm{L}$ of $2 \times$ supermix with low ROX (LGC Genomics), and $0.14 \mu \mathrm{L}$ of KASP by design primer mix. Amplification and analysis were performed using a CFX96 Real-Time PCR detection System (Bio-Rad, Hercules, CA); thermal cycling conditions were $94^{\circ} \mathrm{C}$ for $15 \mathrm{~min}$, followed by 10 cycles of $94^{\circ} \mathrm{C}$ for $20 \mathrm{~s}$ and $61^{\circ} \mathrm{C}$ for $60 \mathrm{~s}$, where the second temperature was decreased $0.6^{\circ} \mathrm{C}$ per cycle to achieve a final annealing temperature of $55^{\circ} \mathrm{C}$ at the end of the 10th cycle. The reaction proceeded for an additional 26 cycles of $94^{\circ} \mathrm{C}$ for $20 \mathrm{~s}$ and $55^{\circ} \mathrm{C}$ for $60 \mathrm{~s}$, and a read step of $37^{\circ} \mathrm{C}$ for $60 \mathrm{~s}$. To improve genotype cluster visibility, 3 additional cycles of $94^{\circ} \mathrm{C}$ for $20 \mathrm{~s}$ and $55^{\circ} \mathrm{C}$ for $60 \mathrm{~s}$ and a final read step at $37^{\circ} \mathrm{C}$ for $60 \mathrm{~s}$ were performed. In each run, DNA samples from whole blood of cows of known genotypes were analyzed as controls. Determination of the genotype was performed using the allelic discrimination feature of the CFX96 machine. A representative output is shown in Figure 1.

\section{Experiments}

Experiment 1 was performed to determine (1) if exposure to heat shock increased ROS production in the embryo, and (2) whether melatonin blocked ROS production. The experiment was a $2 \times 2$ factorial design including 2 temperature treatments (38.5 and $40^{\circ} \mathrm{C}$ ) and 2 melatonin concentrations (0 and $\left.1 \mu M\right)$. Putative zygotes were produced from a single in vitro production of embryos (IVP) procedure involving embryos produced by fertilization with semen pooled from 3 bulls. Groups of putative zygotes supplemented with 0 or $1 \mu M$ melatonin were cultured during $3 \mathrm{~h}$ at either $38.5^{\circ} \mathrm{C}\left[5 \%\right.$ (vol/vol) $\mathrm{O}_{2}$ and $5 \%$ (vol/vol) $\mathrm{CO}_{2}$ with the balance $\left.\mathrm{N}_{2}\right]$, or $40^{\circ} \mathrm{C}\left[5 \%\right.$ (vol/vol) $\mathrm{O}_{2}$ and $6 \%$ (vol/ vol) $\mathrm{CO}_{2}$ with the balance as $\mathrm{N}_{2}$ ] beginning $8 \mathrm{~h}$ after 


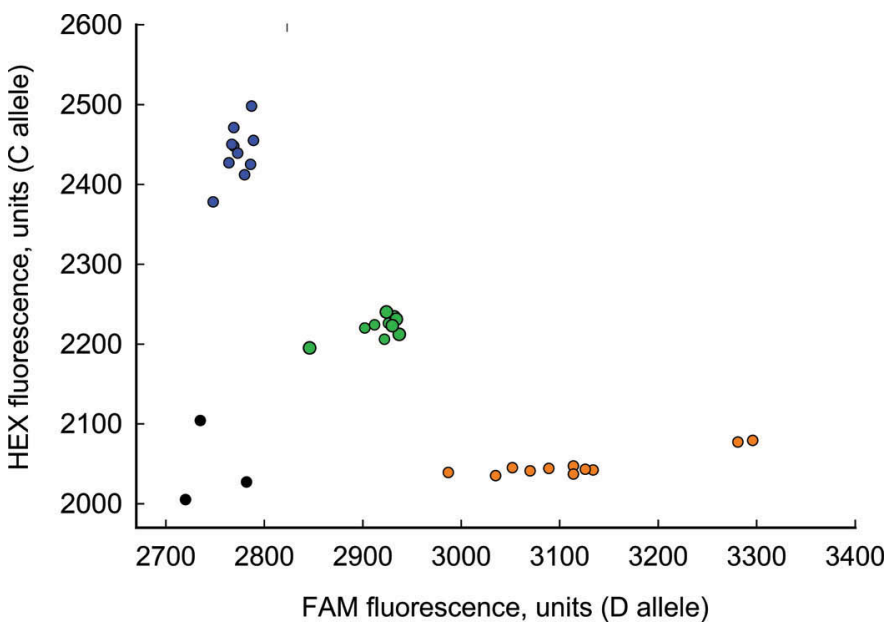

Figure 1. Representative results for genotyping assay for the deletion mutation in HSPA1L. Representative example of results from the genotype assay for the SNP in HSPA1L using the KASP assay (LGC Genomics, Middlesex, UK). In the assay, PCR amplicons from embryos with the cytosine $(\mathrm{C})$ allele hybridize to the hexachlorofluorescein fluorprobe (HEX), whereas amplicons from embryos with the deletion (D) allele hybridize to the fluorescein amidite fluoroprobe (FAM). Embryos classified as homozygous for C are indicated by black (blue) circles, embryos homozygous for the deletion allele are indicated by light gray (orange) circles and heterozygotes are indicated by dark gray (green) circles. The 3 black circles at the bottom left of plot represent no signals (no genotype assigned). Color version available online.

insemination. After treatment, putative zygotes were assessed individually for ROS production as described above. The number of embryos evaluated varied from 91 to 117 per group.

Experiment 2 was conducted similarly to experiment 1 except the effect of oxygen concentration in the culture environment was also determined. The experiment involved a $2 \times 2 \times 2$ factorial design including 2 temperature treatments $\left(38.5\right.$ and $\left.40^{\circ} \mathrm{C}\right), 2$ melatonin concentrations $(0$ and $1 \mu M)$, and 2 oxygen environments $\left(5\right.$ and $21 \% \mathrm{vol} / \mathrm{vol} \mathrm{O}_{2}$ ). Putative zygotes were produced from a single IVP procedure involving fertilization with sperm from a pool of 3 bulls. Beginning $8 \mathrm{~h}$ after insemination, putative zygotes supplemented with 0 or $1 \mu M$ melatonin were cultured for $3 \mathrm{~h}$ in a low oxygen environment at either $38.5^{\circ} \mathrm{C}[5 \%$ ( $\mathrm{vol} / \mathrm{vol}$ ) $\mathrm{O}_{2}$ and $5 \%$ (vol $\left./ \mathrm{vol}\right) \mathrm{CO}_{2}$ with the balance $\mathrm{N}_{2}$ ], or $40^{\circ} \mathrm{C}$ $\left[5 \%(\mathrm{vol} / \mathrm{vol}) \mathrm{O}_{2}\right.$ and $6 \%(\mathrm{vol} / \mathrm{vol}) \mathrm{CO}_{2}$ with the balance as $\mathrm{N}_{2}$ ] or in a high oxygen environment at either 38.5 in a humidified atmosphere of $5 \%$ (vol $/ \mathrm{vol}$ ) $\mathrm{CO}_{2}$ or at or $40^{\circ} \mathrm{C}$ in a humidified atmosphere of $5 \%$ (vol/vol) $\mathrm{CO}_{2}$. The number of putative zygotes per treatment ranged from 20 to 36 .

Experiment 3 was performed to determine if melatonin blocks the negative effects of heat shock at the zygote stage on embryonic development to the blas- tocyst stage. The experiment was a $2 \times 2$ factorial design which included 2 melatonin concentrations (0 and $1 \mu M)$ and 2 temperatures $\left(38.5\right.$ or $\left.40^{\circ} \mathrm{C}\right)$. Putative zygotes supplemented with 0 or $1 \mu M$ were cultured at either $38.5^{\circ} \mathrm{C}\left[5 \%\right.$ (vol $/ \mathrm{vol}$ ) $\mathrm{O}_{2}$ and $5 \%$ (vol $/ \mathrm{vol}$ ) $\mathrm{CO}_{2}$ with the balance $\left.\mathrm{N}_{2}\right]$, or $40^{\circ} \mathrm{C}\left[5 \%\right.$ (vol/vol) $\mathrm{O}_{2}$ and $6 \%$ (vol/vol) $\mathrm{CO}_{2}$ with the balance as $\left.\mathrm{N}_{2}\right]$. Heat shock treatment started $8 \mathrm{~h}$ after insemination and lasted for $12 \mathrm{~h}$, after which all groups were cultured at $38.5^{\circ} \mathrm{C}[5 \%$ (vol/vol) $\mathrm{O}_{2}$ and $5 \%$ (vol/vol) $\mathrm{CO}_{2}$ with the balance $\mathrm{N}_{2}$ ] until Day 7 of development. Endpoints were percent of putative zygotes that cleaved byDay 3 of development, percent of putative zygotes that became a blastocyst at Day 7 of development, and percent of cleaved embryos that became a blastocyst at Day 7 of development. The experiment was conducted in 22 replicates using a total of 25 bulls for fertilization. The total number of putative zygotes per treatment ranged from 1,451 to 1,532.

Experiment 4 was designed to test interactions between melatonin, oxygen concentration, and temperature on embryonic development. The experiment had a $2 \times 2 \times 2$ factorial design including 2 temperature treatments $\left(38.5\right.$ and $\left.40^{\circ} \mathrm{C}\right), 2$ melatonin concentrations $(0$ and $1 \mu M$ ), and 2 oxygen environments (5 and $21 \%$ $\mathrm{vol} / \mathrm{vol} \mathrm{O}_{2}$ ). Beginning $8 \mathrm{~h}$ after insemination, putative zygotes supplemented with 0 or $1 \mu M$ melatonin were cultured for $24 \mathrm{~h}$ at either $38.5^{\circ} \mathrm{C}\left[5 \%\right.$ (vol/vol) $\mathrm{O}_{2}$ and $5 \%$ (vol/vol) $\mathrm{CO}_{2}$ with the balance $\left.\mathrm{N}_{2}\right]$, or $40^{\circ} \mathrm{C}[5 \%$ ( $\mathrm{vol} / \mathrm{vol}$ ) $\mathrm{O}_{2}$ and $6 \%$ (vol/vol) $\mathrm{CO}_{2}$ with the balance as $\mathrm{N}_{2}$ ] in a low oxygen $(5 \% \mathrm{vol} / \mathrm{vol})$ environment or at either 38.5 or $40^{\circ} \mathrm{C}$ in a humidified atmosphere of $5 \%$ (vol/vol) $\mathrm{CO}_{2}$ in a high oxygen environment. Thereafter, all embryos were cultured at $38.5^{\circ} \mathrm{C}[5 \%$ ( $\mathrm{vol} / \mathrm{vol}$ ) $\mathrm{O}_{2}$ and $5 \%$ (vol/vol) $\mathrm{CO}_{2}$ with the balance $\mathrm{N}_{2}$ ] until Day 7 of development. The experiment was performed in 8 replicates with a total of 19 sires and the number of putative zygotes ranged from 510 to 578 per treatment. Endpoints were as for experiment 3. In addition, 542 blastocysts from the experiment were collected individually and genotyped for the deletion mutation in $H S P A 1 L$, as described above.

\section{Statistical Analysis}

Differences in ROS intensity were evaluated by ANOVA using the GLM procedure of SAS version 9.4 (SAS Institute Inc., Cary, NC). For experiment 1, the model included temperature, melatonin treatment, and the interactions as fixed effects. For experiment 2 , the model included temperature, melatonin treatment, oxygen, and their interactions as fixed effects. In both experiments 1 and 2, each embryo was analyzed individually and considered an experimental unit. In experiment 1, the total amount of experimental units 
was 416. In experiment 2, the total amount of experimental units was 205.

For experiments 3 and 4, data on percent cleavage, putative zygotes, and cleaved embryos becoming blastocysts calculated for each replicate were analyzed by ANOVA using the MIXED procedure of SAS. The main effects included in the model were temperature, melatonin, and their interactions for experiment 3; and temperature, melatonin, oxygen, and their interactions for experiment 4 . In both cases, replicate was included as random effect in the model.

To determine effect of treatment on blastocyst genotype, the frequency of each genotype (CC, CD, DD) was calculated for each replicate. Treatment effects on frequency were determined by the ANOVA with the GLIMMIX procedure, using a Poisson distribution. Frequency was the response variable and the model included genotype, temperature, oxygen, and their in- teractions as fixed effects, and replicate as a random effect.

\section{RESULTS}

\section{ROS Production}

In experiment 1 , embryos were cultured in low oxygen. Representative images of ROS labeling are shown in Figure 2. When melatonin was added to culture medium, ROS intensity was reduced at both temperatures and embryos at $40^{\circ} \mathrm{C}$ did not have greater labeling intensity than embryos at $38.5^{\circ} \mathrm{C}$ (compare Figure $2 \mathrm{C}$ and Figure 2D).

Least squares means for ROS labeling intensity are shown in Figure 3. Significant effects were found for temperature $(P=0.0012)$, melatonin $(P=0.0031)$, and the temperature $\times$ melatonin interaction $(P<$

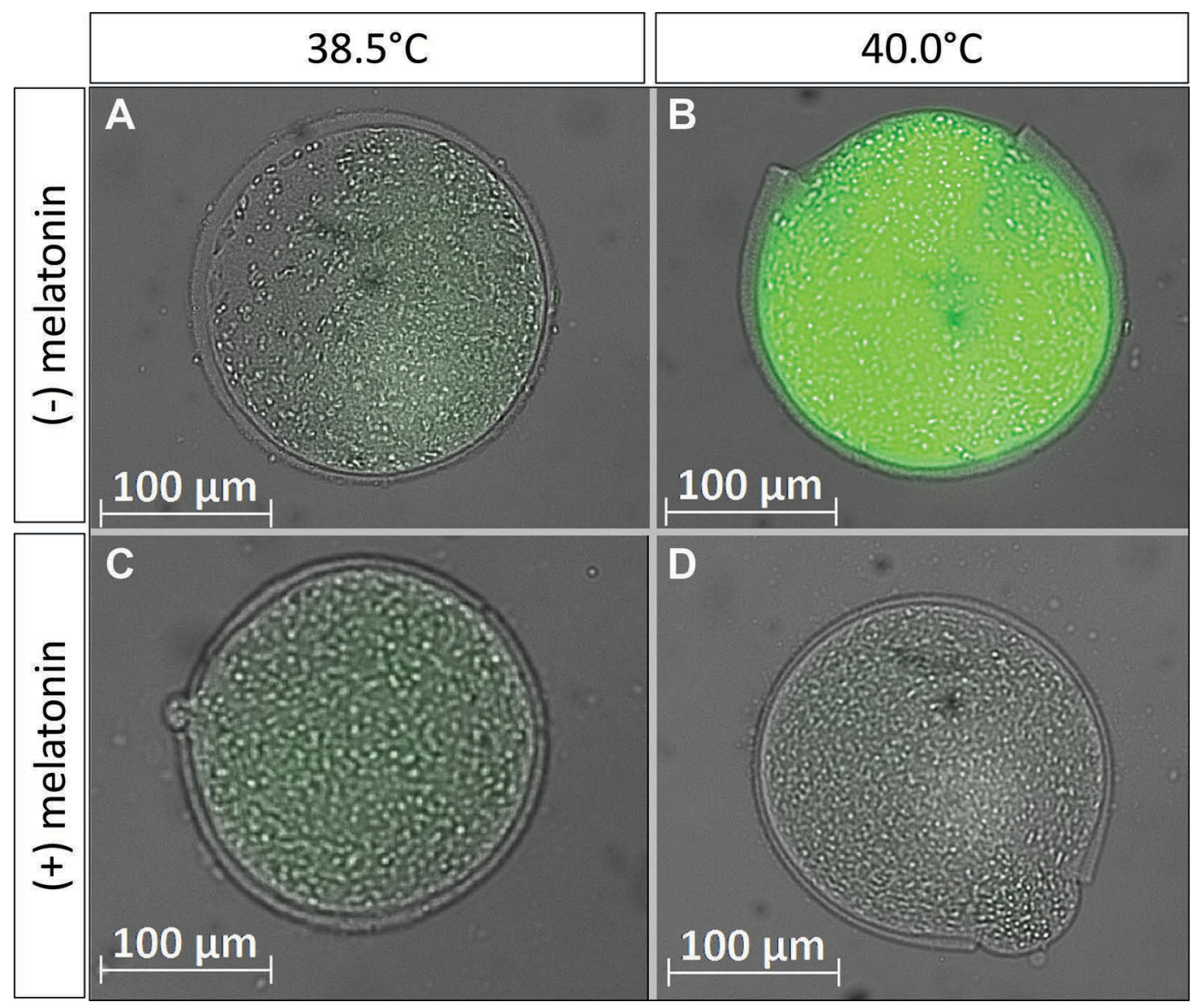

Figure 2. Representative images of zygotes labeled with CellROX (ThermoFisher Scientific, Waltham, MA) to assess production of reactive oxygen species as affected by incubation temperature and melatonin (experiment 1). Images were obtained by merging visualization of the embryo using differential interference and with a fluorescein isothiocyanate (FITC) fluorescent filter. Panels A and B represent embryos cultured without melatonin at $38.5^{\circ} \mathrm{C}(\mathrm{A})$ and $40^{\circ} \mathrm{C}(\mathrm{B})$. Panels $\mathrm{C}$ and D represent embryos cultured with melatonin at $38.5^{\circ} \mathrm{C}(\mathrm{C})$ and $40^{\circ} \mathrm{C}(\mathrm{D})$. Color version available online. 


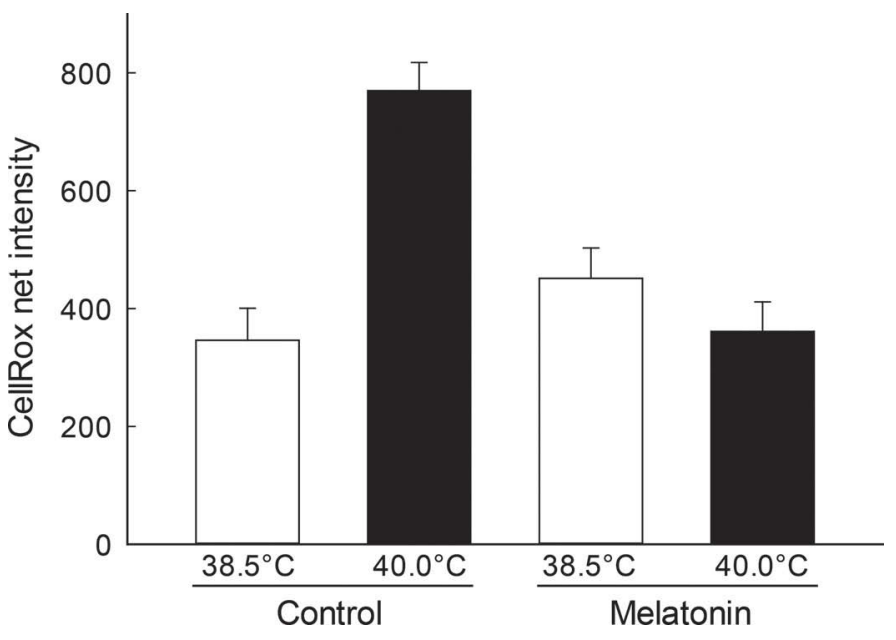

Figure 3. Effect of incubation temperature and melatonin on production of reactive oxygen species in the zygote as determined by CellROX (ThermoFisher Scientific, Waltham, MA) net intensity (experiment 1). Data are LSM \pm SEM of arbitrary units of intensity. Intensity was affected by temperature $(P=0.0012)$, melatonin $(P=$ $0.0031)$, and the temperature by melatonin interaction $(P<0.0001)$.
0.0001). These effects reflected the fact that heat shock increased labeling intensity and that melatonin reduced labeling intensity at both temperatures and prevented the increase in ROS labeling caused by culture at $40^{\circ} \mathrm{C}$.

Experiment 2 was conducted similarly except that the experiment was performed under 2 gaseous atmospheres, high oxygen $\left(21 \% \mathrm{O}_{2}\right)$ and low oxygen $\left(5 \% \mathrm{O}_{2}\right)$ conditions. Representative images of ROS labeling are shown in Figure 4. Intensity of labeling was increased by culture at $40^{\circ} \mathrm{C}$ compared with $38.5^{\circ} \mathrm{C}$ for both oxygen environments (compare Figure $4 \mathrm{~A}$ with $4 \mathrm{~B}$ and $4 \mathrm{E}$ with $4 \mathrm{~F}$ ). Intensity was also greater for embryos in high oxygen than low oxygen (compare Figure 4A with $4 \mathrm{E}$ and $4 \mathrm{~B}$ with Figure $4 \mathrm{~F}$ ). Melatonin decreased ROS production in embryos exposed to heat shock under low oxygen (compare Figure 4D with $4 \mathrm{C}$ ) and high oxygen conditions (compare Figure $4 \mathrm{H}$ with $4 \mathrm{G}$ ).

Least squares means for ROS intensity are shown in Figure 5. Intensity was affected by oxygen concentration $(P=0.004)$ and the interactions of temperature with melatonin treatment $(P=0.0003)$ and oxygen with melatonin treatment $(P=0.0054)$. These interactions occurred because melatonin prevented the increase in ROS intensity caused by culturing embryos in a high oxygen environment or at $40^{\circ} \mathrm{C}$.

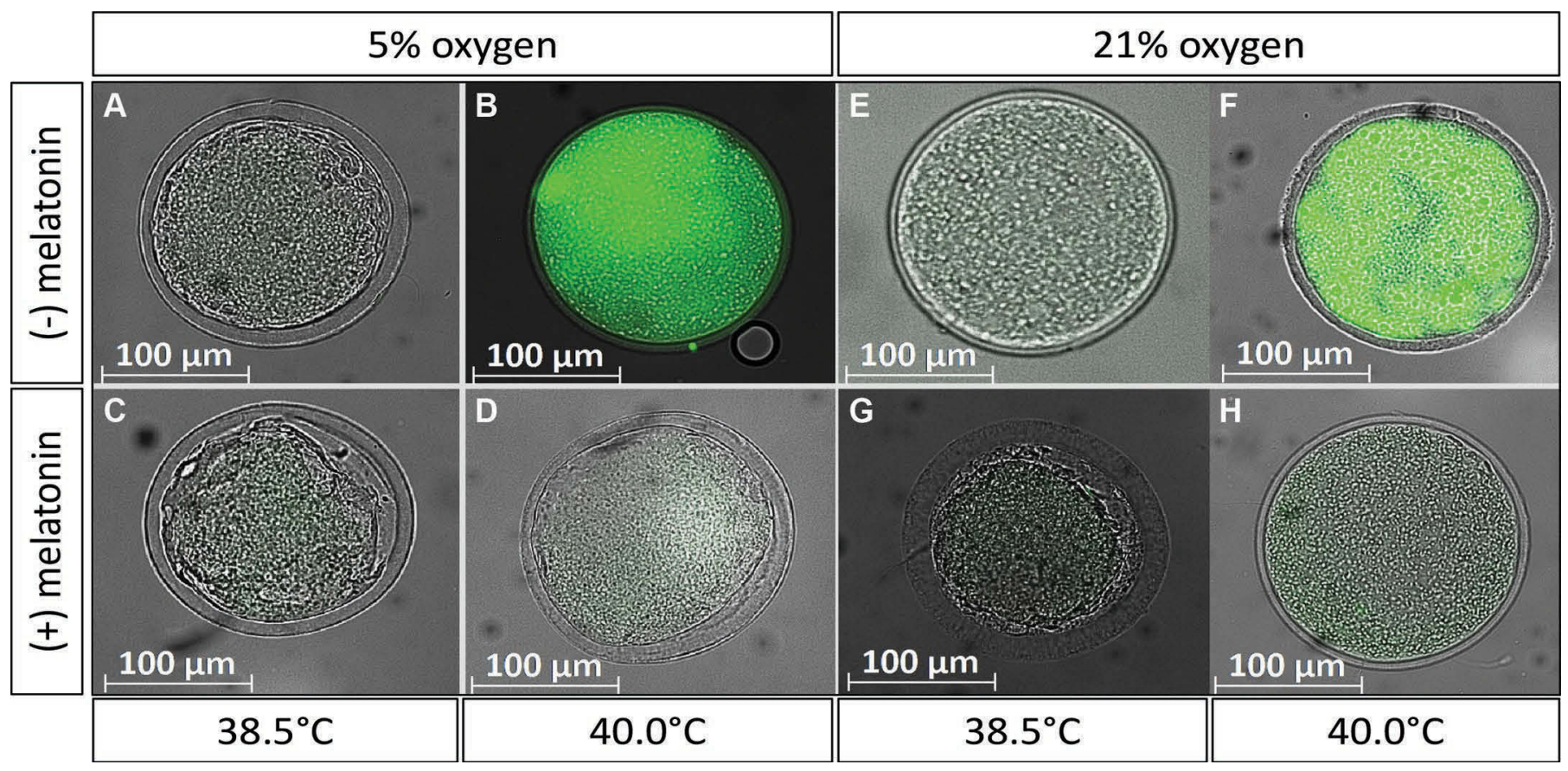

Figure 4. Representative images of zygotes labeled with CellROX (ThermoFisher Scientific, Waltham, MA) to assess production of reactive oxygen species as affected by incubation temperature and melatonin (experiment 2). Images were obtained by merging visualization of the embryo using differential interference and with a fluorescein isothiocyanate (FITC) fluorescent filter. Panels A to D represent embryos cultured in low oxygen $\left[5 \%(\mathrm{vol} / \mathrm{vol}) \mathrm{O}_{2}\right]$ for embryos cultured without melatonin at $38.5^{\circ} \mathrm{C}(\mathrm{A})$ and $40^{\circ} \mathrm{C}(\mathrm{B})$ and with melatonin at $38.5^{\circ} \mathrm{C}(\mathrm{C})$ and $40^{\circ} \mathrm{C}(\mathrm{D})$. Panels $\mathrm{E}$ to $\mathrm{H}$ represent embryos cultured in high oxygen $\left[21 \%\right.$ (vol/vol) $\left.\mathrm{O}_{2}\right]$ without melatonin at $38.5^{\circ} \mathrm{C}(\mathrm{E})$ and $40^{\circ} \mathrm{C}(\mathrm{F})$ or with melatonin at $38.5^{\circ} \mathrm{C}(\mathrm{G})$ and $40^{\circ} \mathrm{C}(\mathrm{H})$. Color version available online. 
9158

\section{Development to the Blastocyst Stage}

For experiment 3, embryos were cultured continuously in low oxygen. Results are shown in Figure 6. Culture at $40^{\circ} \mathrm{C}$ during the first $12 \mathrm{~h}$ of culture decreased the percent of putative zygotes that cleaved $(P$ $=0.0012)$ and that progressed to the blastocyst stage $(P<0.0001)$ as well as the percent of cleaved embryos that became blastocysts $(P<0.0001)$. No effect was found of melatonin or temperature by melatonin interactions on any developmental trait measured.

Experiment 4 was conducted similarly except that heat shock was for $24 \mathrm{~h}$ and embryos were cultured either in low oxygen continuously or were moved to high oxygen during the period corresponding to temperature treatments. Results are presented in Figure 7. No effect was found of temperature treatment, oxygen concentration, or the interaction on the percent of putative zygotes that cleaved, although culture at $40^{\circ} \mathrm{C}$ tended to reduce cleavage $(P=0.09)$. Elevated temperature also reduced the percent of putative zygotes that became blastocysts $(P=0.003)$ and the percent of cleaved embryos developing to blastocysts $(P=0.01)$. Neither oxygen, melatonin, nor interactions with these 2 main effects affected development to the blastocyst stage.

\section{Genotype}

The genotype of embryos that developed to the blastocyst stage was determined in experiment 4. As shown in Figure 8, the distribution of blastocysts according to the 3 genotypes (CC, CD, DD) was affected by temperature (genotype $\times$ temperature, $P<0.0001$ ), oxygen environment (genotype $\times$ oxygen, $P<0.0001$ ), and the interaction of temperature by oxygen (genotype $\times$ temperature $\times$ oxygen, $P=0.0054$ ). These effects reflected the fact that frequency of the $\mathrm{D}$ allele was lower for blastocysts cultured at $38.5^{\circ} \mathrm{C}$ in low oxygen than for blastocysts produced under other conditions. For embryos cultured at $38.5^{\circ} \mathrm{C}$ in low oxygen (i.e., the least stressful environment for the embryo), the overall frequency of the D allele was $33 \%$. In other groups, however, the frequency of the $\mathrm{D}$ allele was higher, ranging from 43 to $56 \%$. No effect was found of melatonin or interactions of melatonin with other main effects on genotype.

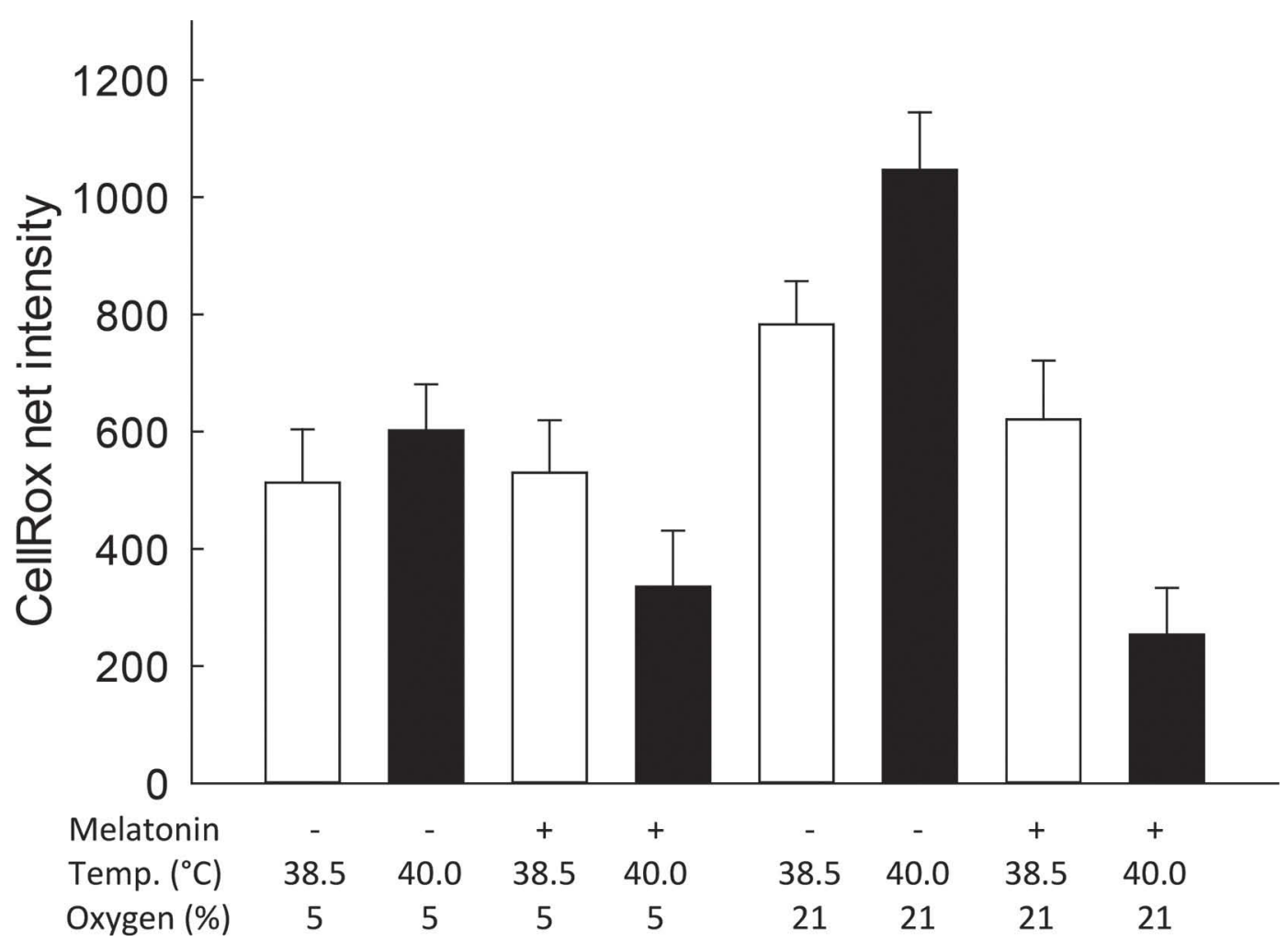

Figure 5. Effect of oxygen environment, incubation temperature (Temp.), and melatonin on production of reactive oxygen species in the zygote as determined by CellROX (ThermoFisher Scientific, Waltham, MA) net intensity (experiment 2). Data are LSM \pm SEM of arbitrary intensity units. Intensity was affected by oxygen concentration $(P=0.004)$ and the interaction of temperature with melatonin treatment $(P=$ $0.0003)$ and oxygen with melatonin treatment $(P=0.0054)$. 


\section{DISCUSSION}

Results of these experiments in which embryos were exposed to heat shock confirm that exposure to elevated temperatures during the zygote stage of development can compromise the competence of the embryo to progress to the blastocyst stage (Sakatani et al., 2012). However, although heat shock resulted in increased ROS production, this action of elevated temperature is not a major cause for the reduced development. This conclusion is based on 2 observations. First, melatonin did not alleviate effects of heat shock on development despite causing a decrease in ROS production. Second, effects of heat shock on development were similar for embryos cultured in a low or high oxygen environment, despite the fact that embryos cultured in high oxygen had higher production of ROS than embryos cultured in low oxygen. The other major conclusion of these experiments is that the genotype for HSPA1L affects survival of embryos in a manner that depends upon culture environment. This is because the proportion of blastocysts with a deletion mutation in $H S P A 1 L$ previously related to cellular thermotolerance (Basiricò et al., 2011) was higher for blastocysts derived from heat-shocked zygotes or for embryos cultured at $38.5^{\circ} \mathrm{C}$ in high oxygen than for those derived from zygotes

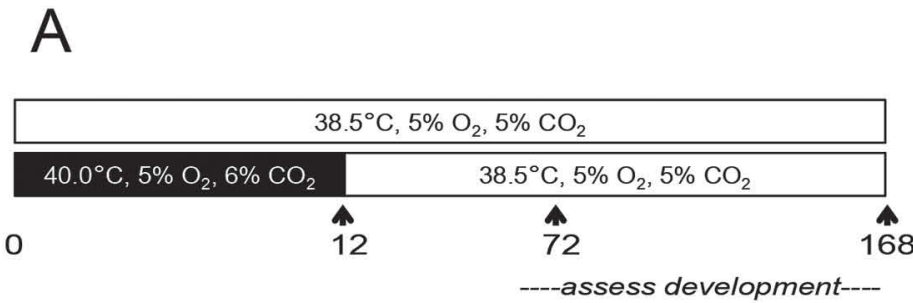

Hours after insemination (not to scale)

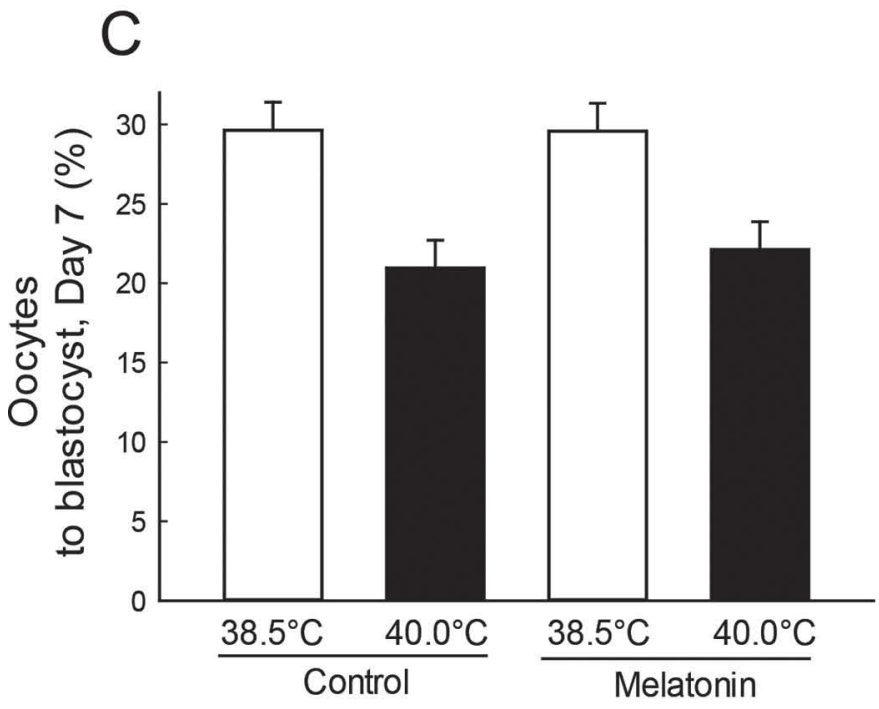

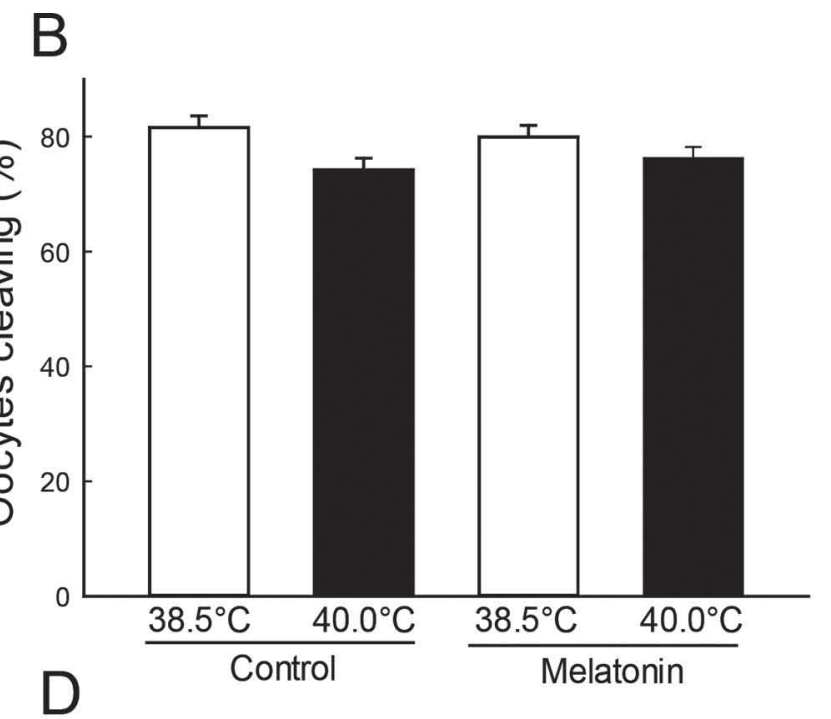

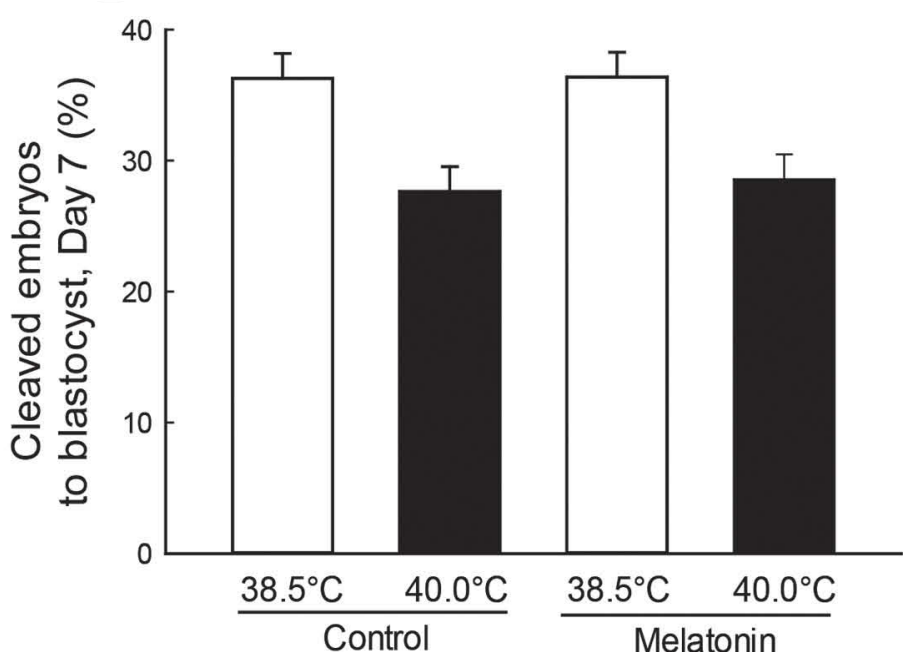

Figure 6. Effect of incubation temperature from 8 to $20 \mathrm{~h}$ after fertilization on cleavage and development to the blastocyst stage as affected by melatonin for embryos cultured in low oxygen (experiment 3). Data are LSM \pm SEM. The timing and design and timing of treatments is shown in panel A, cleavage rate is shown in panel B, the percent oocytes developing to blastocyst are shown in panel $\mathrm{C}$, and the percent of cleaved embryos developing to blastocyst is shown in panel D. Temperature affected the percent of putative zygotes that cleaved $(P=0.0012)$, the percent that became blastocysts $(P<0.0001)$, and the percent of cleaved embryos that became blastocysts $(P<0.0001)$. No effects were found of melatonin or the interaction between heat shock and melatonin. 
not exposed to heat shock and cultured in low oxygen. Thus, there are allelic variants of genes that confer the embryo with protection against adverse environments such as heat shock or high oxygen.
Intracellular ROS are formed by incomplete reduction of oxygen during oxidative phosphorylation and as byproducts of specific enzymatic reactions (Takahashi, 2012). Because of their propensity to strip electrons

B

\begin{tabular}{|c|c|}
\hline \multicolumn{2}{|c|}{$38.5^{\circ} \mathrm{C}, 5 \% \mathrm{O}_{2}, 5 \% \mathrm{CO}_{2}$} \\
\hline $40.0^{\circ} \mathrm{C}, 5 \% \mathrm{O}_{2}, 6 \% \mathrm{CO}_{2}$ & $38.5^{\circ} \mathrm{C}, 5 \% \mathrm{O}_{2}, 5 \% \mathrm{CO}_{2}$ \\
\hline $38.5^{\circ} \mathrm{C}, 21 \% \mathrm{O}_{2}, 6 \% \mathrm{CO}_{2}$ & $38.5^{\circ} \mathrm{C}, 5 \% \mathrm{O}_{2}, 5 \% \mathrm{CO}_{2}$ \\
\hline $40.0^{\circ} \mathrm{C}, 21 \% \mathrm{O}_{2}, 6 \% \mathrm{CO}_{2}$ & $38.5^{\circ} \mathrm{C}, 5 \% \mathrm{O}_{2}, 5 \% \mathrm{CO}_{2}$ \\
\hline $\begin{array}{l}\hat{2} \\
\end{array}$ & $\begin{array}{l}\hat{1} \\
72\end{array}$ \\
\hline
\end{tabular}

Hours after insemination (not to scale)

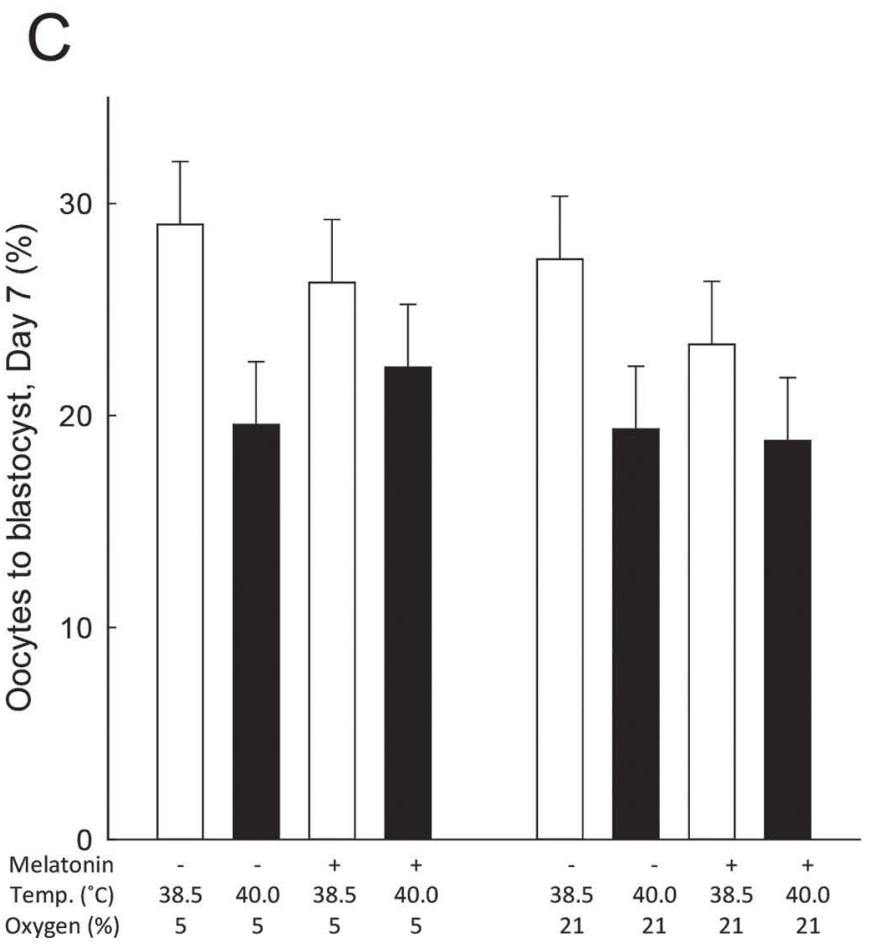

$\mathrm{D}$

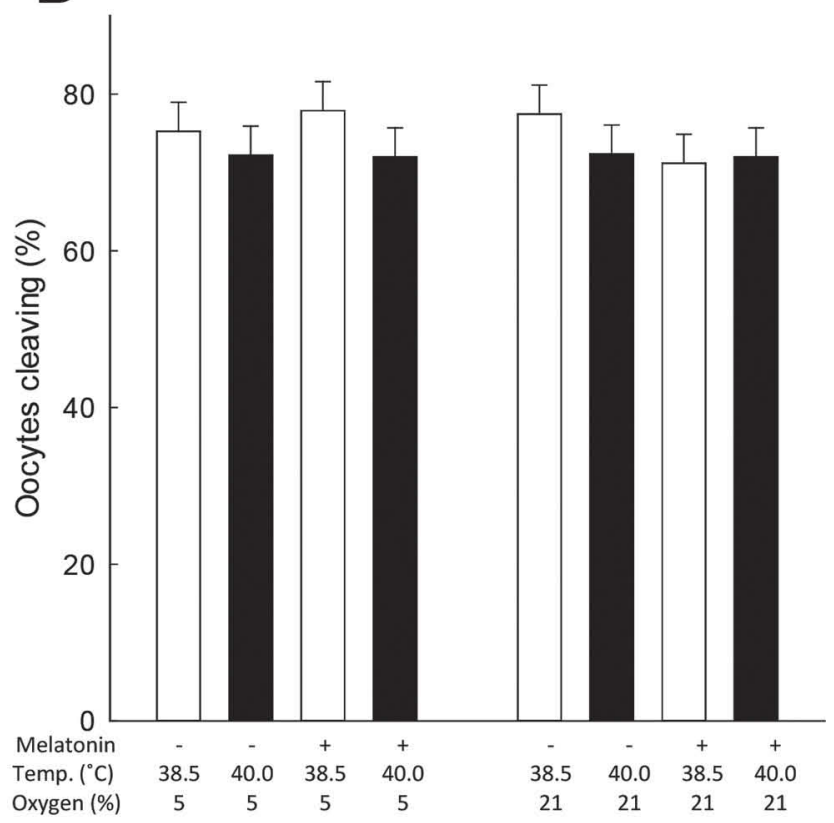

D

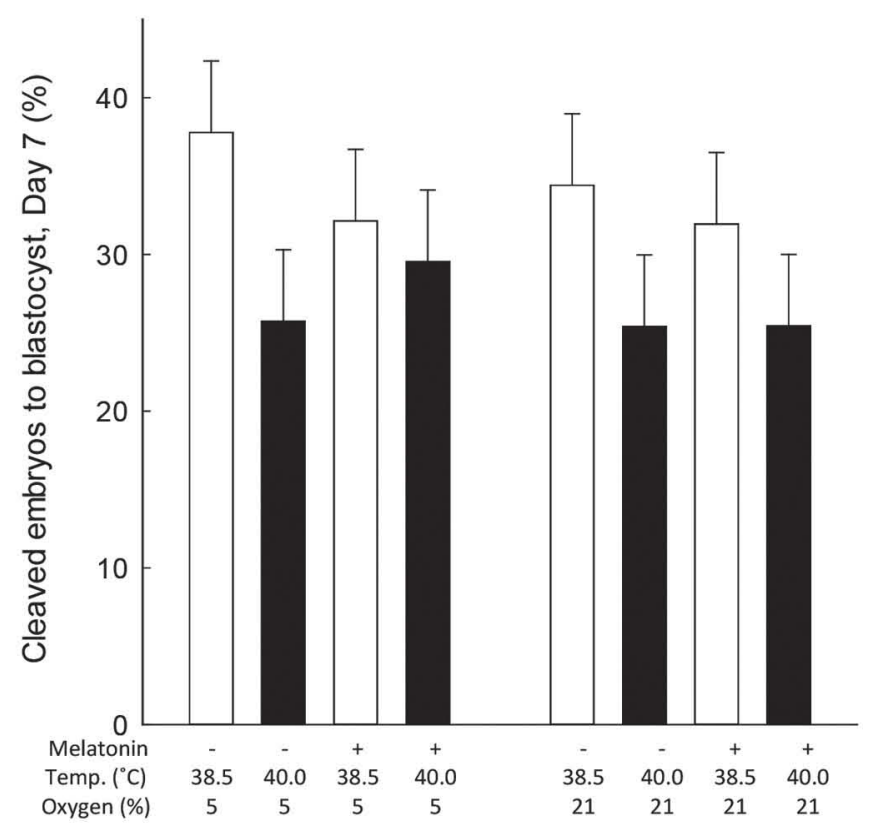

Figure 7. Effect of incubation temperature from 8 to $20 \mathrm{~h}$ after fertilization on cleavage and development to the blastocyst stage as affected by oxygen environment during 8 to $20 \mathrm{~h}$ after fertilization and melatonin (experiment 4 ). Data are LSM \pm SEM. The timing and design and timing of treatments is shown in panel A, cleavage rate is shown in panel B, the percent oocytes developing to blastocyst is shown in panel C, and the percent of cleaved embryos developing to blastocyst is shown in panel D. Temperature affected the percent of putative zygotes that cleaved $(P=0.09)$, the percent of putative zygotes that became blastocysts $(P=0.003)$, and the percent of cleaved embryos that became blastocysts $(P=0.01)$. Oxygen, melatonin, and interactions with these 2 main effects did not affect any developmental trait. 
from other molecules in the cell, ROS can cause cellular damage (Guérin et al., 2001; Ray et al., 2012). As shown here and elsewhere (Sakatani et al., 2004; Nabenishi et al., 2012b), elevated temperature can increase ROS production in embryos. As a result, it has been proposed that increased ROS production is one of the mechanisms by which heat shock reduces embryonic development (Sakatani et al., 2004; Hansen, 2009; Nabenishi et al., 2012a; Hansen, 2013). However, current results are inconsistent with this idea, at least for the bovine zygote. Melatonin did not increase embryonic resistance to heat shock, despite causing a large decrease in ROS production. Likewise, effects of heat shock on development to the blastocyst stage were similar for embryos at high and low oxygen environments, even when ROS production was greater for embryos in a high-oxygen environment. Perhaps the reason why negative effects of high oxygen were not observed in this study is because the exposure to the high oxygen conditions was only for 12 to $24 \mathrm{~h}$ and was not enough time to affect embryonic development to the blastocyst stage. Prolonged exposure to high oxygen (24 h or greater) can decrease embryonic development (Papis et al., 2007; Rho et al., 2007; Sakatani et al., 2012). Under prolonged exposure to high oxygen, melatonin can protect the embryo from the damaging consequences of high oxygen (Papis et al., 2007).

In contrast to results with the zygote reported here, melatonin has been reported to protect cultured bovine oocytes exposed to $41.5^{\circ} \mathrm{C}$ for $24 \mathrm{~h}$ in high oxygen matu-

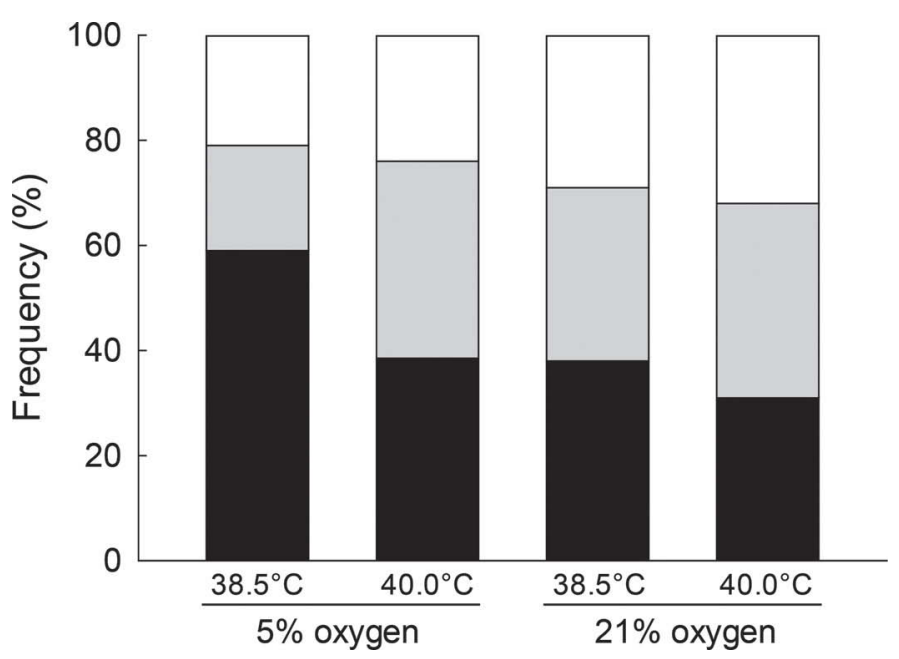

Figure 8. Genotype frequencies of the SNP in HSPA1L for blastocysts formed following exposure to different temperatures, oxygen concentrations, and melatonin concentrations (experiment 4). The distribution of blastocysts according to the 3 genotypes [CC (black), CD (gray), and DD (white)] was affected by the following interactions: genotype by temperature $(P<0.0001)$, genotype by oxygen $(P$ $=0.000184)$, and genotype by temperature by oxygen $(P=0.0054)$. ration from effects of heat shock (Cebrian-Serrano et al., 2013). It is possible that oocytes are more susceptible to ROS than zygotes or that the higher temperatures and incubation periods used increase ROS production beyond what was induced with the lower, but more physiological, heat shock temperatures used here. The effective concentration of melatonin in the experiment of Cebrian-Serrano et al. (2013) was $100 \mu M$ versus a concentration of $1 \mu M$ in the present experiment. It is unlikely, however, that absence of melatonin effects in the present experiment was because concentrations were too low. Indeed, ROS was greatly reduced by treating heat-shocked zygotes with $1 \mu M$ melatonin.

Other antioxidants have been used to reduce effects of heat shock on bovine embryos in vitro and of heat stress in vivo on embryonic survival. Results, which have involved a range of stages of development and culture conditions, have been mixed. No protective effect was found of vitamin E, glutathione, or taurine on preimplantation bovine embryos exposed to heat shock (Ealy et al., 1995; Paula-Lopes et al., 2003a). Similarly, injection of cows with vitamin E (Ealy et al., 1994; Aréchiga et al., 1998b), vitamin E and selenium (Aréchiga et al., 1998a; Paula-Lopes et al., 2003a), or $\beta$-carotene (Aréchiga et al., 1998a) did not improve fertility in summer. In contrast, cultured bovine embryos were protected from heat shock by anthocyanin (Sakatani et al., 2007) and dithiothreitol (de Castro e Paula and Hansen, 2008) and fertility of heat-stressed cows was improved by feeding supplemental $\beta$-carotene (Aréchiga et al., 1998a).

Although a wide range of responses to altering redox status have been observed, it is likely that the lack of involvement of ROS in the negative effects of heat shock with cultured embryos seen here reflects the situation with respect to heat-stressed cows. That is because, as compared with some other studies, the magnitude of heat shock in terms of duration and temperature reflects body temperatures experienced by heat-stressed cows. Rectal temperatures in lactating dairy cows in the summer in Florida are usually below $40^{\circ} \mathrm{C}$ (Dikmen and Hansen, 2009; Dikmen et al., 2015). Also, the stage of development studied here, the zygote, is more relevant to the heat-stressed cows because fertility is more likely to be disrupted when cows are exposed to heat stress at d 1 after estrus than later in development (Ealy et al., 1993).

Administration of subcutaneous implants of melatonin have been reported to increase fertility of lactating cows during heat stress (Garcia-Ispierto et al., 2013a). The concentrations of melatonin in the blood in that study ranged from 30 to $65 \mathrm{pg} / \mathrm{mL}(0.13$ to $0.28 \mathrm{n} M)$, which is much lower than tested here $(1 \mu M)$ and too low to inhibit ROS production (Mayo et al., 2003; Tan 
et al., 2003; Rodriguez et al., 2004). Rather it is likely that the effect of melatonin seen by Garcia-Ispierto et al. (2013a) reflects actions of melatonin mediated by specific receptors located in the brain, cumulus cell and oocyte, placenta, and other peripheral tissues (Cardinali et al., 1979; Iwasaki et al., 2005; El-Raey et al., 2011; Slominski et al., 2012). Melatonin has been reported to increase ipsilateral uterine artery blood flow in pregnant Holstein heifers (Brockus et al., 2016), increase circulating progesterone concentration, and decrease serum prolactin in ewes (Kennaway et al., 1982; Abecia et al., 2002), and evidence indicates that melatonin favors cumulus cell expansion in the cow (ElRaey et al., 2011).

We did not determine consequences of heat shock at the 1-cell stage on characteristics of the blastocyst (i.e., cell numbers, incidence of apoptosis, gene expression, and so on). Heat shock during early development can reduce cell number of the resultant blastocysts (Sakatani et al., 2004, 2012). Therefore, it remains possible that, even though melatonin did not block the effects of heat shock on the proportion of embryos that developed to the blastocyst stage, it might have improved the quality of the embryos that did become a blastocyst. Even if this were the case, however, one would not expect that such an action would appreciably improve fertility in heat-stressed cows because most embryos would not reach the blastocyst stage.

The extent to which heat shock negatively affects embryonic development is also controlled in part by the genetics of the embryo. Embryos of thermotolerant breeds are more resistant to the anti-developmental effects of heat shock than embryos of more thermosensitive breeds (Paula-Lopes et al., 2003b; HernándezCerón et al., 2004; Eberhardt et al., 2009). Here we show that HSPA1L is one gene that contains mutations that confers resistance of embryos to 2 environments: heat shock and high oxygen. The HSP70 family is involved in stabilization of protein structure and inhibition of apoptosis during cellular stress (Radons, 2016). In cattle, 2 genes in the HSP70 family were formed by gene duplication: HSPA1A and HSPA1L (Grosz et al., 1992). Most studies examining expression of $H S P 70$ genes have not distinguished between these 2 genes, but a recent study examining the transcriptome of bovine embryos indicates that transcripts for both $H S P A 1 A$ and $H S P A 1 L$ are present in the 2-cell embryo (Jiang et al., 2014). Although embryonic gene activation in cattle occurs for most genes at the 8-cell stage (Graf et al., 2014), transcription of $H S P A 1 A / L$ in response to heat shock occurs as early as the 2-cell stage (Chandolia et al., 1999). The mutation studied here is a deletion in the promoter of $H S P A 1 L$ that, in bovine mononuclear cells, increases upregulation of transcription of the gene in response to elevated temperature and increased viability after heat shock (Basiricò et al., 2011). In Holsteins, the frequency of the deletion mutation has been estimated at 29\% (Ortega et al., 2016). In the current study, a similar frequency of the deletion mutation (33\%) was observed for blastocysts formed after culture of embryos at $38.5^{\circ} \mathrm{C}$ in a low oxygen environment. In contrast, frequency of the deletion mutation was increased in blastocysts formed following heat shock under either low or high oxygen conditions or for embryos cultured at $38.5^{\circ} \mathrm{C}$ in the presence of a high oxygen environment. Such a finding suggests that inheritance of the deletion mutation increased the probability that embryos could develop to the blastocyst stage after exposure to conditions that compromised development (heat shock) or that has been reported to reduce development in other experiments (high oxygen; Papis et al., 2007; Rho et al., 2007; Sakatani et al., 2012). Even though the effect of oxygen on blastocyst development was not significant in experiment 4 , the percent of embryos becoming blastocysts was numerically lower in the high oxygen group in the absence of melatonin. A negative effect of high oxygen on development has been observed in multiple experiments (Papis et al., 2007; Rho et al., 2007; Sakatani et al., 2012).

This finding has 2 implications. First, culture of embryos may lead to a skewing of frequency of genes that enhance development under suboptimal culture conditions. In addition, it may be possible to improve embryonic survival during heat stress by selecting for alleles such as the deletion mutation of $H S P A 1 L$ that confer protection from elevated temperature.

\section{CONCLUSIONS}

Exposure of bovine zygotes to elevated temperatures reduced competence to develop to the blastocyst stage. This effect is independent of the increased generation of ROS caused by heat shock because reduced development caused by elevated temperature was not alleviated by melatonin or culture in a low oxygen environment even though both treatments reduced generation of ROS. Thus, the previously reported effect of melatonin on fertility of heat-stressed cows might involve actions independent of the antioxidant properties of melatonin. Nevertheless, the effect of melatonin on the oocyte or further embryonic developmental stages should be examined further. Inheritance of a deletion mutation in the promoter region of $H S P A 1 L$ increased the probability that embryos became blastocysts after heat shock or exposure to high oxygen. Thus, genotype may affect whether an embryo survives or not in response 
to adverse environments. Perhaps embryonic survival during heat stress could be improved by selecting for thermotolerant genotypes.

\section{ACKNOWLEDGMENTS}

Research was supported by Binational Research and Development Grant US-4719-14 and Agriculture and Food Research Initiative Competitive Grant no. 2013-68004-20365 from the USDA National Institute of Food and Agriculture (Washington, DC). NASRF was supported by a PhD scholarship from São Paulo Research Foundation (FAPESP), Brazil (2014/06885-7). The authors thank Central Packing LLC for providing ovaries, and James Moss, William Rembert, and Eddie Cummings for technical assistance.

\section{REFERENCES}

Abecia, J. A., F. Forcada, and O. Zúñiga. 2002. The effect of melatonin on the secretion of progesterone in sheep and on the development of ovine embryos in vitro. Vet. Res. Commun. 26:151-158.

Aréchiga, C. F., C. R. Staples, L. R. McDowell, and P. J. Hansen. 1998a. Effects of timed insemination and supplemental $\beta$-carotene on reproduction and milk yield of dairy cows under heat stress. J. Dairy Sci. 81:390-402.

Aréchiga, C. F., S. Vázquez-Flores, O. Ortiz, J. Hernández-Cerón, A. Porras, L. R. McDowell, and P. J. Hansen. 1998b. Effect of injection of $\beta$-carotene or vitamin $\mathrm{E}$ and selenium on fertility of lactating dairy cows. Theriogenology 50:65-76.

Basiricò, L., P. Morera, V. Primi, N. Lacetera, A. Nardone, and U. Bernabucci. 2011. Cellular thermotolerance is associated with heat shock protein 70.1 genetic polymorphisms in Holstein lactating cows. Cell Stress Chaperones 16:441-448.

Brockus, K. E., C. G. Hart, C. L. Gilfeather, B. O. Fleming, and C. O. Lemley. 2016. Dietary melatonin alters uterine artery hemodynamics in pregnant Holstein heifers. Domest. Anim. Endocrinol. $55: 1-10$.

Cardinali, D. P., M. I. Vacas, and E. Esté. Boyer. 1979. Specific binding of melatonin in bovine brain. Endocrinology 105:437-441.

Cebrian-Serrano, A., I. Salvador, E. Raga, A. Dinnyes, and M. Silvestre. 2013. Beneficial effect of melatonin on blastocyst in vitro production from heat-stressed bovine oocytes. Reprod. Domest. Anim. 48:738-746.

Chandolia, R. K., M. R. Peltier, W. Tian, and P. J. Hansen. 1999. Transcriptional control of development, protein synthesis, and heat-induced heat shock protein 70 synthesis in 2-cell bovine embryos. Biol. Reprod. 61:1644-1648.

Christians, E. S., Q. Zhou, J. Renard, and I. J. Benjamin. 2003. Heat shock proteins in mammalian development. Semin. Cell Dev. Biol. $14: 283-290$.

Cochran, S. D., J. B. Cole, D. J. Null, and P. J. Hansen. 2013. Single nucleotide polymorphisms in candidate genes associated with fertilizing ability of sperm and subsequent embryonic development in cattle. Biol. Reprod. 89:69.

de Castro e Paula, L. A., and P. J. Hansen. 2008. Modification of actions of heat shock on development and apoptosis of cultured preimplantation bovine embryos by oxygen concentration and dithiothreitol. Mol. Reprod. Dev. 75:1338-1350.

Dikmen, S., and P. J. Hansen. 2009. Is the temperature-humidity index the best indicator of heat stress in lactating dairy cows in a subtropical environment? J. Dairy Sci. 92:109-116.

Dikmen, S., X.-Z. Wang, M. S. Ortega, J. Cole, D. Null, and P. Hansen. 2015. Single nucleotide polymorphisms associated with ther- moregulation in lactating dairy cows exposed to heat stress. J. Anim. Breed. Genet. 132:409-419.

Ealy, A. D., C. F. Arechiga, D. Bray, C. A. Risco, and P. J. Hansen. 1994. Effectiveness of short-term cooling and vitamin $\mathrm{E}$ for alleviation of infertility induced by heat stress in dairy cows. J. Dairy Sci. 77:3601-3607.

Ealy, A. D., M. Drost, and P. J. Hansen. 1993. Developmental changes in embryonic resistance to adverse effects of maternal heat stress in cows. J. Dairy Sci. 76:2899-2905.

Ealy, A. D., J. L. Howell, V. H. Monterroso, C. F. Arechiga, and P. J. Hansen. 1995. Developmental changes in sensitivity of bovine embryos to heat shock and use of antioxidants as thermoprotectants. J. Anim. Sci. 73:1401-1407.

Eberhardt, B. G., R. A. Satrapa, C. R. L. Capinzaiki, L. A. Trinca, and C. M. Barros. 2009. Influence of the breed of bull (Bos taurus indicus vs. Bos taurus taurus) and the breed of cow (Bos taurus indicus, Bos taurus taurus and crossbred) on the resistance of bovine embryos to heat. Anim. Reprod. Sci. 114:54-61.

Edwards, J. L., and P. J. Hansen. 1997. Differential responses of bovine oocytes and preimplantation embryos to heat shock. Mol. Reprod. Dev. 46:138-145.

El-Raey, M., M. Geshi, T. Somfai, M. Kaneda, M. Hirako, A. E. Abdel-Ghaffar, G. A. Sosa, M. E. A. A. El-Roos, and T. Nagai. 2011. Evidence of melatonin synthesis in the cumulus oocyte complexes and its role in enhancing oocyte maturation in vitro in cattle. Mol. Reprod. Dev. 78:250-262.

Flamenbaum, I., and N. Galon. 2010. Management of heat stress to improve fertility in dairy cows in Israel. J. Reprod. Dev. 56:S36S41.

Garcia-Ispierto, I., A. Abdelfatah, and F. López-Gatius. 2013a. Melatonin treatment at dry-off improves reproductive performance postpartum in high-producing dairy cows under heat stress conditions. Reprod. Domest. Anim. 48:577-583.

Garcia-Ispierto, I., M. A. Roselló, F. D. Rensis, and F. López-Gatius. 2013b. A five-day progesterone plus ECG-based fixed-time AI protocol improves fertility over spontaneous estrus in high-producing dairy cows under heat stress. J. Reprod. Dev. 59:544-548.

Graf, A., S. Krebs, V. Zakhartchenko, B. Schwalb, H. Blum, and E. Wolf. 2014. Fine mapping of genome activation in bovine embryos by RNA sequencing. Proc. Natl. Acad. Sci. USA 111:4139-4144.

Grosz, M. D.. J. E. Womack, and L. C. Skow. 1992. Syntenic conservation of HSP70 genes in cattle and humans. Genomics 14:863-868.

Guérin, P., S. E. Mouatassim, and Y. Ménézo. 2001. Oxidative stress and protection against reactive oxygen species in the pre-implantation embryo and its surroundings. Hum. Reprod. Update 7:175189.

Gwazdauskas, F. C., W. W. Thatcher, and C. J. Wilcox. 1973. Physiological, environmental, and hormonal factors at insemination which may affect conception. J. Dairy Sci. 56:873-877.

Hansen, P. J. 2009. Effects of heat stress on mammalian reproduction. Philos. Trans. R. Soc. B Biol. Sci. 364:3341-3350.

Hansen, P. J. 2013. Cellular and molecular basis of therapies to ameliorate effects of heat stress on embryonic development in cattle. Anim. Reprod. 10:322-333.

Hansen, P. J., and C. F. Aréchiga. 1999. Strategies for managing reproduction in the heat-stressed dairy cow. J. Anim. Sci. 77:36-50.

Hernández-Cerón, J., C. C. Chase Jr., and P. J. Hansen. 2004. Differences in heat tolerance between preimplantation embryos from Brahman, Romosinuano, and Angus breeds. J. Dairy Sci. 87:53-58.

Iwasaki, S., K. Nakazawa, J. Sakai, K. Kometani, M. Iwashita, Y. Yoshimura, and T. Maruyama. 2005. Melatonin as a local regulator of human placental function. J. Pineal Res. 39:261-265.

Jiang, Z., J. Sun, H. Dong, O. Luo, X. Zheng, C. Obergfell, Y. Tang, J. Bi, R. O'Neill, Y. Ruan, and J. Chen., and X. (Cindy) Tian. 2014. Transcriptional profiles of bovine in vivo pre-implantation development. BMC Genomics 15:756. http://dx.doi.org/10.1186/14712164-15-756.

Kennaway, D. J., T. A. Gilmore, and R. F. Seamark. 1982. Effect of melatonin feeding on serum prolactin and gonadotropin levels and the onset of seasonal estrous cyclicity in sheep. Endocrinology 110:1766-1772. 
Mayo, J. C., D. X. Tan, R. M. Sainz, M. Natarajan, S. Lopez-Burillo, and R. J. Reiter. 2003. Protection against oxidative protein damage induced by metal-catalyzed reaction or alkylperoxyl radicals: Comparative effects of melatonin and other antioxidants. Biochim. Biophys. Acta 1620:139-150.

Nabenishi, H., H. Ohta, T. Nishimoto, T. Morita, K. Ashizawa, and Y. Tsuzuki. 2012a. The effects of cysteine addition during in vitro maturation on the developmental competence, ROS, GSH and apoptosis level of bovine oocytes exposed to heat stress. Zygote 20:249-259.

Nabenishi, H., S. Takagi, H. Kamata, T. Nishimoto, T. Morita, K. Ashizawa, and Y. Tsuzuki. 2012b. The role of mitochondrial transition pores on bovine oocyte competence after heat stress, as determined by effects of cyclosporin A. Mol. Reprod. Dev. 79:31-40.

Ortega, M. S., A. C. Denicol, J. B. Cole, D. J. Null, and P. J. Hansen. 2016. Use of single nucleotide polymorphisms in candidate genes associated with daughter pregnancy rate for prediction of genetic merit for reproduction in Holstein cows. Anim. Genet. 47:288-297.

Papis, K., O. Poleszczuk, E. Wenta-Muchalska, and J. A. Modlinski. 2007. Melatonin effect on bovine embryo development in vitro in relation to oxygen concentration. J. Pineal Res. 43:321-326.

Paula-Lopes, F. F., Y. M. Al-Katanani, A. C. Majewski, L. R. McDowell, and P. J. Hansen. 2003a. Manipulation of antioxidant status fails to improve fertility of lactating cows or survival of heatshocked embryos. J. Dairy Sci. 86:2343-2351.

Paula-Lopes, F. F., C. Cc, Y. M. Al-Katanani, K. Ce, R. M. Rivera, S. Tekin, A. C. Majewski, O. M. Ocon, T. A. Olson, and P. J. Hansen. 2003b. Genetic divergence in cellular resistance to heat shock in cattle: differences between breeds developed in temperate versus hot climates in responses of preimplantation embryos, reproductive tract tissues and lymphocytes to increased culture temperatures. Reproduction 125:285-294.

Putney, D. J., M. Drost, and W. W. Thatcher. 1989. Influence of summer heat stress on pregnancy rates of lactating dairy cattle following embryo transfer or artificial insemination. Theriogenology $31: 765-778$

Radons, J. 2016. The human HSP70 family of chaperones: Where do we stand? Cell Stress Chaperones 21:379-404.

Ray, P. D., B.-W. Huang, and Y. Tsuji. 2012. Reactive oxygen species (ROS) homeostasis and redox regulation in cellular signaling. Cell. Signal. 24:981-990.

Rho, G.-J., S. B, D.-S. Kim, W.-J. Son, S.-R. Cho, J.-G. Kim, M. K. B, and S.-Y. Choe. 2007. Influence of in vitro oxygen concen- trations on preimplantation embryo development, gene expression and production of Hanwoo calves following embryo transfer. Mol. Reprod. Dev. 74:486-496.

Rodriguez, C., J. C. Mayo, R. M. Sainz, I. Antolín, F. Herrera, V. Martín, and R. J. Reiter. 2004. Regulation of antioxidant enzymes: A significant role for melatonin. J. Pineal Res. 36:1-9.

Rosenkrans, C. Jr., A. Banks, S. Reiter, and M. Looper. 2010. Calving traits of crossbred Brahman cows are associated with Heat Shock Protein 70 genetic polymorphisms. Anim. Reprod. Sci. 119:178182.

Sakatani, M., N. V. Alvarez, M. Takahashi, and P. J. Hansen. 2012. Consequences of physiological heat shock beginning at the zygote stage on embryonic development and expression of stress response genes in cattle. J. Dairy Sci. 95:3080-3091.

Sakatani, M., S.-I. Kobayashi, and M. Takahashi. 2004. Effects of heat shock on in vitro development and intracellular oxidative state of bovine preimplantation embryos. Mol. Reprod. Dev. 67:77-82.

Sakatani, M., I. Suda, O. Tomoyuki, S. Kobayashi, S. Kobayashi, and M. Takahashi. 2007. Effects of purple sweet potato anthocyanins on development and intracellular redox status of bovine preimplantation embryos exposed to heat shock. J. Reprod. Dev. 53:605-614.

Sartori, R., R. Sartor-Bergfelt, S. A. Mertens, J. N. Guenther, J. J. Parrish, and M. C. Wiltbank. 2002. Fertilization and early embryonic development in heifers and lactating cows in summer and lactating and dry cows in winter. J. Dairy Sci. 85:2803-2812.

Silva, C. F., E. S. Sartorelli, A. C. S. Castilho, R. A. Satrapa, R. Z. Puelker, E. M. Razza, J. S. Ticianelli, H. P. Eduardo, B. Loureiro, and C. M. Barros. 2013. Effects of heat stress on development, quality and survival of Bos indicus and Bos taurus embryos produced in vitro. Theriogenology 79:351-357.

Slominski, R. M., R. J. Reiter, N. Schlabritz-Loutsevitch, R. S. Ostrom, and A. T. Slominski. 2012. Melatonin membrane receptors in peripheral tissues: Distribution and functions. Mol. Cell. Endocrinol. 351:152-166.

Takahashi, M. 2012. Oxidative stress and redox regulation on in vitro development of mammalian embryos. J. Reprod. Dev. 58:1-9.

Tan, D. X., R. Hardeland, L. C. Manchester, B. Poeggeler, S. LopezBurillo, J. C. Mayo, R. M. Sainz, and R. J. Reiter. 2003. Mechanistic and comparative studies of melatonin and classic antioxidants in terms of their interactions with the ABTS cation radical. J. Pineal Res. 34:249-259. 


\section{Interpretive summary}

\section{Interactions of human chorionic gonadotropin with genotype and parity on fertility}

3 responses of lactating dairy cows. by Adriana Zolini et al. There is much variability in response

4 of cows to treatments that potentially improve fertility. In this study, it was demonstrated that the

5 effectiveness of treatment of lactating cows with human chorionic gonadotropin (hCG) at day 5

6 after AI depended on parity and genotype. In particular, hCG was more effective for primiparous

7 cows than multiparous cows, and was associated with a single nucleotide polymorphisms (SNP)

8 in COQ9. Fertility of cows treated with vehicle was greatest for the AA allele whereas fertility

9 was lowest for the same genotype for cows treated with hCG. These results indicate that

10 information on a cow's parity and genotype can be used to identify populations of animals that

11 respond positively to fertility treatment. 
RUNNING HEAD: GENOTYPE AND PARITY EFFECT ON HCG RESPONSE

14 Interactions of human chorionic gonadotropin with genotype and parity on fertility responses of lactating dairy cows

16 A.M. Zolini*, W.G. Ortiz*, E. Estrada-Cortes*, M.S. Ortega*§, S. Dikmen†, F. Sosa,‡ J.O.

17 Giordano¥, and P.J Hansen*\#

$18 *$ Department of Animal Sciences, D.H. Barron Reproductive and Perinatal Biology Research 19 Program, and Genetics Institute, University of Florida, Gainesville Florida 32611-0910 USA

20 University of Uludag, Faculty of Veterinary Medicine, Department of Animal Science, Bursa, 21 Turkey.

‡ Department of Animal Science, Cornell University, Ithaca, New York 14853.

$\S$ Present address: Division of Animal Sciences, University of Missouri, Columbia, Missouri 65211.

\# Corresponding author: Peter J. Hansen, PO Box 110910, University of Florida, Gainesville, FL 32611-0910, USA; Tel.: +1-352-392-5590; Fax: +1-352-392-5595; pjhansen@ufl.edu 


\begin{abstract}
Fertility-promoting effects of treatment of lactating dairy cattle with human chorionic gonadotropin (hCG) after artificial insemination (AI) have been variable. Here, we tested whether fertility response to hCG in lactating Holsteins cows interacts with genotype and parity. Primiparous ( $n=538)$ and multiparous $(n=613)$ cows were treated with hCG $(3,300$ IU) or vehicle $5 \mathrm{~d}$ after AI. Pregnancy was diagnosed on days 32 and 60 after AI. A subset of cows ( $\mathrm{n}=593$ 701) were genotyped for four single nucleotide polymorphisms (SNP) previously associated with fertility. Treatment with hCG increased progesterone concentration on day 12 after AI regardless of genotype or parity. Pregnancy per AI was improved by hCG in primiparous cows but not in multiparous cows. Moreover, hCG treatment interacted with a SNP in COQ9 to affect fertility. Fertility of cows treated with vehicle was greatest for the AA allele whereas fertility was lowest for the same genotype among cows treated with hCG. Pregnancy per AI was also affected by genotype for HSPA1L and PGR, but there were no interactions with treatment. Genotype for a SNP in PARM1 was not associated with fertility. Overall, results show that variation in response to hCG treatment on fertility depends on parity and interacts with a SNP in COQ9.

Keywords: hCG, genotype, parity, SNP, pregnancy, fertility
\end{abstract}


45

46

47

\section{INTRODUCTION}

Personalized medicine is a form of individualized medical therapy in which knowledge from genetics is combined with clinical data to guide clinical treatment. An example of personalized treatment is exclusion of women with breast cancer from tamoxifen treatment based on screening for a SNP in CYP2D6 associated with reduced function of the enzyme (Schroth et al., 2009; Zeng et al., 2013; Elia et al., 2018). Personalized treatments could conceivably be important in livestock production. Use of genetic information to identify animals for which treatments are likely to be efficacious could reduce the number of animals receiving treatment and thereby achieving cost savings from reduced drug use, labor costs, and withdrawal of milk and meat from the human food chain. Moreover, effectiveness of treatment would increase because only those animals with predisposition for positive response would receive treatment.

In cattle, one type of therapy that could potentially be made more effective through use of personalized medicine is hormonal administration to improve fertility. There is a great deal of between-study variation in effectiveness of some hormonal treatments administered after AI for improving fertility including GnRH (Peters et al., 2000), human chorionic gonadotropin (hCG) (Nascimento et al., 2013), and progesterone (Yan et al., 2016). Some of this variation is likely due to small sample size but there may also be environmental or genetic differences between herds affecting efficacy of treatment.

Here we tested whether effects of one of these hormonal treatments on the fertility of lactating cows depends upon genotype as well as parity. The hormonal therapy tested was hCG treatment at day 5 after AI. Administration of hCG during the early luteal phase can be used to induce ovulation of the first-wave dominate follicle, formation of a functional accessory corpus 
luteum and an increase in circulating progesterone concentrations (Schmitt et al., 1996; Santos et al., 2001). Progesterone is critical for pregnancy maintenance and can regulate secretion of proteins and other molecules from the uterine endometrium (Forde et al., 2010) and advance the timing of trophoblast elongation that is a prerequisite inhibition of luteolysis (Lonergan et al., 2013; Lonergan and Forde, 2014). Treatment with hCG at day 5 after artificial insemination (AI) has been reported to improve pregnancy per AI in lactating cows but there is substantial variation in effectiveness of the treatment in the literature (Nascimento et al., 2013). One factor affecting the efficacy of hCG treatment is parity, with hCG treatment being more effective for primiparous females than multiparous animals (Nascimento et al., 2013). Season of the year may also be important because heat stress can decrease circulating concentrations of progesterone (Howell et al., 1994) and treatment with the related molecule, equine chorionic gonadotropin, at day 5 after AI improved pregnancy per AI in lactating cows exposed to heat stress (Garcia-Ispierto et al., 2013).

To evaluate hCG $\mathrm{x}$ genotype interactions, animals in the present experiment were genotyped for SNP at 4 loci previously associated with reproductive function in cattle. One SNP is a $\mathrm{G} \rightarrow \mathrm{A}$ missense mutation in coenzyme Q9 (COQ9) that causes an amino acid change from aspartic acid to asparagine at position 53 of the protein. The A allele is associated with higher genetic merit for daughter pregnancy rate (DPR) and cow conception rate (Cochran et al., 2013b; Ortega et al., 2016a) and higher phenotypic measurements of fertility (Ortega et al., 2017c). The A allele is also associated with more efficient mitochondria in peripheral blood mononuclear cells, and increased mitochondrial DNA copy number in oocytes (Ortega et al., 2017c). Heterozygotes had increased follicle number and antimullerian hormone concentrations than either homozygote (Ortega et al., 2017c). The second SNP is a cytosine deletion in the promoter 
region of $H S P A 1 L$ which encodes for a member of the heat shock protein 70 family. This SNP is associated with increased transcript abundance for HSPA1L in response to heat shock (Basiricò et al., 2011) and increased survival of cells (Basiricò et al., 2011) and embryos (Ortega et al., 2016b) after heat shock. The mutation is also associated with increased proportion of cultured embryos developing to the blastocyst stage (Cochran et al., 2013b) but with reduced calf crop in Brahman cows (Rosenkrans et al., 2010). The third SNP examined is a $\mathrm{G} \rightarrow \mathrm{C}$ missense mutation in prostate androgen-regulated mucin-like protein 1 (PARM1) that induces an amino acid change from glycine to alanine at position 232 (Ortega et al., 2017b). The G allele has been associated with higher DPR (Cochran et al., 2013b) and increased embryonic development in vitro (Cochran et al., 2013a). The last SNP examined is a $\mathrm{C} \rightarrow \mathrm{G}$ mutation in the third intronic region of PGR (Driver et al., 2009). The G allele has been related to increased capacity of embryos to develop to the blastocyst stage in vitro (Driver et al, 2009), reduced number of oocytes recovered after superovulation (Yang et al., 2011) and increased ability of cows to maintain lower body temperature during the summer (Dikmen et al., 2015).

\section{Animals and Management}

\section{MATERIALS AND METHODS}

The experiment was conducted on a commercial dairy farm in northern Florida (Alliance

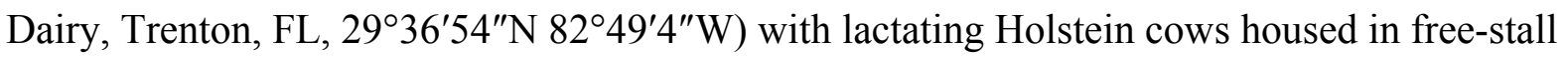
barns equipped with fans and sprinklers. Cows were milked three times daily and fed a total mixed ration. Animal procedures were approved by the University of Florida Institutional Animal Care and Use Committee. All procedures, including injections, pregnancy diagnosis, 
blood collection, and timed artificial insemination (TAI) were performed while cows were restrained in self-locking head gates at the feed line.

\section{Experimental Design and Treatments}

Cows were randomly assigned to receive intramuscular injection of either 3,300 IU hCG (Chorulon, Merck Animal Health, Millsboro, DE) or equivalent volume (3.3 ml) of vehicle (diluent) on day 5 after the first insemination following calving. The study was conducted over two years. The first year involved 283 primiparous cows and 489 multiparous cows that received first insemination after calving from June to September 2016, corresponding to hot months of the year. For the second year, the experiment was replicated for 297 primiparous cows receiving first insemination after calving in July and August of 2017.

Twice weekly, a group of 20 to 50 cows were enrolled in the Double-Ovsynch protocol (Souza et al., 2008) to allow TAI at 75 to $80 \mathrm{~d}$ after calving. Multiparous cows were inseminated with conventional semen and primiparous cows were inseminated with either conventional $(\mathrm{n}=$ $343)$ or sexed-sorted $(\mathrm{n}=237)$ semen. At the time of hCG or vehicle injection (day 5 after AI), body condition score (BCS) was estimated as described (Ferguson et al., 1994).

For cows in year 1 only, a blood sample $(7 \mathrm{~mL})$ was collected on day 12 after AI by puncture of the coccygeal blood vessels using vacutainer tubes containing sodium ethylenediamine tetraacetic acid (Becton \& Dickinson, Rutherford, NJ, USA). The samples were placed immediately on ice and brought to the laboratory within $6 \mathrm{~h}$ of collection. At the laboratory, $2 \mathrm{~mL}$ of blood were collected and stored at $-20^{\circ} \mathrm{C}$ for later genotype analyses. The remaining sample was centrifuged at $2,000 \times \mathrm{g}$ at $-4^{\circ} \mathrm{C}$ for $20 \mathrm{~min}$ for separation of plasma.

Plasma samples were frozen at $-20^{\circ} \mathrm{C}$ for later progesterone analyses. 

$60 \pm 3$ after artificial insemination. A cow was determined pregnant when an embryonic vesicle with a viable embryo (presence of heartbeat) was detected.

\section{Genotyping}

Cows from the first year of the experiment were genotyped for SNP present in COQ9 (rs109301586), HSPA1L (HSP70C895D), PARM1 (rs111027720), and PGR (rs109506766).

Details of these SNP are presented in supplemental material in Cochran et al. (2013b). Frozen samples of whole blood were thawed and DNA extraction was performed using the Puregene Blood Core Kit (Qiagen, Germantown, MD, USA) according to the manufacturer's instructions. Genotyping was performed by PCR-based KASP assay (LGC Genomics, Middlesex, UK). The assay is a polymerase-chain reaction (PCR)-based technique involving a common reverse primer and two allele-specific forward primers, where one allele-specific primer is labeled with fluorescein amidite and the second to hexachlorofluorescein. Primers used for genotyping are described in Table 1. Depending on SNP, the total number of animals genotyped varied between 593 and 701 because of no-calls.

Each PCR reaction included $5 \mu \mathrm{L}$ extracted DNA $(20 \mathrm{ng} / \mathrm{ml}), 5 \mu \mathrm{L} 2 \times$ supermix with low ROX (LGC Genomics), and $0.14 \mu \mathrm{L}$ KASP by design primer mix. Amplification and analysis were performed using a CFX96 Real-Time PCR detection System (Bio-Rad, Hercules, CA, USA). Thermal cycling conditions were $94^{\circ} \mathrm{C}$ for $15 \mathrm{~min}$, followed by 10 cycles of $94^{\circ} \mathrm{C}$ for $20 \mathrm{~s}$ and $61^{\circ} \mathrm{C}$ for $60 \mathrm{~s}$, where the second temperature was decreased $0.6^{\circ} \mathrm{C}$ per cycle to achieve a final annealing temperature of $55^{\circ} \mathrm{C}$ at the end of the 10 th cycle. The reaction proceeded for an additional 26 cycles of $94^{\circ} \mathrm{C}$ for $20 \mathrm{~s}$ and $55^{\circ} \mathrm{C}$ for $60 \mathrm{~s}$, and a read step of $37^{\circ} \mathrm{C}$ for $60 \mathrm{~s}$. To improve genotype cluster visibility, 3 additional cycles of $94^{\circ} \mathrm{C}$ for $20 \mathrm{~s}$ and $55^{\circ} \mathrm{C}$ for $60 \mathrm{~s}$ and a 
final read step at $37^{\circ} \mathrm{C}$ for $60 \mathrm{~s}$ were performed. In each run, DNA samples from whole blood of cows of known genotypes were analyzed as controls. Determination of the genotype was performed using the allelic discrimination feature of the CFX96 machine.

\section{Determination of Progesterone Concentrations}

Plasma concentrations of progesterone were determined in duplicate using a commercial solid-phase, no-extraction radioimmunoassay (ImmuChem Coated Tube, MP Biomedicals, Costa Mesa, CA). In the five assays performed, quality control samples with concentrations of progesterone representative of the diestrous phase of the estrous cycle $(3.7 \mathrm{ng} / \mathrm{mL})$ were included twice (at the beginning and end) of each assay to determine variation within-and across assays. The sensitivity of the assay was $0.1 \mathrm{ng} / \mathrm{mL}$ and the average intra-assay and inter-assay CV for the quality control sample was $6.1 \%$ and $6.6 \%$.

\section{Statistical Analysis}

Data on pregnancy per AI were analyzed with the GLIMMIX procedure of the Statistical Analysis System (SAS) v 9.4 (SAS Institute, Cary, NC, USA) with the independent variable, pregnancy outcome (pregnant, non-pregnant), modeled as having a binomial distribution. Data from year 1 of the experiment were analyzed using two types of models. The first analysis included effects of hCG treatment, parity, month of insemination, and two-way interactions between hCG treatment, month and parity. BCS was included in the model as a covariate. The second model was used to analyze the effect of each SNP in four separate analyses. For each analysis, the model included hCG treatment, parity, month of insemination, genotype, two-way interactions of hCG treatment with month, parity and genotype and with BCS as a covariate. 
An additional analysis of pregnancy data from primiparous cows in years 1 and 2 was performed. The statistical model included effects of hCG treatment, type of semen (sexed vs conventional), month-year of insemination, BCS, and two-way interactions between hCG treatment, month-year and parity.

Effects on progesterone concentrations were first analyzed by GLIMMIX procedure of SAS to estimate the effect of parity and treatmet on the proportion of cows considered to have a functional corpus luteum (progesterone concentration $>1 \mathrm{ng} / \mathrm{ml}$ ) at day 12 after TAI. For this analysis the independent variable, presence of a functional corpus luteum, was modeled as having a binomial distribution. The second set of analyses was peformed by the GLM procedure of SAS and only included data from cows classified as having a functional corpus luteum. The model included hCG treatment, parity, month of insemination, genotype, two-way interactions of hCG treatment with month, parity and genotype and with BCS as a covariate.

For all analyses, a mean separation test using the DIFF option of Proc GLIMMIX was performed to compare differences between individual means for those effects with $\mathrm{P}<0.100$ and and that involved multiple degrees-of-freedom. Differences identified by the DIFF option with a $\mathrm{P}=0.05$ or less are reported.

\section{Interaction between hCG Treatment and Parity on Pregnancy per AI}

\section{RESULTS}

In year 1 , there was no overall effect of hCG on pregnacy per AI at either $\mathrm{d} 32$ or 60 after insemination. Treatment with hCG tended to increase pregnancy per AI in primiparous cows but not in multiparous cows (Figure $1 \mathrm{~A}$ and $\mathrm{B}$ ). The probability value for the treatment $\mathrm{x}$ parity interaction was 0.098 for pregnancy per $\mathrm{AI}$ at $\mathrm{d} 32$ and 0.063 for pregnancy per $\mathrm{AI}$ at $\mathrm{d}$ 
60. Inclusion of genotype for HSPA1L in the model resulted in the parity $\mathrm{x}$ treatment interaction being significant for pregnancy per $\mathrm{AI}$ at $\mathrm{d} 32$ of gestation $(P=0.038)$ and close to significant at $\mathrm{d}$ 60 of gestation $(P=0.059)$. Similar results were found for inclusion of genotype for COQ9 and PGR (results not shown).

Analysis of all data from primiparous cows in year 1 and 2 (Figure $1 \mathrm{C}$ and D) also indicated that hCG treatment tended to increase pregnancy per AI in primiparous cows. The effect of hCG was $P=0.159$ for pregnancy per $\mathrm{AI}$ at $\mathrm{d} 32$ of gestation and $P=0.063$ for pregnancy per AI at d 60 of gestation. There was no effect $(\mathrm{P}>0.200)$ of semen type (conventional vs sexed) or interaction with hCG treatment for pregnancy per AI at d 32 or 60 .

\section{Interactions of hCG Treatment and Genotype on Pregnancy per AI (Year 1)}

The effect of the SNP in COQ9 and its interaction with hCG treatment is presented in Figure 2. There was a hCG $\mathrm{x}$ genotype interaction for pregnancy per $\mathrm{AI}$ at $\mathrm{d} 32(P=0.016)$ and 60 $(P=0.012)$ of gestation. When treated with vehicle, AA cows had a higher pregnancy per AI at d 32 and 60 of gestation than AG cows, with GG cows being intermediate. When treated with hCG, AA cows had lower pregnancy per AI at d 32 than AG cows, with GG cows being intermediate.

Results for the effect of the SNP in HSPA1L and its interaction with hCG treatment on pregnancy per AI and response to hCG is presented in Figure 3. Pregnancy per AI was affected by genotype for HSPA1L at d $32(\mathrm{P}=0.009)$ and $60(\mathrm{P}=0.001)$ after TAI. There were, however, no interactions between hCG treatment and HSPA1L genotype for pregnancy per AI at either day. For pregnancy per $\mathrm{AI}$ at d 32, mean separation tests indicated that $\mathrm{CD}$ differed from $\mathrm{CC}$ $(\mathrm{P}=0.005)$ and $\mathrm{DD}(\mathrm{P}=0.041)$ but that $\mathrm{CC}$ and $\mathrm{DD}$ were similar $(\mathrm{P}>0.10)$. For pregnancy per $\mathrm{AI}$ 
at $\mathrm{d} 60$, mean separation tests indicated that $\mathrm{CD}$ differed from $\mathrm{CC}(\mathrm{P}=0.001)$ and $\mathrm{DD}(\mathrm{P}=0.052)$ and CC and DD were similar $(\mathrm{P}>0.100)$.

There was no effect $(\mathrm{P}>0.100)$ of the genotype for the SNP in PARM1 on pregnancy per $\mathrm{AI}$ at $\mathrm{d} 32$ or 60 or any interactions between genotype and hCG (Figure 4).

Pregnancy per AI was affected by genotype for $P G R$ at d $32(P=0.041)$ after TAI and tended to be affected $(P=0.080)$ at d 60 after TAI (Figure 5). There was no interaction between the SNP and hCG treatment. For pregnancy per AI at d 32, mean separation tests indicated that CC differed from $\mathrm{CG}(\mathrm{P}=0.034)$ but other means were not different from each other $(\mathrm{P}>0.100)$. For pregnancy per $\mathrm{AI}$ at d 60, mean separation tests indicated that $\mathrm{CC}$ differed from $\mathrm{CG}$ $(\mathrm{P}=0.025)$ but other means were not different from each other.

\section{Progesterone Concentrations}

Presence of a functional corpus luteum was defined as a progesterone concentration at $\mathrm{d}$ 12 after insemination $>1 \mathrm{ng} / \mathrm{ml}$ in $90.6 \%$ of the primiparous cows and $93.2 \%$ of the multiparous cows. Presence of a functional corpus luteum was not affected by parity, hCG treatment or genotype $(\mathrm{P}>0.100)$.

Progesterone concentration at d 12 after insemination for animals with a functional corpus luteum was higher $(P=0.0001)$ for cows treated with hCG than for cows treated with vehicle $(3.2 \pm 0.08$ vs. $4.6 \pm 0.09 \mathrm{ng} / \mathrm{mL})$. The difference in progesterone concentration was greater (interaction, $P=0.051)$ for primiparous cows $(3.4 \pm 0.13 \mathrm{vs.} 5.1 \pm 0.13 \mathrm{ng} / \mathrm{mL})$ than for multiparous cows $(3.1 \pm 0.10$ vs. $4.3 \pm 0.10 \mathrm{ng} / \mathrm{mL})$. Progesterone concentration was not affected by genotype $(P>0.100)$ and there were no interactions $(P>0.100)$ between genotype and hCG treatment. 


\section{DISCUSSION}

Here we confirm previous results that fertility response to hCG is greater for primiparous cows than multiparous cows (Nascimento et al., 2013). We also show, for the first time, that there was an interaction between genotype and hCG affecting fertility. In particular, the association between a SNP in COQ9 previously shown to be related to fertility in cattle (Cochran 2013b, Ortega et al., 2017b) and pregnancy per AI depended upon whether cows were treated with hCG. Associations of SNPs in HSPA1L and PGR with pregnancy per AI were also found. fertility in dairy cattle (Cochran et al., 2013b; Ortega et al., 2017b). In the present study, pregnancy per AI among animals treated with vehicle was highest for cows with the AA genotype. Differences among genotypes were altered for cows treated with hCG with AA cows being the least fertile. Indeed, hCG increased pregnancy per AI in AG cows but decreased pregnancy per AI in cows AA cows. Thus, results are indicative that one can use genotyping for COQ9 to identify animals that would respond positively to hCG as compared to those that will experience, on average, decreased fertility.

The mechanism by which hCG decreased pregnancy per AI in cows with the AA genotype while increasing pregnancy per $\mathrm{AI}$ in $\mathrm{AG}$ cows is not known. COQ9, along with other COQ proteins (COQ2-COQ8), is involved in the biosynthesis of COQ10 (Tran and Clarke, 2007; Ben-Meir et al., 2015), which is a component of the mitochondrial electron transport system that is required for mitochondrial adenosine triphosphate synthesis. The A allele, which has a

267 frequency of 49-51\% in Holsteins (Ortega et al., 2016a), is associated with enhanced mitochondrial function (Ortega et al., 2017c). One possibility is that actions of hCG on reproductive tissues like endometrium (Shemesh et al., 2001) and corpus luteum (Niswender et 
al., 2000) have negative consequences when mitochondrial function is enhanced. In the endometrium, activation of $\mathrm{LH}$ receptor induces expression of cyclooxygenase which is associated with increased $\mathrm{PGF}_{2 \alpha}$ production that can trigger luteolysis (Shemesh et al., 2001).

Since expression of endometrial LH receptor is low during the luteal phase (Shemesh et al., 2001) treatment with hCG $5 \mathrm{~d}$ after TAI may not be able to stimulate enough $\mathrm{PGF}_{2 \alpha}$ synthesis to trigger luteolysis. However, in cows carrying the AA allele, higher mitochondrial function could conceivably increase cytoplasmic ATP concentration and intensify cellular response to hCG in a way that leads to luteolytic release of $\mathrm{PGF}_{2 \alpha}$.

There was no effect of COQ9 genotype on progesterone concentration at d 12 after AI, indicating either no effect of genotype on luteolysis or that luteolysis induced by the interaction between treatment and the SNP for COQ9 occurs after d 12. Results regarding progesterone response to hCG are also indicative that the relationship between the SNP in COQ9 and response to hCG was not caused by a differential effect on ability of hCG to induce accessory corpus luteum because progesterone concentrations were similar between groups.

It is also possible that the SNP in COQ9 is acting through additional mechanisms [note that the SNP is related to follicle number on the ovary; (Ortega et al., 2017c)] or that the SNP is in linkage disequilibrium with a causative mutation located elsewhere in COQ9 or in other nearby genes.

Although SNP in HSPA1L and PGR did not affect response to hCG treatment, pregnancy per AI was associated with allelic variation in both genes. For HSPA1L, cows that were heterozygous for the locus in HSPA1L had a higher pregnancy per AI than cows homozygous for either allele. For $P G R, C C$ cows were the least fertile. These results were surprising. There was a lack of association between the mutation in HSPA1L and PGR for genetic or phenotypic 
measurements of fertility in Holsteins (Cochran et al., 2013a; Ortega et al., 2016b, 2017a) and the deletion mutation was associated with a reduced proportion of females pregnant during the breeding season for Brahman cows (Rosenkrans et al., 2010). Small sample size could explain some of these discrepanices. In addition, the present experiment was performed during the hot months of the year and it is possible that the increase in pregnacy rate for cows heterozygous for the deletion mutation in HSPA1L is related to embryonic resistance to the deleterious effect of heat stress on embryonic survival (Hansen, 2015). The deletion mutation in HSPA1L, which encodes for a member of the heat shock protein 70 family, results in increased expression of the protein in response to heat shock (Basiricò et al., 2011) and is associated with cellular resistance to elevated temperature (Basiricò et al., 2011), and increased competence of embryos to develop to the blastocyst stage in culture (Cochran et al., 2013a) and survive to heat shock (Ortega et al., 2016b). Heat stress may also be a factor in the inconsistency in results for PGR. The G variant in this gene has been related to maintenance of low body temperature in Holteins cattle during heat stress (Dikmen et al., 2015).

Although the G allele in PARM1 was described to be associated with higher DPR, heifer conception rate and cow conception rate (Cochran et al., 2013b), the mutation in PARM1 was not associated with pregnacy rate in the present study. Ortega et al. (2016b) also did not find an association between the SNP in PARM1 and fertility traits. Inconsistency between studies casts doubt on the importance of the SNP in PARM1 being an important predictor of fertility in Holsteins

It was also found that hCG treatment was more effective for primiparous cows than multiparous cows. One possible reason for a higher fertility response to hCG in primiparous cows is that the increase in progesterone concentration at $\mathrm{d} 12$ after insemination caused by hCG 
was greater for primiparous cows than multiparous cows. High progesterone concentration

317 during the early pregnancy is associated with higher embryonic elongation and IFNT production

318 (Clemente et al., 2009; Lonergan et al., 2013). In addition, one possible reason for the difference in responses to hCG may reside in the fact that induction of a second ovulation on the side contralateral of the first ovulation reduces pregnancy per AI in multiparous but not primiparous cows (Baez et al., 2017). These authors proposed that the pregnancy response of multiparous cows to formation of a corpus luteum contralateral to the original corpus luteum results in early regression of both structures. Due to the large uterine size in multiparous cows, the physical diffusion of IFNT from the developing conceptus to the contralateral horn may be compromised as well as the maintenance of the accessory CL (Baez et al., 2017).

There are at least two possible explanations for why hCG increased progesterone concentrations to a greater degree for primiparous cows than for multiparous cows. First, it is possible that primiparous cows are more likely to form an accessory CL than multiparous cows. Also, primiparous cows tend to produce less milk than multiparous cows (Nebel and McGilliard, 1993). Progesterone clearance is inversely related to milk yield (Sangsritavong et al., 2002) and differences in rate of metabolism due to parity could affect circulating concentrations of progesterone.

In conclusion, treatment with hCG at $\mathrm{d} 5$ after TAI can increase fertility in primiparous cows exposed to heat stress while not being effective for multiparous cows. In addition, fertility is affected by genotype for COQ9, HSPA1L and PGR and there is an interaction between hCG treatment and genotype at the COQ9 locus. This last result is the first evidence in cattle that consideration of genetic information could be informative regarding effectiveness of a fertility treatment. Under current genetic screening systems in cattle, cattle are genotyped at thousands 
of individual loci. It is likely that use of all this genetic information can improve the precision of predicting which animals are most likely to respond to therapeutic treatments. Targeting treatment to those animals most likely to respond could increase efficicacy of therapeutics and avoid waste caused by treating animals that will not respond to the therapy.

3

\section{ACKNOWLEDGEMENTS}

The authors thank the owners and staff of Alliance Dairies (Trenton, FL) for the use of cows and facilities and, in particular, Nilo Francisco and Bong Velasquez for help in implementing the study. The authors also thank Dr. Todd Bilby and Merck \& Co. for providing hCG and Susanne Pelton from the Department of Animal Science at Cornell University for processing the radioimmunoassy analyses. This research was supported by Research Grant Award No. US4719-14, the United States - Israel Binational Agricultural Research and Development Fund, Agriculture and Food Research Initiative Competitive Grant no. 2013-68004-20365 from the USDA National Institute of Food and Agriculture and Coordenação de Aperfeiçoamento de Pessoal de Nível Superior. 
356

357

358

359

360

361

362

363

364

365

366

367

368

369

370

371

372

373

Baez, G.M., E. Trevisol, R. V. Barletta, B.O. Cardoso, A. Ricci, J.N. Guenther, N.E. Cummings, and M.C. Wiltbank. 2017. Proposal of a new model for CL regression or maintenance during pregnancy on the basis of timing of regression of contralateral, accessory CL in pregnant cows. Theriogenology 89:214-225. doi:10.1016/j.theriogenology.2016.09.055.

Basiricò, L., P. Morera, V. Primi, N. Lacetera, A. Nardone, and U. Bernabucci. 2011. Cellular thermotolerance is associated with heat shock protein 70.1 genetic polymorphisms in Holstein lactating cows. Cell Stress Chaperones 16:441-448. doi:10.1007/s12192-0110257-7.

Ben-Meir, A., E. Burstein, A. Borrego-Alvarez, J. Chong, E. Wong, T. Yavorska, T. Naranian, M. Chi, Y. Wang, Y. Bentov, J. Alexis, J. Meriano, H.-K. Sung, D.L. Gasser, K.H. Moley, S. Hekimi, R.F. Casper, and A. Jurisicova. 2015. Coenzyme Q10 restores oocyte mitochondrial function and fertility during reproductive aging. Aging Cell 14:887-895. doi:10.1111/acel.12368.

Clemente, M., J. de La Fuente, T. Fair, A. Al Naib, A. Gutierrez-Adan, J.F. Roche, D. Rizos, and P. Lonergan. 2009. Progesterone and conceptus elongation in cattle: a direct effect on the embryo or an indirect effect via the endometrium?. Reproduction 138:507-17. doi:10.1530/REP-09-0152.

Cochran, S.D., J.B. Cole, D.J. Null, and P.J. Hansen. 2013a. Single nucleotide polymorphisms in candidate genes associated with fertilizing ability of sperm and subsequent embryonic development in cattle. Biol. Reprod. 89:69-75. doi:10.1095/biolreprod.113.111260.

Cochran, S.D., J.B. Cole, D.J. Null, and P.J. Hansen. 2013b. Discovery of single nucleotide polymorphisms in candidate genes associated with fertility and production traits in Holstein cattle. BMC Genet. 14:49-72. doi:10.1186/1471-2156-14-49.

Dikmen, S., X.Z. Wang, M.S. Ortega, J.B. Cole, D.J. Null, and P.J. Hansen. 2015. Single nucleotide polymorphisms associated with thermoregulation in lactating dairy cows exposed to heat stress. J. Anim. Breed Genet. 132:409-419. doi:10.1111/jbg.12176.

Driver, A.M., W. Huang, S. Gajic, R.L. Monson, G.J.M. Rosa, and H. Khatib. 2009. Short communication: Effects of the progesterone receptor variants on fertility traits in cattle. J. Dairy Sci. 92:4082-4085. doi:10.3168/jds.2009-2013. 
Elia, J., G. Ungal, C. Kao, A. Ambrosini, N. De Jesus-Rosario, L. Larsen, R. Chiavacci, T. Wang, C. Kurian, K. Titchen, B. Sykes, S. Hwang, B. Kumar, J. Potts, J. Davis, J. Malatack, E. Slattery, G. Moorthy, A. Zuppa, A. Weller, E. Byrne, Y.R. Li, W.K. Kraft, and H. Hakonarson. 2018. Fasoracetam in adolescents with ADHD and glutamatergic gene network variants disrupting mGluR neurotransmitter signaling. Nat. Commun. 9:4-12. doi:10.1038/s41467-017-02244-2.

Ferguson, J.D., D.T. Galligan, and N. Thomsen. 1994. Principal descriptors of body condition score in Holstein cows. J. Dairy Sci. 77:2695-2703. doi:10.3168/JDS.S00220302(94)77212-X.

Forde, N., T.E. Spencer, F.W. Bazer, G. Song, J.F. Roche, and P. Lonergan. 2010. Effect of pregnancy and progesterone concentration on expression of genes encoding for transporters or secreted proteins in the bovine endometrium. Physiol. Genomics 41:53-62. doi:10.1152/physiolgenomics.00162.2009.

Garcia-Ispierto, I., M.A. Roselló, F. De Rensis, and F. López-Gatius. 2013. A five-day progesterone plus eCG-based fixed-time AI protocol improves fertility over spontaneous estrus in high-producing dairy cows under heat stress. J. Reprod. Dev. 59:544-51. doi:10.1262/jrd.2013-041.

Hansen, P.J. 2015. Genetic variation in resistance of the preimplantation bovine embryo to heat shock. Reprod. Fertil. Dev. 27:22-30. doi:10.1071/RD14311.

Howell, J.L., J.W. Fuquay, and A.E. Smith. 1994. Corpus luteum growth and function in lactating Holstein cows during spring and summer. J. Dairy Sci. 77:735-739. doi:10.3168/JDS.S0022-0302(94)77007-7.

Lonergan, P., and N. Forde. 2014. Maternal-embryo interaction leading up to the initiation of implantation of pregnancy in cattle. Animal 8:64-69. doi:10.1017/S1751731114000470.

Lonergan, P., L. O 'hara, and N. Forde. 2013. Role of diestrus progesterone on endometrial function and conceptus development in cattle. Anim. Reprod 10:223-227.

Nascimento, A.B., R.W. Bender, A.H. Souza, H. Ayres, R.R. Araujo, J.N. Guenther, R. Sartori, and M.C. Wiltbank. 2013. Effect of treatment with human chorionic gonadotropin on day 5 after timed artificial insemination on fertility of lactating dairy cows. J. Dairy Sci. 96:28732882. doi:10.3168/JDS.2012-5895. 
Nebel, R.L., and M.L. McGilliard. 1993. Interactions of high milk yield and reproductive performance in dairy cows. J. Dairy Sci. 76:3257-3268. doi:10.3168/JDS.S00220302(93)77662-6.

Niswender, G.D., J.L. Juengel, P.J. Silva, M.K. Rollyson, and E.W. McIntush. 2000. Mechanisms controlling the function and life span of the corpus luteum. Physiol. Rev. 80:129. doi:10.1152/physrev.2000.80.1.1.

Ortega, M.S., A.C. Denicol, J.B. Cole, D.J. Null, and P.J. Hansen. 2016a. Use of single nucleotide polymorphisms in candidate genes associated with daughter pregnancy rate for prediction of genetic merit for reproduction in Holstein cows. Anim. Genet. 47:288-297. doi:10.1111/age.12420.

Ortega, M.S., A.C. Denicol, J.B. Cole, D.J. Null, J.F. Taylor, R.D. Schnabel, and P.J. Hansen. 2017a. Association of single nucleotide polymorphisms in candidate genes previously related to genetic variation in fertility with phenotypic measurements of reproductive function in Holstein cows. J. Dairy Sci. 100:3725-3734. doi:10.3168/jds.2016-12260.

Ortega, M.S., J.J. Kurian, R. McKenna, and P.J. Hansen. 2017b. Characteristics of candidate genes associated with embryonic development in the cow: Evidence for a role for WBP1 in development to the blastocyst stage. PLoS One 12:1-20. doi:10.1371/journal.pone.0178041.

Ortega, M.S., N.A.S. Rocha-Frigoni, G.Z. Mingoti, Z. Roth, and P.J. Hansen. 2016 b. Modification of embryonic resistance to heat shock in cattle by melatonin and genetic variation in HSPA1L. J. Dairy Sci. 99:9152-9164. doi:10.3168/JDS.2016-11501.

Ortega, M.S., S. Wohlgemuth, P. Tribulo, L.G.B. Siqueira, D.J. Null, J.B. Cole, M. V. Da Silva, and P.J. Hansen. 2017c. A single nucleotide polymorphism in COQ9 affects mitochondrial and ovarian function and fertility in Holstein cows. Biol. Reprod. 96:652-663. doi:10.1093/biolre/iox004.

Peters, A.R., T.A. Martinez, and A.J. Cook. 2000. A meta-analysis of studies of the effect of GnRH 11-14 days after insemination on pregnancy rates in cattle. Theriogenology 54:13171326.

Rosenkrans, C., A. Banks, S. Reiter, and M. Looper. 2010. Calving traits of crossbred Brahman cows are associated with heat shock protein 70 genetic polymorphisms. Anim. Reprod. Sci. 119:178-182. doi:10.1016/j.anireprosci.2010.02.005. 
Sangsritavong, S., D.K. Combs, R. Sartori, L.E. Armentano, and M.C. Wiltbank. 2002. High feed intake increases liver blood flow and metabolism of progesterone and estradiol-17 $\beta$ in dairy cattle. J. Dairy Sci. 85:2831-2842. doi:10.3168/jds.S0022-0302(02)74370-1.

Santos, J.E.P., W.W. Thatcher, L. Pool, and M.W. Overton. 2001. Effect of human chorionic gonadotropin on luteal function and reproductive performance of high-producing lactating Holstein dairy cows. J. Anim. Sci. 79:2881-2894.

Schmitt, E.J., C.M. Barros, P.A. Fields, M.J. Fields, T. Diaz, J.M. Kluge, and W.W. Thatcher. 1996. A cellular and endocrine characterization of the original and induced corpus luteum after administration of a gonadotropin-releasing hormone agonist or human chorionic gonadotropin on day five of the estrous cycle. J. Anim. Sci. 74:1915-1929.

Schroth, W., M.P. Goetz, U. Hamann, P.A. Fasching, M. Schmidt, S. Winter, P. Fritz, W. Simon, V.J. Suman, M.M. Ames, S.L. Safgren, M.J. Kuffel, H.U. Ulmer, J. Boländer, R. Strick, M.W. Beckmann, H. Koelbl, R.M. Weinshilboum, J.N. Ingle, M. Eichelbaum, M. Schwab, and H. Brauch. 2009. Association between CYP2D6 polymorphisms and outcomes among women with rearly stage breast cancer treated with tamoxifen. J.am. Med. Assn. 302:14291436. doi:10.1001/jama.2009.1420.

Shemesh, M., D. Mizrachi, M. Gurevich, Y. Stram, L.S. Shore, and M.J. Fields. 2001. Functional importance of bovine myometrial and vascular LH receptors and cervical FSH receptors.Semin. Reprod. Med. 19:87-96.

Souza, A.H., H. Ayres, R.M. Ferreira, and M.C. Wiltbank. 2008. A new presynchronization system (Double-Ovsynch) increases fertility at first postpartum timed AI in lactating dairy cows. Theriogenology 70: 208-215 doi:10.1016/j.theriogenology.2008.03.014.

Tran, U.C., and C.F. Clarke. 2007. Endogenous synthesis of coenzyme Q in eukaryotes. Mitochondrion 7 Suppl: S62-S71. doi:10.1016/j.mito.2007.03.007.

Yan, L., R. Robinson, Z. Shi, and G. Mann. 2016. Efficacy of progesterone supplementation during early pregnancy in cows: A meta-analysis. Theriogenology 85:1390-1398. doi:10.1016/j.theriogenology.2015.12.027.

Yang, W., K. Tang, S. Li, and L. Yang. 2011. Association analysis between variants in bovine progesterone receptor gene and superovulation traits in Chinese Holstein cows. Reprod. Domest. Anim. 46:1029-1034. doi:10.1111/j.1439-0531.2011.01780.x. 
475 Zeng, Z., Y. Liu, Z. Liu, J. You, Z. Chen, J. Wang, Q. Peng, L. Xie, R. Li, S. Li, and X. Qin.

476 2013. CYP2D6 polymorphisms influence tamoxifen treatment outcomes in breast cancer 477 patients: a meta-analysis. Cancer Chemother. Pharmacol. 72:287-303. doi:10.1007/s00280$478 \quad 013-2195-9$.

479 
480 Table 1. Nucleotide sequence of the forward and reverse primers used in the PCR481 based KASP assay genotype analysis.

\begin{tabular}{lll}
\hline Gene & Allele & Primer sequence \\
\hline COQ9 & A & 5'-AAGGTCTTTGGATCAGCAGAAGA-3' \\
& G & 5'-AAGGTCTTTGGATCAGCAGAAGG-3' \\
& Common reverse primer & 5'-GAAGAAGAGGGCGGGGGTTGAT-3' \\
HSPA1L & Deletion & 5'-CAAGTCCTGCCCCCTGC-3' \\
& C & 5'-CTCAAGTCCTGCCCCCTGG-3' \\
& Common reverse primer & 5'-GCATCCAGGGCGCTGATTGGTT-3' \\
& & \\
PARM1 & G & 5'-AAGGGCGATGAGGCTGGCG-3' \\
& C & 5'-AAGGGCGATGAGGCTGGCC-3' \\
& Common reverse primer & 5'-TCCCACACTCACCTCCCCTCAA-3' \\
& & \\
& G & 5'-ACCTAATCTTGAAATAATGGTGATCTAAAG- \\
& & 3' \\
& C & 5'-ACCTAATCTTGAAATAATGGTGATCTAAAC- \\
& Common reverse primer & 5'-TCTTATTAATGGTGTCAGCAGATCACCAT-3' \\
\hline
\end{tabular}

483

484

485

486

487 
A

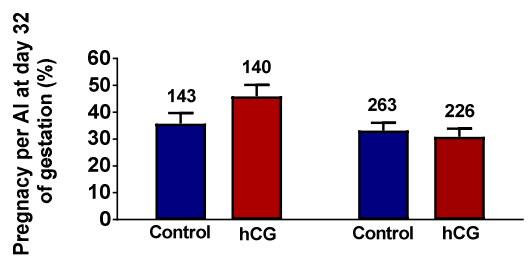

B

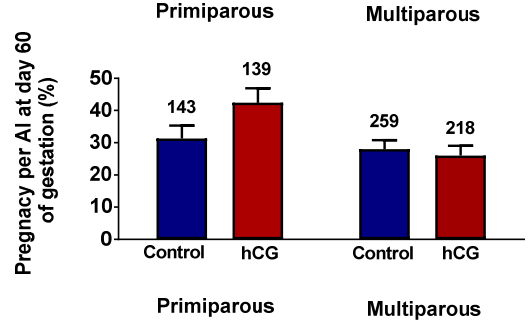

C

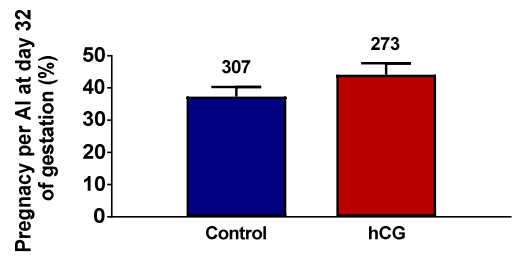

488

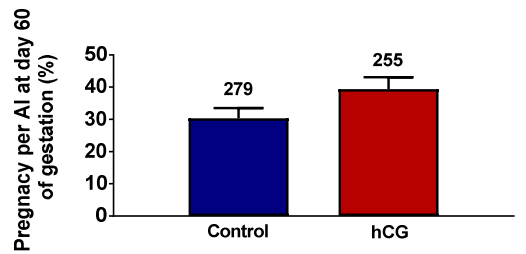

489 Figure 1. Effect of hCG treatment on pregnancy per AI. Values are least-squares means \pm SEM

491 and multiparous cows (B) in year 1. There was a tendency for a treatment $\mathrm{x}$ parity interaction on $492 \mathrm{~d} 32(\mathrm{~A} ; P=0.098)$ and $\mathrm{d} 60(\mathrm{~B} ; P=0.063)$ of gestation, with hCG increasing pregnancy per $\mathrm{AI}$ in 493 primiparous cows but not in multiparous cows. (C and D) Effect of hCG treatment on pregnancy 494 per AI of primiparous cows (year 1 and 2). The probability value for effect of treatment was $P=0.159$ at $\mathrm{d} 32$ of gestation and $P=0.063$ at $\mathrm{d} 60$ of gestation. 


\section{A}
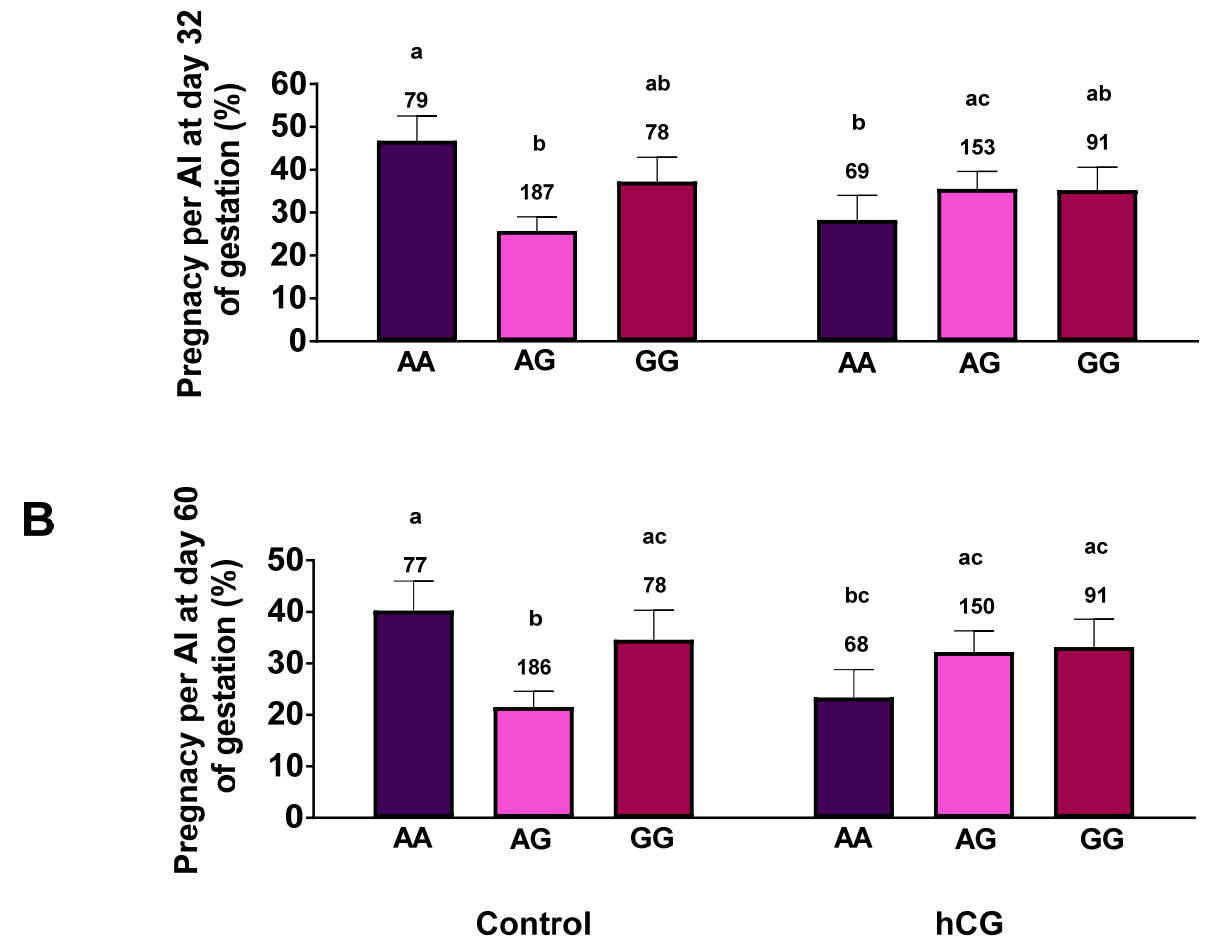

497

498

499 Figure 2. Effect of COQ9 genotype on the response to hCG treatment on pregnancy per AI.

500 Values are least-squares means \pm SEM of pregnancy per AI after TAI. There was a significant 501 interaction between treatment with hCG and genotype for COQ9 on d $32[\mathrm{P}=0.016(\mathbf{A})]$ and d $60[\mathrm{P}=0.012(\mathbf{B})]$ of gestation. Bars with different superscripts differ $(\mathrm{P}<0.05)$. When treated with vehicle, AA cows had a higher pregnancy per AI at d 32 and 60 of gestation than AG cows,

504 with GG cows being intermediate. When treated with hCG, AA cows had lower pregnancy per $505 \mathrm{AI}$ at $\mathrm{d} 32$ than $\mathrm{AG}$ cows, with GG cows being intermediate. 
A

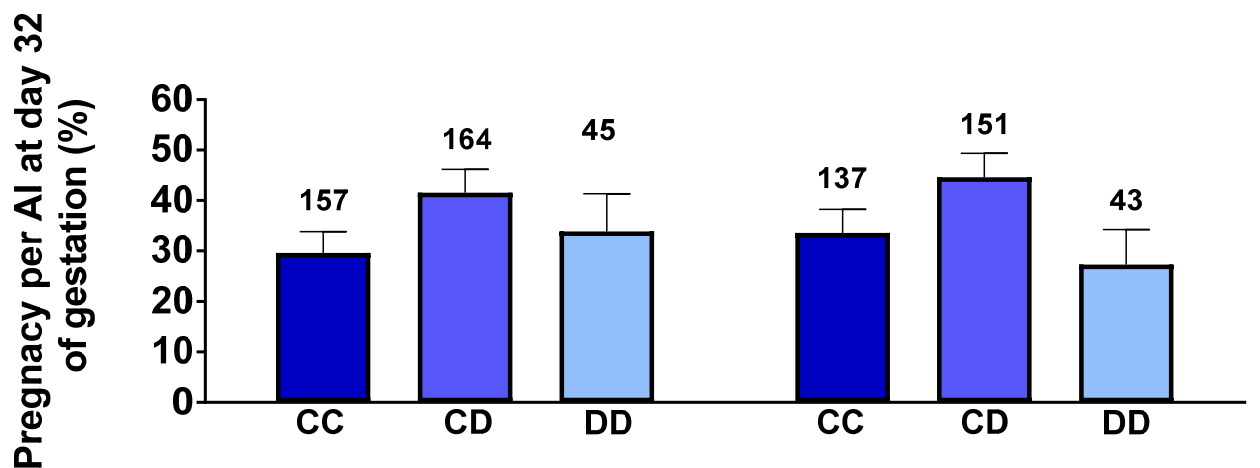

B

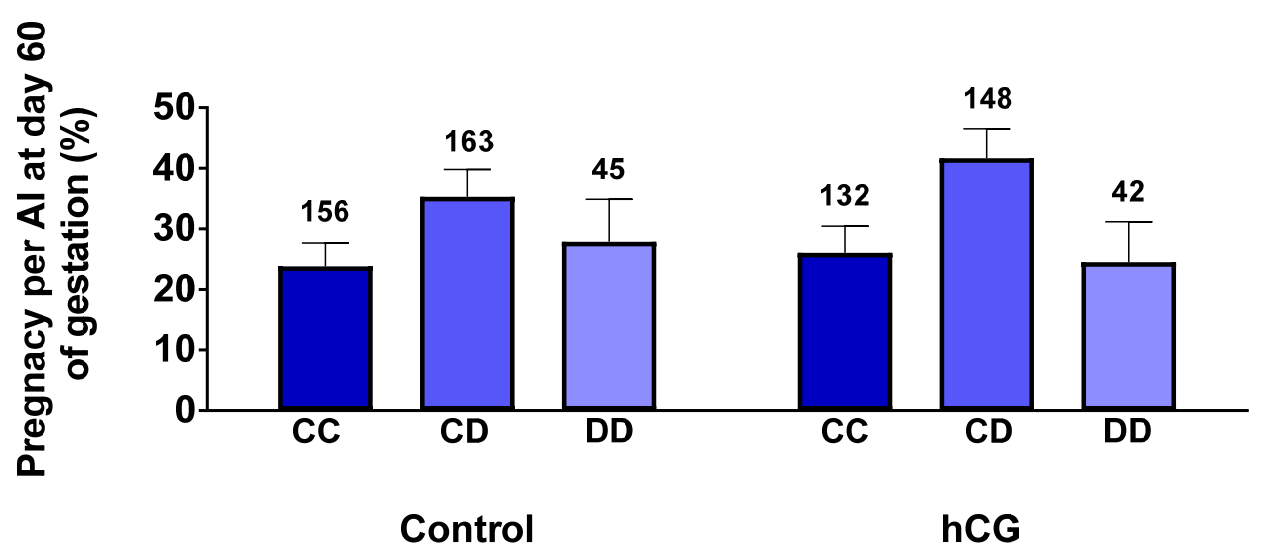

507

508 Figure 3. Effect of HSPA1L genotype on pregnancy per AI. Values are least-squares means \pm 509 SEM of pregnancy per AI after TAI. Genotype affected pregnancy per AI at d $32[P=0.009$ (A)] 510 and $60[(P=0.001$ (B) $]$ after insemination. For pregnancy per AI at $\mathrm{d} 32$, mean separation tests 511 indicated that $\mathrm{CD}$ differed from $\mathrm{CC}(\mathrm{P}=0.005)$ and $\mathrm{DD}(\mathrm{P}=0.041)$ but that $\mathrm{CC}$ and $\mathrm{DD}$ were 512 similar $(\mathrm{P}>0.10)$. For pregnancy per $\mathrm{AI}$ at $\mathrm{d} 60$, mean separation tests indicated that $\mathrm{CD}$ differed 513 from $\mathrm{CC}(\mathrm{P}=0.001)$ and $\mathrm{DD}(\mathrm{P}=0.052)$ and $\mathrm{CC}$ and $\mathrm{DD}$ were similar $(\mathrm{P}>0.100)$. There were no 514 interactions between genotype effect and response to hCG treatment. 


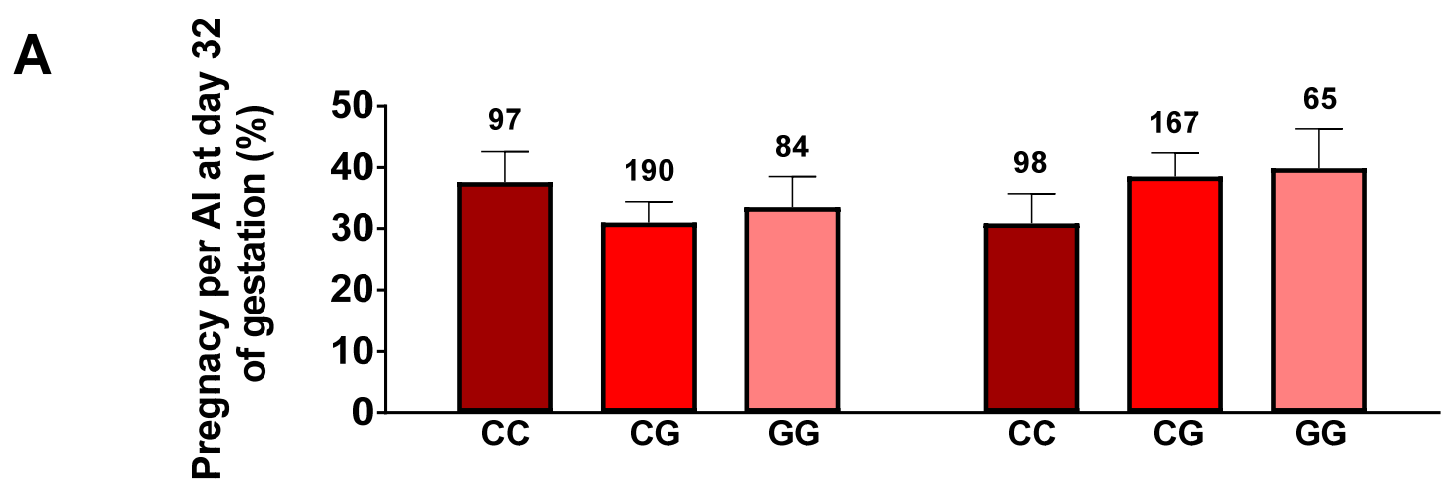

B

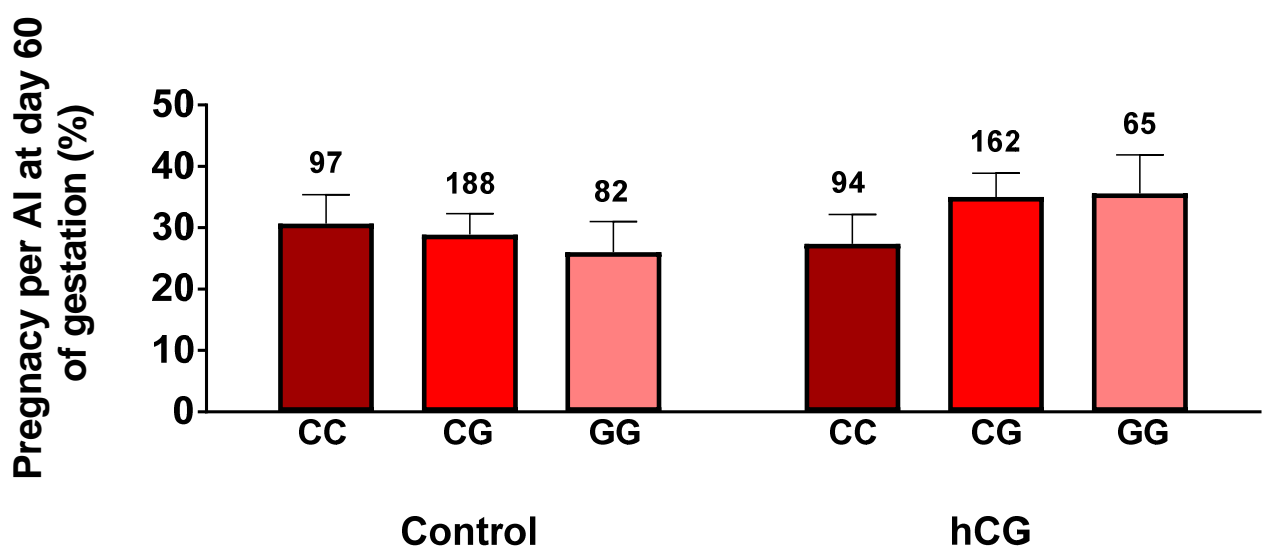

Figure 4. Effect of PARM1 genotype on the response to hCG treatment on pregnancy per AI.

519 Values are least-squares means \pm SEM of pregnancy after TAI. There was no effect of PARM1 on pregnancy per AI and no interaction between treatment with hCG and genotype for PARM1 at d 32 (A) and d 60 (B) of gestation. 

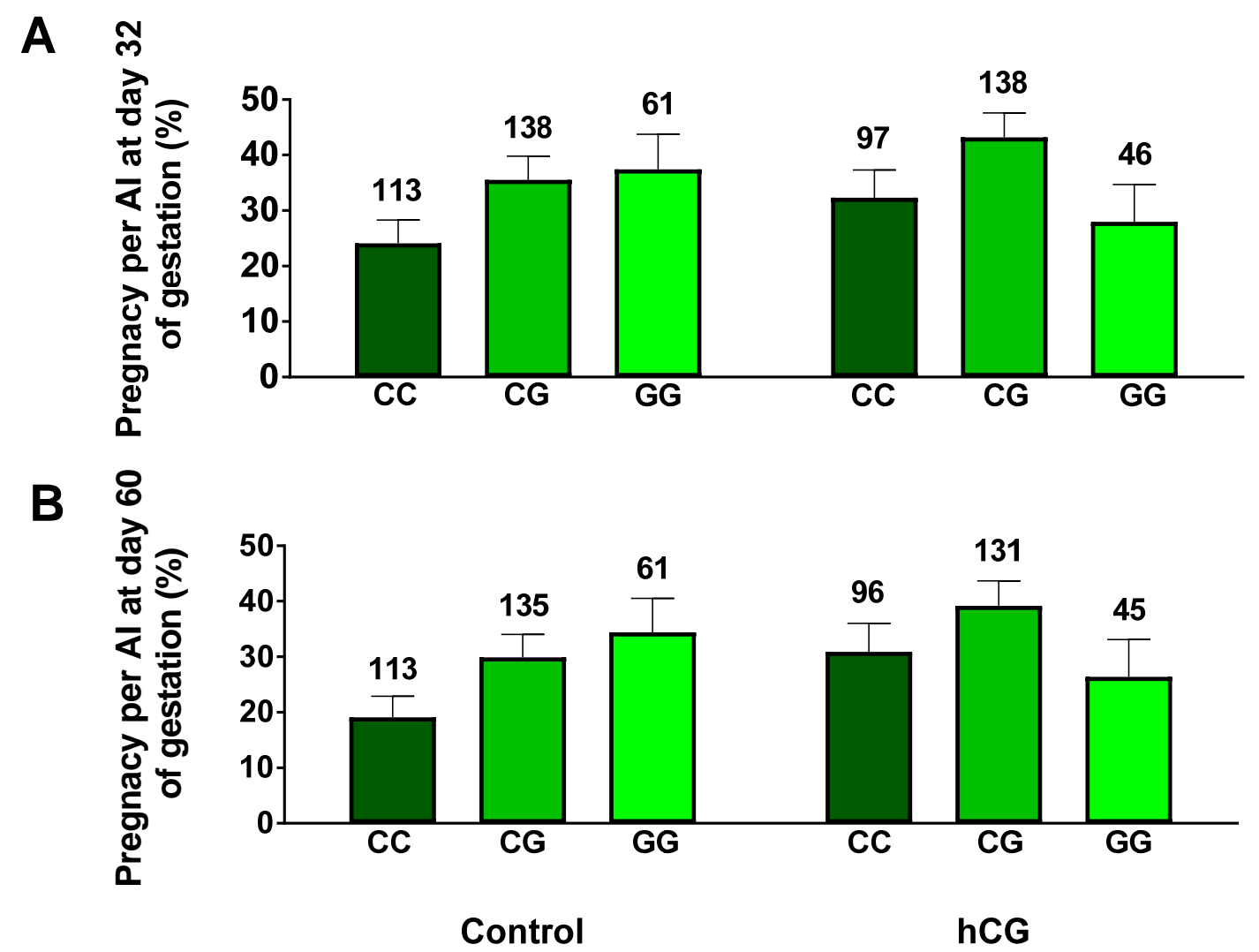

524

525

526 Figure 5. Effect of PGR genotype on pregnancy per AI. Values are least-squares means \pm SEM 527 of pregnancy per AI after TAI. Genotype affected pregnancy per AI at d $32[(P=0.041)$ A $]$ and 528 tended to affect pregnancy at d $60[(0.080)$ B $]$ of gestation. For pregnancy per AI at d 32, mean 529 separation tests indicated that $\mathrm{CC}$ differed from $\mathrm{CG}(\mathrm{P}=0.012)$ but other means were not different 530 from each other $(\mathrm{P}>0.100)$. For pregnancy per AI at d 60, mean separation tests indicated that $531 \mathrm{CC}$ differed from $\mathrm{CG}(\mathrm{P}=0.025)$ but other means were not different from each other. There were 532 no interactions between PGR genotype and hCG treatment. 
A

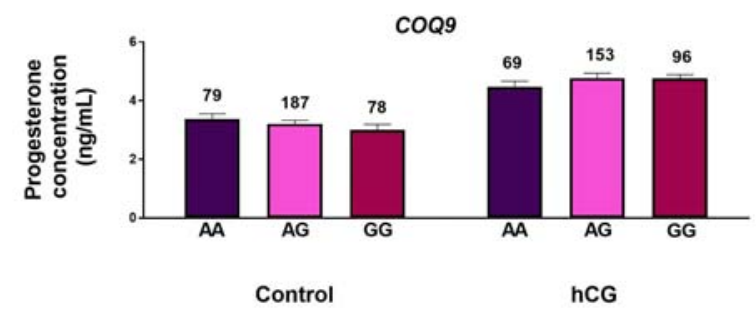

B

HSPA1L

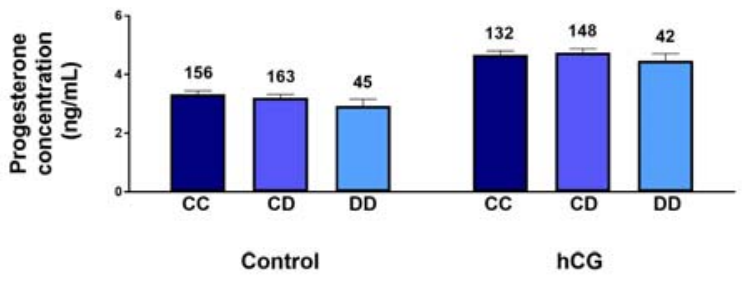

C

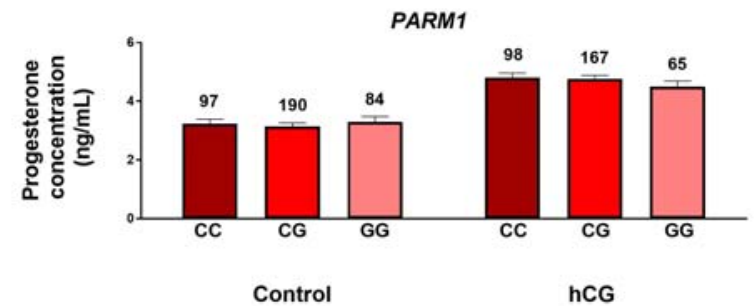

D

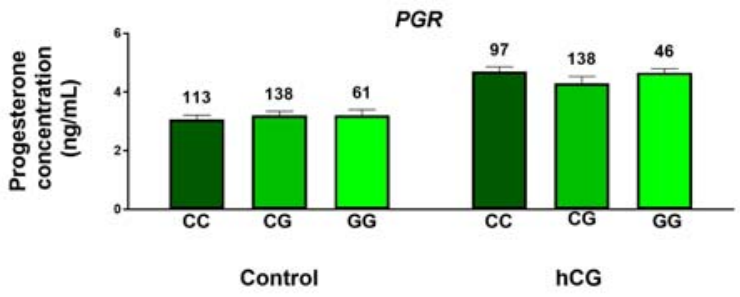

533

534 Figure 6. Effects of allelic variation for COQ9 (A), HSPA1L (B), PARM1 (C), PGR (D) on

535 progesterone concentration at d 12 after insemination for cows with a functional corpus luteum

536 (progesterone concentrations $>1 \mathrm{ng} / \mathrm{mL}$ ). Values are least-squares means $\pm \mathrm{SEM}$ of plasma

537 progesterone concentration. There was no effect of genotype on progesterone concentration and

538 no interaction between treatment with hCG and genotype for any locus on progesterone concentration. 
1 Running title: Melatonin improves oocyte competence

2 Effects of melatonin on production of reactive oxygen species and developmental

3 competence of bovine oocytes exposed to heat shock and oxidative stress during in

4 vitro maturation

5

6 Fernanda Cavallari de Castro ${ }^{1,2}$, Claudia Lima Verde Leal ${ }^{1}$, Roth $\mathrm{Zvi}^{3}$, and Peter J.

7 Hansen $^{2,4}$

$8{ }^{1}$ Department of Veterinary Medicine, Faculty of Animal Science and Food Engineering,

9 University of São Paulo, Pirassununga, Brazil, 13635-900; ${ }^{2}$ Department of Animal

10 Sciences, D. H. Barron Reproductive and Perinatal Biology Research Program and

11 Genetics Institute, University of Florida, Gainesville, Florida, USA, 32611-0910;

$12{ }^{3}$ Department of Animal Sciences, Robert H. Smith Faculty of Agricultural, Food \&

13 Environment, Hebrew University of Jerusalem, Rehovot, Israel, 76100

$14{ }^{4}$ Corresponding author. E-mail Hansen@animal.ufl.edu 
16 Abstract. Heat shock may disrupt oocyte function by increasing generation of reactive oxygen species (ROS). We evaluated capacity of the antioxidant melatonin to protect oocytes using two models of oxidative stress - heat shock and the prooxidant menadione. Bovine cumulus-oocyte complexes (COC) were exposed in the presence or absence of 1 $\mu \mathrm{M}$ melatonin to the following treatments during maturation: $38.5^{\circ} \mathrm{C}, 41^{\circ} \mathrm{C}$, and $38.5^{\circ} \mathrm{C}+5$ $\mu \mathrm{M}$ menadione. In the first experiment, COC were matured for $3 \mathrm{~h}$ with $5 \mu \mathrm{M}$ CellROX ${ }^{\circledR}$ and analyzed by epifluorescence microscopy to quantify production of ROS. The intensity of ROS was greater for oocytes exposed to heat shock and menadione than for control oocytes. Melatonin reduced ROS intensity for heat-shocked oocytes and oocytes exposed to menadione but not for control oocytes. In the second experiment, $\mathrm{COC}$ were matured for $22 \mathrm{~h}$. After maturation, oocytes were fertilized and the embryos cultured for 7.5 days. The proportion of oocytes that cleaved after fertilization was lower for oocytes exposed to heat shock and menadione than for control oocytes. Melatonin increased cleavage for heatshocked oocytes and oocytes exposed to menadione but not for control oocytes. Melatonin tended to increase development for embryos from heat-shocked oocytes but not for embryos from oocytes exposed to menadione or from control oocytes. In conclusion, melatonin reduced production of ROS of maturing oocytes and protected oocytes from deleterious effects of both stresses on competence of the oocyte to cleave after coincubation with sperm. These results suggest that excessive production of ROS compromises oocyte function.

Keywords: Melatonin, heat shock, menadione, reactive oxygen species, embryo. 


\section{INTRODUCTION}

39 Exposure of cows to thermal stress at estrus can reduce oocyte competence for subsequent

40 development after fertilization (Putney et al., 1988). This action of heat stress is likely to

41 involve direct effects of elevated body temperature on function of the maturing oocyte.

42 Exposure of oocytes during maturation to elevated culture temperature (i.e., heat shock)

43 can disrupt mitochondrial function (Rodriques et al., 2016; Payton et al., 2018) and reduce

44 oocyte competence to complete nuclear maturation (Roth and Hansen, 2005; Nabenishi et

45 al., 2012; Sebrian-Serrano et al., 2013; Meiyu et al., 2015), be fertilized and undergo

46 cleavage (Roth and Hansen, 2004a, 2005, de Castro e Paula and Hansen, 2007; Meiyu et

47 al., 2015). Moreover, competence of the resultant embryos to develop to the blastocyst

48 stage can be compromised (Roth et al., 2004ab; Nabenishi et al., 2012; Rodriques et al.,

49 2016).

50 Heat shock may disrupt oocyte function, at least in part, by increasing generation of

51 reactive oxygen species (ROS). Production of ROS is increased by heat shock (Nabenishi

52 et al., 2012; Ispada et al., 2018) and antioxidants such as retinol (Lawrence et al., 2004),

53 cysteine (Nabenishi et al., 2012) and astaxanthin (Ispada et al., 2018) can reduce negative

54 consequences of heat shock on the oocyte. Moreover, function of the maturing oocyte can

55 be disrupted by other oxidative stresses, as shown for the nitric oxide donor sodium

56 nitroprusside in the bovine (Soto et al., 2003; Cheuquemán et al., 2015) and hydrogen

57 peroxide in the mouse (Tamura et al., 2008) and pig (Yazaki et al., 2013).

58 One molecule that may exert protective effects on the oocyte is the multifunctional

59 hormone melatonin ( $\mathrm{N}$-acetyl-5-methoxytryptamine). Administration of melatonin to heat- 
60 stressed females improved embryo competence for development in mice (Matsuzuka et al.,

61 2005) and fertility in lactating cows (Garcia-Ispierto et al., 2013). Melatonin affects

62 cellular function by interacting with membrane and nuclear receptors and by functioning as

63 an antioxidant (Tan et al., 2002; Mayo et al., 2017). Melatonin improved oocyte 64 maturation in the pig (Shi et al., 2009), sheep (Tian et al., 2017) and bovine (El-Raey et al., 65 2011; Tian et al., 2014; Marques et al., 2018).

Experiments to test whether melatonin protects oocytes from heat shock have

67 yielded inconclusive results, however. Effects of melatonin in the pig were evaluated in

68 heat-shocked oocytes but not in oocytes cultured at normal temperature (Li et al., 2015, 69 2016). Protective effects of high concentrations of melatonin (10 mM) on bovine oocytes 70 cultured at $41.5^{\circ} \mathrm{C}$ were difficult to interpret because $10 \mathrm{mM}$ melatonin reduced oocyte 71 competence in the absence of heat shock (Cebrian-Serrano et al., 2013).

In the current experiment, we evaluated capacity of melatonin to protect oocytes

73 using two models of oxidative stress. In addition to heat shock, cytoprotective properties of

74 melatonin against the prooxidant menadione were examined. Menadione, (2-methyl-1,4-

75 naphtoquinone), is a vitamin $\mathrm{K}$ precursor that can react with a single electron to produce a

76 free radical derivative that can cause superoxide anion formation (Comporti, 1989).

77 Menadione can reduce developmental capacity of the preimplantation bovine embryo

78 (Moss et al., 2009) and act on bovine spermatozoa to reduce fertilizing ability and 79 compromise developmental competence of the resultant embryos (Hendricks and Hansen, 80 2010).

\section{1 \\ 2. MATERIALS AND METHODS}




\section{$82 \quad 2.1$ Oocyte collection and maturation}

83 Ovaries were obtained from a local abattoir from cows of a variety of genotypes including

84 Bos taurus and admixtures of $B$. taurus and B. indicus. Ovaries were transported within 10

$85 \mathrm{~h}$ to the laboratory at $23^{\circ} \mathrm{C}$ in a solution of $0.9 \%(\mathrm{w} / \mathrm{v}) \mathrm{NaCl}$. Cumulus-oocyte complexes

86 (COC) were harvested from follicles 2 to $8 \mathrm{~mm}$ in diameter by cutting the surface of the

87 ovary with a scalpel and swirling the ovary in BoviPRO ${ }^{\mathrm{TM}}$ Oocyte Washing Medium (with

88 BSA) (MOFA Global, Verona, WI, USA). Only COC with at least 3 to 4 layers of compact

89 cumulus and with an oocyte with a uniform cytoplasm were selected for maturation.

90 Selected COC were washed and matured in 6-well plates in groups of 25-30 in $300 \mu \mathrm{L}$ BO-

91 IVM oocyte maturation medium (IVF Bioscience, Falmouth, UK) that was prepared \pm 1

$92 \mu \mathrm{M}$ melatonin (Santa Cruz Biotechnology, Dallas, TX, USA) and with either $5 \mu \mathrm{M}$ 93 menadione (Sigma-Aldrich, St. Louis, MO, USA) or an equivalent volume of vehicle.

94 Melatonin was prepared as described by Ortega et al. (2016) and menadione as described 95 by Moss et al. (2009). Depending on the experiment, maturation was carried out for 3 or 22 $96 \mathrm{~h}$ at $38.5^{\circ} \mathrm{C}$ or $41.0^{\circ} \mathrm{C}$ under an atmosphere of either $5 \%(\mathrm{v} / \mathrm{v}) \mathrm{CO}_{2}$ in humidified air $97\left(38.5^{\circ} \mathrm{C}\right)$ or $7 \%(\mathrm{v} / \mathrm{v}) \mathrm{CO}_{2}$ in humidified air $\left(41.0^{\circ} \mathrm{C}\right)$. The higher $\mathrm{CO}_{2}$ for maturation at $9841.0^{\circ} \mathrm{C}$ was used to maintain $\mathrm{pH}$ at 7.4 in the face of lower solubility of $\mathrm{CO}_{2}$ at the higher 99 temperature.

\subsection{Production of ROS}

101 An experiment was conducted to determine whether heat shock and menadione would 102 increase production of ROS by oocytes at the beginning of exposure to stress and whether 103 increased production would be blocked by melatonin. For each replicate, COC $(\sim 100)$ were 
104 randomly assigned to one of 6 treatments in a $3 \times 2$ factorial arrangement with main effects 105 of stress (control, heat shock, or menadione) and melatonin $(0$ or $1 \mu \mathrm{M})$. Controls were 106 cultured at $38.5^{\circ} \mathrm{C}$, heat shock was $41.0^{\circ} \mathrm{C}$ and menadione involved culture at $38.5^{\circ} \mathrm{C}$ in 107 BO-IVM containing $5 \mu \mathrm{M}$ menadione. For all treatments, medium contained $5 \mu \mathrm{M}$ 108 CellROX $^{\circledR}$ Green, a cell-permeant dye that exhibits bright green photostable fluorescence 109 upon oxidation and subsequent binding to DNA.

After $3 \mathrm{~h}$ of maturation, COCs were denuded of cumulus cells by vortexing groups of 25 to 30 for $5 \mathrm{~min}$ in $200 \mu \mathrm{L}$ hyaluronidase as described earlier (Ortega et al., 2017).

112 Oocytes were then washed 3 times in $50-\mu \mathrm{L}$ droplets of Dulbecco's phosphate-buffered 113 saline (DPBS) containing 1\% (w/v) polyvinylpyrrolidone (PVP), fixed in 4\% (w/v) 114 paraformaldehyde in DPBS, washed 3 more times in DPBS-PVP and mounted in groups of 10 oocytes on microscope slides using Prolong Gold anti-fade reagent (Invitrogen, 116 Carlsbad, CA, USA). Oocytes were examined for fluorescence within $10 \mathrm{~h}$ after labeling 117 by fluorescence microscopy using a green emission filter with a Zeiss Axioplan 2 118 epifluorescence microscope (Zeiss, Göttingen, Germany). Digital images of each oocyte were acquired using AxioVision software (v. 4.8.2, Zeiss) and a high-resolution black and white Zeiss Axiocam MRM digital camera. Analysis of the images was performed using

121 ImageJ V. 1.48 (National Institutes of Health, Bethesda, MD, USA). Net fluorescent 122 intensity was calculated by obtaining the average pixel intensity of each oocyte (obtained 123 after manually drawing a boundary around the oocyte) and subtracting the background 124 intensity obtained from a region of the image not containing the oocyte. 
The experiment was replicated four times using a total of 41-72 oocytes per treatment $(\mathrm{n}=326$ total).

\subsection{Competence of oocytes to cleave and develop after fertilization}

128

An experiment was conducted to determine whether 1) heat shock and menadione would alter competence of matured oocytes to cleave after fertilization and alter ability of the resultant embryos to develop to the blastocyst stage and 2) if actions of heat shock and menadione would be blocked by melatonin. For each replicate ( $\mathrm{n}=12$ replicates total), COC ( 200) were randomly assigned to one of 6 treatments in a $3 \times 2$ factorial arrangement with main effects of stress (control, heat shock, or menadione) and melatonin (0 or $1 \mu \mathrm{M})$. Control COC were matured for $22 \mathrm{~h}$ at $38.5^{\circ} \mathrm{C}$, heat shocked $\mathrm{COC}$ were matured for $14 \mathrm{~h}$ at $41.0^{\circ} \mathrm{C}$ and for $8 \mathrm{~h}$ at $38.5^{\circ} \mathrm{C}$, and menadione-treated COC were matured for $22 \mathrm{~h}$ at $38.5^{\circ} \mathrm{C}$ in medium containing $5 \mu \mathrm{M}$ menadione.

After maturation, COC were washed 3 times in HEPES-TALP (Tyrodes albuminlactate-pyruvate) and placed in wells of 6-well plates containing $425 \mu \mathrm{L}$ fertilization medium [in vitro fertilization-TALP; see Ortega et al. (2017) for recipes for TALP media] and $1 \times 10^{6} / \mathrm{mL}$ spermatozoa. For each replicate, fertilization was performed with semen pooled from 3 individual bulls of various taurine breeds; the total number of bulls used in the experiment was 17. Sperm were purified from frozen-thawed straws of extended semen using an Isolate ${ }^{\circledR}$ gradient [Irvine Scientific, Santa Ana, CA USA; 50\% (v/v) and 90\% (v/v) Isolate]. In addition, $20 \mu \mathrm{L}$ of penicillamine-hypotaurine-epinephrine solution (Ortega et al., 2017) was added to each fertilization well to improve sperm motility. 
146 Fertilization proceeded for 14 to $16 \mathrm{~h}$ at $38.5^{\circ} \mathrm{C}$ in an atmosphere of $5 \%(\mathrm{v} / \mathrm{v}) \mathrm{CO}_{2}$ in 147 humidified air.

148 Putative zygotes (i.e., oocytes exposed to sperm) were denuded from the 149 surrounding cumulus cells at the end of fertilization ( 14 to $16 \mathrm{~h}$ ) by vortexing groups of 25 150 to 30 zygotes for $5 \mathrm{~min}$ in $200 \mu \mathrm{L}$ of HEPES-TALP containing $10,000 \mathrm{U} / \mathrm{mL}$ of 151 hyaluronidase. Embryos were cultured in groups of $25-30$ in $50 \mu \mathrm{L}$ drops of culture medium (SOF-BE2; Ortega et al., 2017) that were covered with mineral oil. Embryos were cultured at $38.5^{\circ} \mathrm{C}$ in a humidified atmosphere of $5 \%(\mathrm{vol} / \mathrm{vol}) \mathrm{O}_{2}$ and $5 \%$ (vol $\left./ \mathrm{vol}\right) \mathrm{CO}_{2}$ with the balance $\mathrm{N}_{2}$. The percent of oocytes that cleaved was determined at Day 3.5 of development (Day $0=$ day of fertilization) and the percent of cleaved embryos that became blastocysts was determined at Day 7.5 of development.

The experiment was replicated 12 times with the total number of COC ranging from 299 to 444 per treatment (total number $=2491)$.

\subsection{Statistical analysis}

Data were analyzed using SAS version 9.4 (SAS Institute Inc., Cary, NC). Data on ROS production were analyzed by analysis of variance using the MIXED procedure. The model included main effects of stress and melatonin and the interaction of stress and melatonin as fixed effects and replicate as a random effect. Effects of stress and melatonin on the proportion of oocytes cleaving and on the proportion of cleaved embryos becoming blastocysts was evaluated using the GLIMMIX procedure. Each embryo was considered an observation with binary response $(0=$ not developed to blastocyst, $1=$ developed to blastocyst) and analysis was performed by logistic regression fitting binary data 
168 distribution. The statistical model included the fixed effects of stress, melatonin, stress $\mathrm{x}$ 169 melatonin interaction and random effect of replicate.

170 For both analyses, two sets of orthogonal contrasts were used to make individual

171 degree-of-freedom comparisons of resolve multilevel effects of stress and interactions of

172 stress and melatonin. In the first set of contrasts, differences between types of stress

173 (control, heat shock, and menadione) were evaluated by two orthogonal contrasts: 1) the comparison of control vs heat shock + menadione and 2) the comparison of heat shock vs.

175 menadione. In the second set of contrasts, differences in the effect of melatonin for each stress were evaluated by comparisons of 1) control vs control + melatonin, 2) heat shock vs

177 heat shock + melatonin and 3) menadione vs menadione + melatonin.

\section{RESULTS}

\subsection{Production of ROS}

181

Representative images of labeling of oocytes using CellROX are shown in Figure 1. Intensity of fluorescence was higher for oocytes exposed to heat shock $\left(41.0^{\circ} \mathrm{C}\right)$ or $5 \mu \mathrm{M}$ menadione than for oocytes matured at $38.5^{\circ} \mathrm{C}$ (compare Figure $1 \mathrm{C}$ and Figure $1 \mathrm{E}$ with Figure 1A). Addition of $1 \mu \mathrm{M}$ melatonin reduced fluorescent intensity under all culture conditions (compare Figure 1A, Figure 1C and Figure 1E with Figure 1B, Figure 1D and Figure 1F).

Results of quantification of ROS labeling are shown in Figure 2. The intensity of ROS was greater $(\mathrm{P}=0.0577)$ for oocytes exposed to heat shock and menadione than for control oocytes. Overall, melatonin reduced ROS intensity $(\mathrm{P}=0.0002)$ and there was no 
190 interaction between stress and melatonin $(\mathrm{P}=0.4806)$. However, analysis of the effects of 191 melatonin for each stress indicated that melatonin reduced ROS intensity for heat-shocked oocytes $(\mathrm{P}=0.0305)$ and oocytes exposed to menadione $(\mathrm{P}=0.0007)$ but not for control oocytes $(\mathrm{P}=0.2002)$.

\subsection{Competence of oocytes to cleave and develop after fertilization}

Results on cleavage of oocytes after fertilization are presented in Figure 3A. The proportion of oocytes that cleaved after fertilization was lower $(\mathrm{P}<0.0001)$ for oocytes exposed to heat shock and menadione than for control oocytes. Overall, melatonin increased cleavage $(\mathrm{P}=0.0041)$. While the interaction between stress and melatonin was not significant $(\mathrm{P}=0.2944)$, analysis of the effects of melatonin for each stress indicated that melatonin increased cleavage for heat-shocked oocytes $(\mathrm{P}=0.0305)$ and oocytes exposed to menadione $(\mathrm{P}=0.0122)$ but not for control oocytes $(\mathrm{P}=0.6675)$.

As shown in Figure 3B, the proportion of cleaved embryos that became blastocysts was not affected by stress (heat shock + menadione vs control, $\mathrm{P}=0.7871$ ) but was increased by melatonin $(\mathrm{P}=0.0634)$. Despite a lack of a stress $\mathrm{x}$ melatonin interaction $(\mathrm{P}=0.5991)$, analysis of effects of melatonin for each stress indicated that melatonin tended

to increase development for embryos from heat-shocked oocytes $(\mathrm{P}=0.0702)$ but not for embryos from oocytes exposed to menadione $(\mathrm{P}=0.5426)$ or from control oocytes $(\mathrm{P}=0.4384)$.

\section{DISCUSSION}

Present results indicate that melatonin can reduce ROS production by the bovine oocyte exposed to conditions that promote production of ROS and partially preserve 
212 developmental competence of the oocyte exposed to those stresses. These results confirm

213 the importance of oxidative stress for damaging the oocyte and show how administration 214 of an antioxidant can block that effect.

215 It has been repeatedly demonstrated, both in the present experiments and by others, 216 that heat shock increases ROS production by the bovine oocyte (Nabenishi et al., 2012; 217 Ispada et al., 2018) and reduces the percent of oocytes that cleave after coincubation with 218 spermatozoa (Roth and Hansen, 2004a; de Castro e Paula and Hansen, 2007). In some 219 cases, the deleterious actions of heat shock on the oocyte also compromise the ability of 220 the subsequent embryo to develop to the blastocyst stage (Roth et al., 2004ab; Nabenishi et 221 al., 2012; Rodriques et al., 2016) although this consequence of heat shock has not always 222 observed (de Castro e Paula and Hansen, 2007; Sebrian-Serrano et al., 2013). In the 223 present experiment, the percent of cleaved embryos becoming blastocysts for oocytes 224 cultured without melatonin was $26.7 \%$ for control oocytes and $22.0 \%$ for heat-shocked 225 oocytes. Thus, the primary defect caused by heat shock here was the competence of the 226 oocyte to cleave after fertilization. Treatment of the oocyte with the prooxidant menadione 227 also reduced percent of oocytes that cleaved while not affecting subsequent development 228 of cleaved embryos. Previous experiments with heat shock would indicate that reduced 229 competence for cleavage is due to disruption of nuclear maturation (Roth and Hansen, 230 2005; Nabenishi et al., 2012; Sebrian-Serrano et al., 2013; Meiyu et al., 2915) as well as 231 disruption of mitochondrial function (Rodrigues et al., 2016; Payton et al., 2018) and 232 induction of oocyte apoptosis (Roth and Hansen, 2004a, 2005; Meiyu et al., 2015). 
Deleterious effects of both heat shock and menadione on percent of oocytes that cleaved were reduced by melatonin. Moreover, there was a tendency for melatonin to increase the competence of embryos derived from heat-shocked oocytes to develop to the blastocyst stage. Earlier experiments to evaluate the thermoprotective effect of melatonin

237 on the oocyte have been difficult to interpret either because of lack of control oocytes not 238 exposed to heat shock ( $\mathrm{Li}$ et al., 2015, 2016) or the high concentrations of melatonin (10 $\mathrm{mM}$ ) required to protect oocytes from heat shock reduced oocyte competence in the 240 absence of heat shock (Cebrian-Serrano et al., 2013). The experiments conducted here did 241 not allow determination of whether the cytoprotective effects of melatonin were mediated 242 by reducing ROS production or through changes in cellular function mediated by 243 activation of melatonin receptors. The former explanation seems more likely because 244 addition of melatonin caused a large reduction in ROS generation, melatonin was 245 protective against two different stresses (heat shock and menadione) that both increase 246 ROS production, and there were little effects of melatonin on oocyte competence in the 247 absence of heat shock or menadione. There are reports of the existence of melatonin 248 receptors or their mRNA in the bovine oocyte and cumulus cell (El-Raey et al., 2011; Tian 249 et al., 2014) and further studies are necessary to resolve the mechanism of action of the cytoprotective effects of melatonin on the oocyte.

An additional indication of the mechanism of action of melatonin is the effective

252 concentration of the hormone. The concentration of melatonin used here, $1 \mu \mathrm{M}$, is much 253 higher than the reported $\mathrm{Kd}$ of membrane melatonin receptors, having values of $\sim 30-225$ 254 pM (Poon et al., 1994; Kobayashi et al., 2003; Liu et al., 2013). In an earlier study, there 
255 was no thermoprotective effect of $1 \mathrm{pM}$ or $1 \mathrm{nM}$ melatonin on bovine oocytes exposed to 256 heat shock (Cebrian-Serrano et al., 2013).

There is a report that administration of melatonin to cows via subcutaneous 258 implants can improve fertility of heat-stressed cows (Garcia-Ispierto et al., 2013). In that 259 study, concentrations of melatonin in peripheral blood of treated cows peaked at 60-70 $260 \mathrm{pg} / \mathrm{mL}$ (i..e, 260-300 pM). Thus, beneficial effects of melatonin in that study may have 261 involved receptor-mediated actions of melatonin on one or more components of the reproductive system rather than a direct cytoprotective action of the molecule.

264 the oocyte is in contrast with recent results with the bovine two-cell embryo. Culture of 265 embryos at this stage of development causes an increase in ROS production and a decrease 266 in the proportion of embryos that develop to the blastocyst stage (Ortega et al., 2016). 267 While melatonin treatment blocked the increase in ROS production caused by heat shock, 268 it did not rescue embryos in terms of development to the blastocyst stage. One explanation 269 for this difference between the oocyte and embryo is that ROS are a more important 270 mediator of heat shock effects in the oocyte than in the two-cell embryo.

271 In conclusion, melatonin reduced production of ROS by maturing oocytes, 272 especially when they were exposed to heat shock or menadione, and protected oocytes 273 from deleterious effects of both stresses on competence to cleave after coincubation with 274 sperm. These results suggest that excessive production of ROS compromises oocyte 275 function. Such a mechanism may be important for effects of elevated temperature on 276 damage to the oocyte during maturation. 


\section{Acknowledgements}

278 Research was supported by grant number US-4719-14 from the Binational Agriculture and 279 Development Fund to PJ Hansen and Z Roth, by Fundação de Amparo à Pesquisa do 280 Estado de São Paulo (grant number 2015/20379-0 to Cláudia Lima Verde Leal, and PhD 281 scholarship number 2017/04376-6 to Fernanda Cavallari de Castro), and by funds from the 282 L.E. "Red" Larson Endowment. The authors thank Florida Beef, Wauchula, Florida, for 283 allowing us to procure ovaries and Eddie Cummings and Dr. Paula Tribulo for technical 284 assistance.

\section{Conflict of interest}

286 The authors have no conflict to declare. 


\section{References}

289 Cebrian-Serrano, A., Salvador, I., Raga, E., Dinnyes, A., \& Silvestre, M.A. (2013).

290 Beneficial effect of melatonin on blastocyst in vitro production from heat-stressed bovine 291 oocytes. Reprod. Domest. Anim. 48, 738-746.

292 Cheuquemán, C., Loren, P., Arias, M., Risopatrón, J., Felmer, R., Álvarez, J., Mogas, T., 293 \& Sánchez, R. (2015). Effects of short-term exposure of mature oocytes to sodium 294 nitroprusside on in vitro embryo production and gene expression in bovine. 295 Theriogenology 84, 1431-1437.

296 Comporti, M. (1989). Three models of free radical-induced cell injury. Chem. Biol. 297 Interact. 72, 1-56.

298 de Castro e Paula, L.A., \& Hansen, P.J. (2007) Interactions between oxygen tension and 299 glucose concentration that modulate actions of heat shock on bovine oocytes during in 300 vitro maturation. Theriogenology 68, 763-770.

301 El-Raey, M., Geshi, M., Somfai, T., Kaneda, M., Hirako, M., Abdel-Ghaffar, A.E., Sosa, 302 G.A., El-Roos, M.E., \& Nagai T. (2011) Evidence of melatonin synthesis in the cumulus 303 oocyte complexes and its role in enhancing oocyte maturation in vitro in cattle. Mol.

304 Reprod. Dev. 78, 250-262.

305 Garcia-Ispierto, I., Abdelfatah, A., \& López-Gatius, F. (2013). Melatonin treatment at dry306 off improves reproductive performance postpartum in high-producing dairy cows under 307 heat stress conditions. Reprod. Domest. Anim. 2013 48, 577-583.

308 Hendricks, K.E. \& Hansen, P.J. (2010). Consequences for the bovine embryo of being 309 derived from a spermatozoon subjected to oxidative stress. Aust. Vet. J. 88, 307-310. 
310 Ispada, J., Rodrigues, T.A., Risolia, P.H.B., Lima, R.S., Gonçalves, D.R., Rettori, D.,

311 Nichi, M., Feitosa, W.B., \& Paula-Lopes, F.F. (2018) Astaxanthin counteracts the effects 312 of heat shock on the maturation of bovine oocytes. Reprod. Fertil. Dev., in press.

313 Kobayashi, Y., Itoh, M.T., Kondo, H., Okuma, Y., Sato, S., Kanishi, Y., Hamada, N., 314 Kiguchi, K., \& Ishizuka, B. (2003). Melatonin binding sites in estrogen receptor-positive 315 cells derived from human endometrial cancer. J. Pineal Res. 35, 71-74.

316 Lawrence, J.L., Payton, R.R., Godkin, J.D., Saxton, A.M., Schrick, F.N., \& Edwards, J.L. 317 (2004). Retinol improves development of bovine oocytes compromised by heat stress 318 during maturation. J. Dairy. Sci. 87, 2449-2454.

319 Li, Y., Wang, J., Zhang, Z., Yi, J., He, C., Wang, F., Tian, X., Yang, M., Song, Y., He, P., 320 \& Liu, G. (2016). Resveratrol compares with melatonin in improving in vitro porcine 321 oocyte maturation under heat stress. J. Anim. Sci. Biotechnol. 7, 33 Li, Y., Zhang, Z., He, C., Zhu, K., Xu, Z., Ma T., Tao, J., \& Liu, G. (2015). Melatonin protects porcine oocyte in vitro maturation from heat stress. J Pineal Res. 2015 59, 365-75.

324 Liu, X.Y., Xu, Y.T., Shi, Q., Lu, Q.S., Ma, S.R., Xu, X.Y., \& Guo, X.Z. (2013). 325 Alterations of reproductive hormones and receptors of male rats at the winter and summer 326 solstices and the effects of pinealectomy. Neuroendocrinol. Lett. 34, 143-153.

327 Marques, T.C., da Silva Santos, E.C., Diesel, T.O., Leme, L.O., Martins, C.F., Dode, M., 328 Alves, B.G., Costa, F., de Oliveira, E.B., \& Gambarini, M.L. (2018). Melatonin reduces 329 apoptotic cells, SOD2 and HSPB1 and improves the in vitro production and quality of 330 bovine blastocysts. Reprod. Domest. Anim. 53, 226-236. 
331 Matsuzuka, T., Sakamoto, N., Ozawa, M., Ushitani, A., Hirabayashi, M., \& Kanai, Y. 332 (2005). Alleviation of maternal hyperthermia-induced early embryonic death by 333 administration of melatonin to mice. J. Pineal Res. 39, 217-223

334 Mayo, J.C., Sainz, R.M., González-Menéndez, P., Hevia, D., \& Cernuda-Cernuda, R. 335 (2017). Melatonin transport into mitochondria. Cell. Mol. Life Sci. 74, 3927-3940.

336 Meiyu, Q., Liu, D., \& Roth, Z. (2015). IGF-I slightly improves nuclear maturation and 337 cleavage rate of bovine oocytes exposed to acute heat shock in vitro. Zygote 23, 514-524.

338 Moss, J.I., Pontes, E., \& Hansen, P.J. (2009). Insulin-like growth factor-1 protects 339 preimplantation embryos from anti-developmental actions of menadione. Arch. Toxicol. $340 \quad 83,1001-1007$.

341 Nabenishi, H., Ohta, H., Nishimoto, T., Morita, T., Ashizawa, K., \& Tsuzuki Y. (2012). 342 The effects of cysteine addition during in vitro maturation on the developmental 343 competence, ROS, GSH and apoptosis level of bovine oocytes exposed to heat stress. 344 Zygote 20, 249-259.

345 Ortega, M.S., Rocha-Frigoni, N.A.S., Mingoti, G.Z., Roth, Z., \& Hansen, P.J. (2016). 346 Modification of embryonic resistance to heat shock in cattle by melatonin and genetic 347 variation in HSPA1L. J. Dairy Sci. 99, 9152-9164.

348 Ortega, M.S., Wohlgemuth, S., Tribulo, P., Siqueira, L.G., Cole, J.B., \& Hansen, P.J. 349 (2017). A single nucleotide polymorphism in COQ9 affects mitochondrial and ovarian 350 function and fertility in Holstein cows. Biol. Reprod. 96, 652-663. 
351 Payton, R.R., Rispoli, L.A., Nagle, K.A., Gondro, C., Saxton, A.M., Voy, B.H., \& 352 Edwards, J.L. (2018) Mitochondrial-related consequences of heat stress exposure during 353 bovine oocyte maturation persist in early embryo development. J. Reprod. Dev., in press. 354 Poon, A.M., Liu, Z.M., Pang, C.S., Brown, G.M., \& Pang, S.F. (1994). Evidence for a 355 direct action of melatonin on the immune system. Biol. Signals 3, 107-117.

356 Putney, D.J., Drost, M., \& Thatcher, W.W. T.S. (1988). Embryonic development in 357 superovulated dairy cattle exposed to elevated ambient temperatures between the onset of 358 estrus and insemination. Theriogenology 30, 195-209.

359 Rodrigues, T.A., Ispada, J., Risolia, P.H., Rodrigues, M.T., Lima, R.S., Assumpção, M.E., 360 Visintin, J.A., \& Paula-Lopes, F.F. (2016). Thermoprotective effect of insulin-like growth 361 factor 1 on in vitro matured bovine oocyte exposed to heat shock. Theriogenology 86, $362 \quad 2028-2039$.

363 Roth, Z., \& Hansen, P.J. (2004a). Involvement of apoptosis in disruption of developmental 364 competence of bovine oocytes by heat shock during maturation. Biol. Reprod. 71, 18983651906.

366 Roth, Z., \& Hansen, P.J. (2004b). Sphingosine 1-phosphate protects bovine oocytes from 367 heat shock during maturation. Biol. Reprod. 71, 2072-2078.

368 Roth, Z. \& Hansen, P.J. (2005). Disruption of nuclear maturation and rearrangement of 369 cytoskeletal elements in bovine oocytes exposed to heat shock during maturation.

370 Reproduction 129, 235-244.

371 Soto, P., Natzke, R.P., \& Hansen, P.J. (2003). Identification of possible mediators of 372 embryonic mortality caused by mastitis: actions of lipopolysaccharide, prostaglandin $\mathrm{F}_{2 \alpha}$, 
373 and the nitric oxide generator, sodium nitroprusside dihydrate, on oocyte maturation and 374 embryonic development in cattle. Am. J. Reprod. Immunol. 50, 263-272.

375 Shi, J.M., Tian, X.Z., Zhou, G.B., Wang, L., Gao, C., Zhu, S.E., Zeng, S.M., Tian, J.H., \& 376 Liu, G.S. (2009). Melatonin exists in porcine follicular fluid and improves in vitro 377 maturation and parthenogenetic development of porcine oocytes. J. Pineal Res. 47, 318378323.

379 Tamura, H., Takasaki, A., Miwa, I., Taniguchi, K., Maekawa, R., Asada, H., Taketani, T., 380 Matsuoka, A., Yamagata, Y., Shimamura, K., Morioka, H., Ishikawa, H., Reiter, R.J., \& 381 Sugino, N. (2008). Oxidative stress impairs oocyte quality and melatonin protects oocytes 382 from free radical damage and improves fertilization rate. J. Pineal Res. 44, 280-287.

383 Tan, D.X., Reiter, R.J., Manchester, L.C., Yan, M.T., El-Sawi, M., Sainz, R.M., Mayo, 384 J.C., Kohen, R. Allegra. M., \& Hardeland, R. (2002). Chemical and physical properties 385 and potential mechanisms: melatonin as a broad spectrum antioxidant and free radical 386 scavenger. Curr. Top. Med. Chem. 2, 181-197.

387 Tian X, Wang F, He C, Zhang L, Tan D, Reiter RJ, Xu J, Ji P, \& Liu G. (2014). Beneficial 388 effects of melatonin on bovine oocytes maturation: a mechanistic approach. J. Pineal Res. $389 \quad 57,239-247$.

390 Tian, X., Wang, F., Zhang, L., He, C., Ji, P., Wang, J., Zhang, Z., Lv, D., Abulizi, W., 391 Wang, X., Lian, Z., \& Liu G. (2017). Beneficial effects of melatonin on the in vitro 392 maturation of sheep oocytes and its relation to melatonin receptors. Int. J. Mol. Sci. 18, $393 \quad$ E834. 
394 Yazaki, T., Hiradate, Y., Hoshino, Y., Tanemura, K., \& Sato, E. (2013) L-carnitine

395 improves hydrogen peroxide-induced impairment of nuclear maturation in porcine oocytes.

396 Anim. Sci. J. 84, 395-402.

397 
$(-)$

Melatonin

\section{Control $\left(38.5^{\circ} \mathrm{C}\right)$}

Heat Shock $\left(4 I .0^{\circ} \mathrm{C}\right)$
$(+)$

\section{Melatonin}

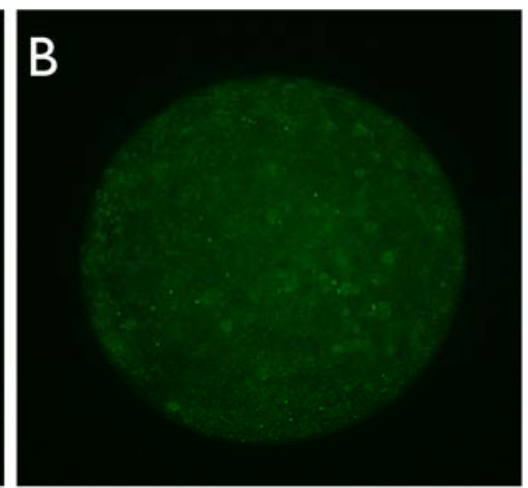

D
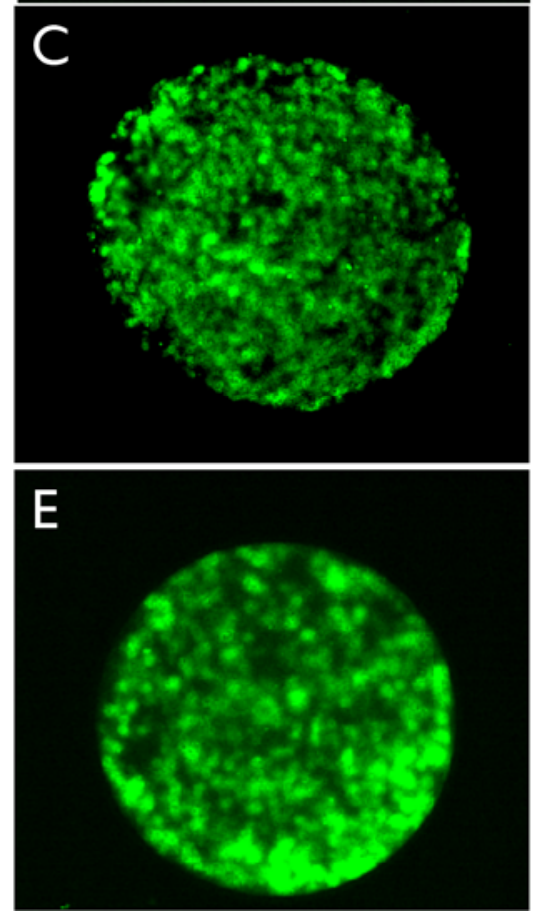

$\mathrm{F}$
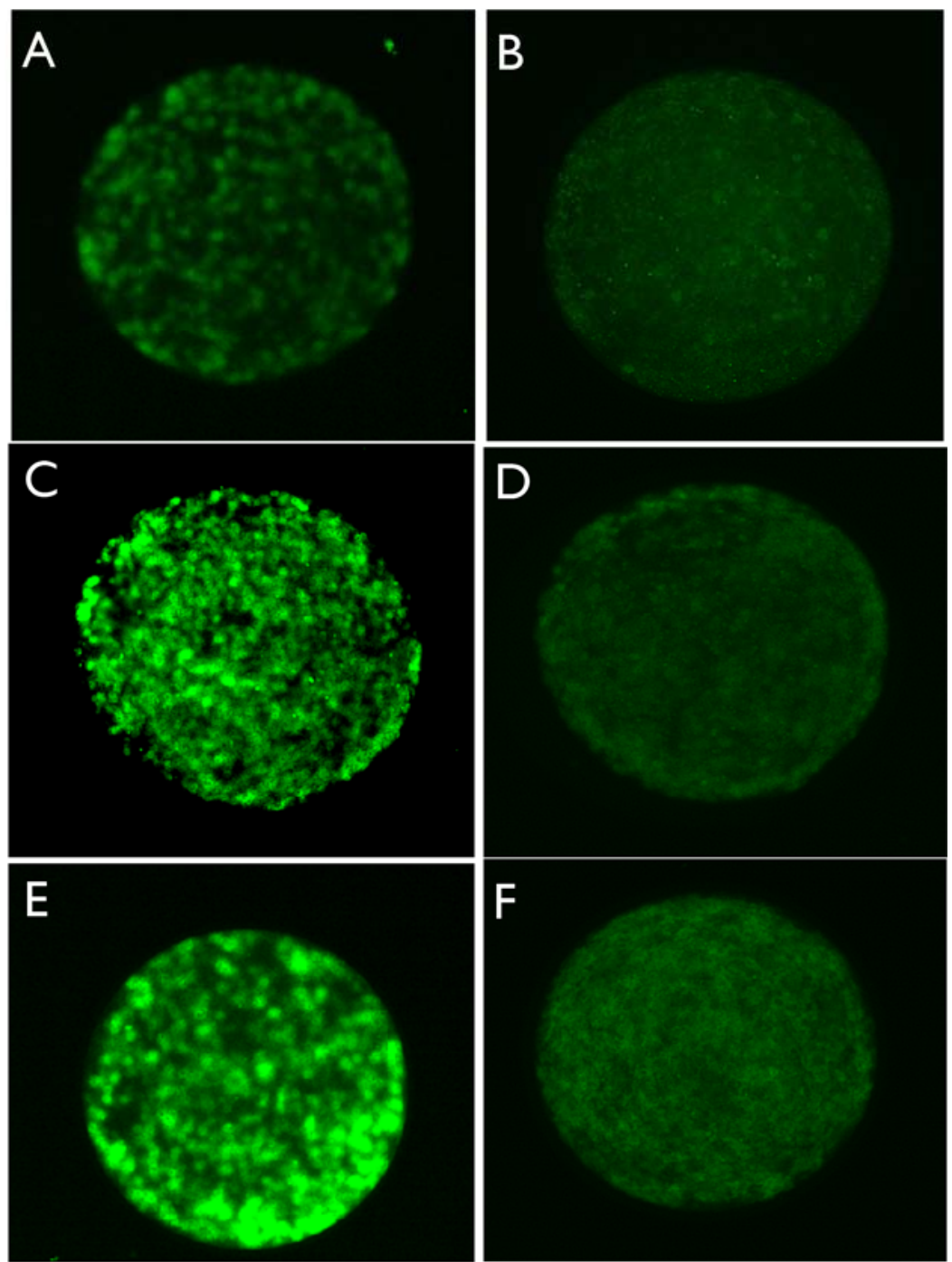

\section{Menadione} $\left(38.5^{\circ} \mathrm{C}\right)$

FIGURE. 1. Representative images of oocytes labeled with CellROX (ThermoFisher Scientific, Waltham, MA) to assess production of ROS as affected by incubation temperature, menadione and melatonin. 


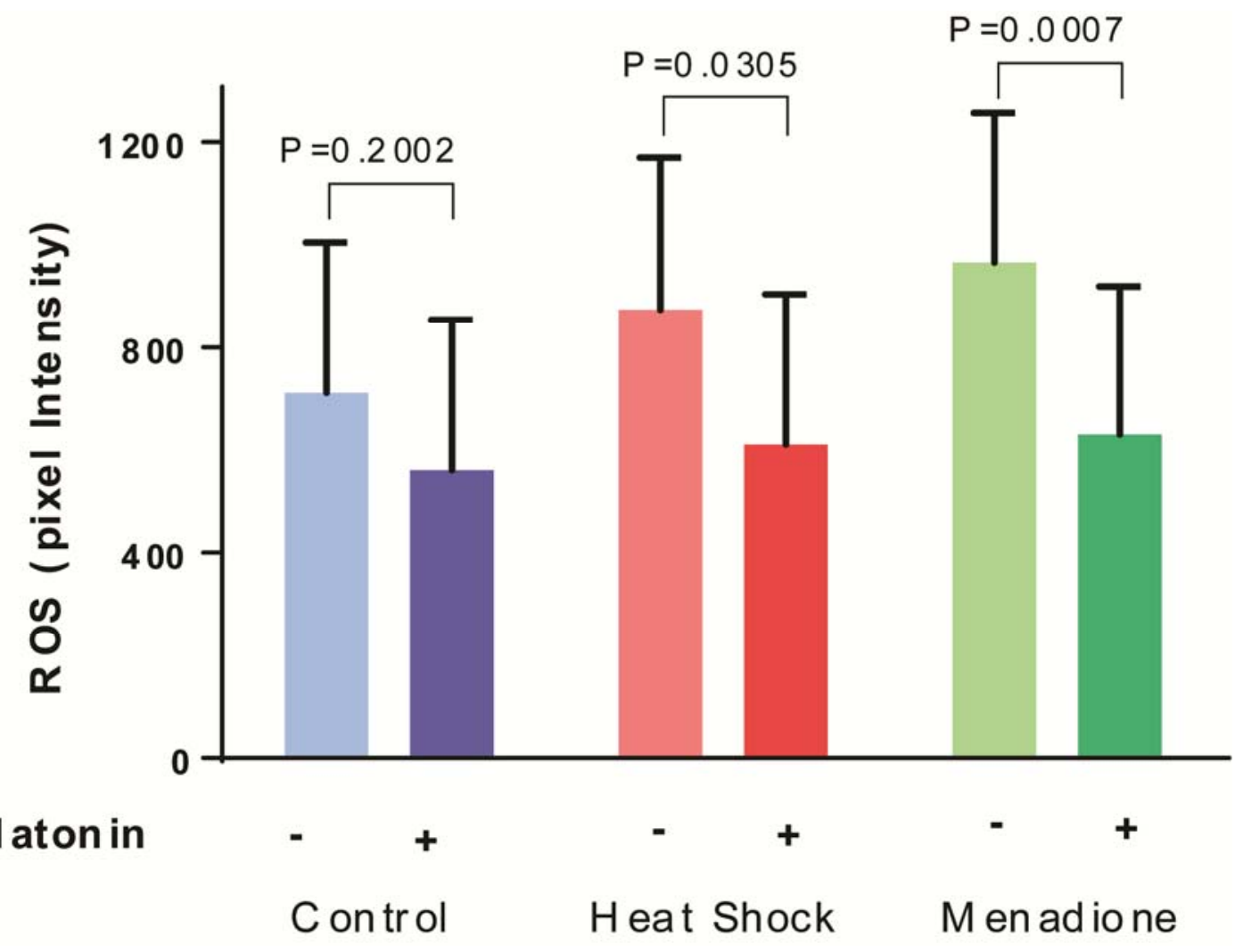

404 FIGURE 2. Effects of melatonin $(1 \mu \mathrm{M})$ on production of reactive oxygen species (ROS)

405 by maturing oocytes exposed to control conditions $\left(38.5^{\circ} \mathrm{C}\right)$, heat shock $\left(41.0^{\circ} \mathrm{C}\right)$ and 406 menadione $\left(5 \mu \mathrm{M}\right.$ at $\left.38.5^{\circ} \mathrm{C}\right)$. Data are least-squares means \pm SEM of pixel intensity. 407 Overall, the intensity of ROS was greater $(\mathrm{P}=0.0577)$ for oocytes exposed to heat shock 408 and menadione than for control oocytes. Probability values for the effect of melatonin for 409 each stress are indicated above the bars. 410 


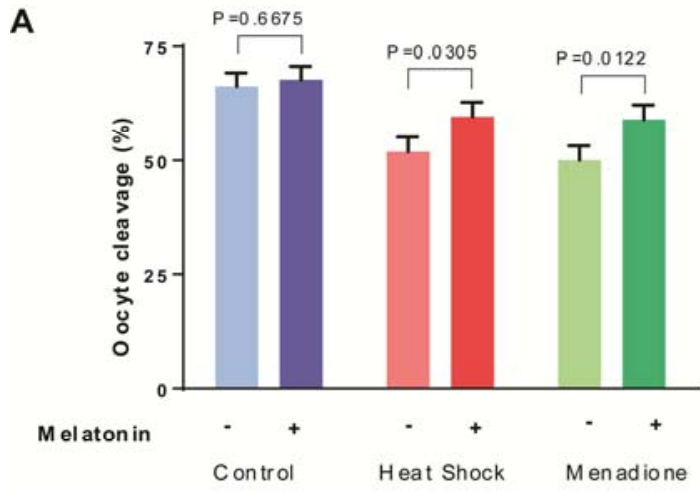

B

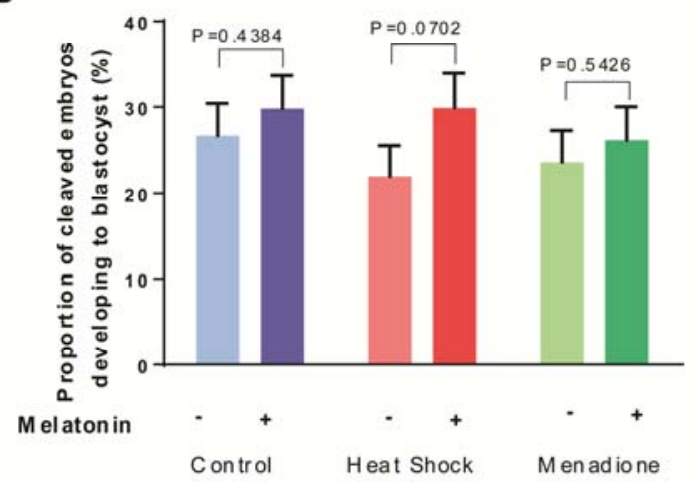

412 FIGURE 3. Effects of melatonin $(1 \mu \mathrm{M})$ on developmental competence of oocytes 413 exposed to control conditions $\left(38.5^{\circ} \mathrm{C}\right)$, heat shock $\left(41.0^{\circ} \mathrm{C}\right)$ and menadione $(5 \mu \mathrm{M}$ at $41438.5^{\circ} \mathrm{C}$ ) during in vitro maturation. Data are least-squares means $\pm \mathrm{SEM}$ of proportion of 415 oocytes that cleaved after fertilization (A) and the proportion of cleaved embryos 416 developing to the blastocyst stage (B). Overall, the proportion of oocytes that cleaved after 417 fertilization was lower $(\mathrm{P}<0.0001)$ for oocytes exposed to heat shock and menadione than 418 for control oocytes. The proportion of cleaved embryos that became blastocysts was not 419 affected by stress (heat shock + menadione vs control, $\mathrm{P}=0.7871$ ). Probability values for 420 the effect of melatonin for each stress are indicated above the bars. 
1 Follicular fluid exosomes act on the bovine oocyte to improve oocyte

2 competence to support development and survive heat shock

3 Thais A. Rodrigues ${ }^{A}$, Kubra M. Tuna ${ }^{B}$, Abdel A. Alli ${ }^{B}$, P. Tribulo ${ }^{C}$, P.J. Hansen ${ }^{C}$, Jin Koh ${ }^{D}$, and

$4 \quad$ F.F. Paula-Lopes ${ }^{A}$

$5 \quad$ A Department of Biological Sciences, Federal University of São Paulo, SP, Brazil

$6{ }^{\mathrm{B}}$ Department of Physiology and Functional Genomics, ${ }^{\mathrm{C}}$ Department of Animal Sciences, and

$7 \quad$ DProteomics \& Mass Spectrometry Laboratory, Interdisciplinary Center for Biotechnology

8 Research, University of Florida, Gainesville, Florida, 32611-0910 USA

9 Running head: Exosomes enhance oocyte function

10 Summary sentence: Bovine follicular fluid exosomes increase oocyte competence to support

11 development and survive heat shock.

12 Grant support: Grant US-4719-14 from the Binational Agriculture Research \& Development

13 Fund and CAPES PDSE 88881.135502/2016-01

$14{ }^{4}$ Correspondence: Fabíola Freitas de Paula-Lopes, Department of Biological Sciences, Federal

15 University of Sao Paulo, 275 Professor Arthur Riedel St., 09972-270, Diadema, Sao Paulo,

16 Brazil. Email: ffpaulalopes@gmail.com; Telephone: +55 (11) 4044-0500, extension 3474. 
18 Abstract. Addition of follicular fluid to oocyte maturation medium can affect cumulus cell

19 function, increase competence of the oocytes to be fertilized and develop to the blastocyst stage,

20 and protect the oocyte from heat shock. Here, it was tested whether exosomes in follicular fluid

21 are responsible for effects of follicular fluid on function of the cumulus-oocyte complex (COC).

22 This was accomplished by culturing COC during oocyte maturation at $38.5^{\circ} \mathrm{C}$ (body temperature

23 of the cow) or $41^{\circ} \mathrm{C}$ (heat shock) with follicular fluid or exosomes derived from follicular fluid

24 and evaluating various aspects of function of the oocyte and embryo derived from it. Both

25 follicular fluid and exosomes increased cumulus cell expansion and the percent of oocytes that cleaved and developed to the blastocyst stage. Negative effects of heat shock on cleavage and blastocyst development, but not cumulus expansion, were reduced by follicular fluid and exosomes. Fluorescently labelled exosomes were taken up by cumulus cells but not the oocyte, suggesting that actions of follicular fluid exosomes are mediated through changes in cumulus cell function. Results support the idea that exosomes in follicular fluid play important roles during oocyte maturation to enhance oocyte function and protect it from stress.

Additional keywords: Exosomes, oocyte maturation, heat shock 


\section{Introduction}

The thermal environment is an important determinant of fertility in mammals with heat stress in particular compromising sexual behavior, gametogenesis and fertility (Hansen, 2009). In the bovine, for example, the percent of lactating cows in Israel that became pregnant averaged 39$40 \%$ for cows bred in winter vs 3-25\% for cows bred in summer (Flamenbaum and Galon, 2010). One cause of reduced fertility in heat-stressed females is damage to the oocyte. Heat stress can reduce oocyte function as early as 100 days before ovulation (Torres-Júnior et al., 2008) and as late as the peri-ovulatory period when the oocyte undergoes nuclear and cytoplasmic maturation (Putney et al., 1988).

Reduced oocyte function during heat stress is caused, at least in part, by damage to the oocyte caused by exposure to elevated body temperatures (i.e., heat shock). Exposure of oocytes to elevated temperatures during maturation leads to cytoskeletal alterations (Roth and Hansen, 2005), induction of apoptosis (Roth and Hansen, 2004a, 2005; Rodrigues et al., 2016), mitochondrial dysfunction (Rodrigues et al., 2016), increased generation of reactive oxygen species (Nabenishi et al., 2012; Ispada et al., 2018), compromised nuclear maturation (Roth and Hansen, 2005; Nabenishi et al., 2012), reduction in fertilization (Roth and Hansen, 2005) and cleavage (Roth and Hansen, 2004a; de Castro e Paula and Hansen, 2007). Additionally, cleaved embryos derived from heat-shocked oocytes had reduced capacity to develop to the blastocyst stage (Roth and Hansen, 2004b; Nabenishi et al., 2012; Rodrigues et al., 2016).

Oocyte maturation takes place in the follicle (Mehlmann, 2005) and it is possible that regulatory molecules produced by cumulus cells adjacent to the oocyte or present in follicular fluid could protect the oocyte from heat shock. Indeed, addition of either follicular fluid or insulin-like growth factor 1 (IGF1) to maturation medium reduced effects of elevated culture 
temperature on oocyte cleavage and development of the resultant embryo to the blastocyst stage (Rodrigues et al., 2015, 2016). One component of follicular fluid that could potentially be involved in regulation of oocyte function in response to heat shock is the pool of exosomes. These extracellular vesicles interact with target cells through either internalization and delivery of cargo molecules to the cytoplasm or endosome or via interaction with membrane receptors on the cell surface without internalization (Urbanelli et al., 2013). In the cow, follicular exosomes have been shown to alter transcript abundance in oocytes (Dalenezi and Ferreira, 2016) and granulosa cells (Sohel et al., 2013; Hung et al., 2015), increase cumulus expansion during oocyte maturation (Hung et al., 2015), enhance competence of oocytes matured in vitro to form blastocysts after fertilization (da Silveira et al., 2017) and stimulate proliferation of granulosa cells (Hung et al., 2017).

Here, we verified earlier observations (Rodriques et al., 2015) that follicular fluid can reduce effects of heat shock during maturation on function of the oocyte and tested whether this activity is associated with follicular fluid exosomes. Results support the concept that exosomes present in follicular fluid from small follicles can enhance oocyte function and protect it from deleterious effects of heat shock.

\section{Materials and Methods}

\section{Collection of follicular fluid}

Follicular fluid was collected by aspiration of $\sim 2-8 \mathrm{~mm}$ follicles present on the surface of ovaries obtained from a local abattoir. The cattle used as a source of ovaries were either Bos taurus or admixtures of $B$. taurus and $B$. indicus. The ovaries were transported from the abattoir in $0.9 \%$ (wt/vol) $\mathrm{NaCl}$ containing $100 \mathrm{U} / \mathrm{mL}$ penicillin-G and $100 \mu \mathrm{g} / \mathrm{mL}$ streptomycin at $23^{\circ} \mathrm{C}$. A total of four batches of follicular fluid (32-50 mL per batch) were collected in March and April 2017 
81 from $48-70$ ovaries per batch. Each batch was stored at $-80^{\circ} \mathrm{C}$ until processing for follicular fluid

82 or exosome purification.

83

84

85

\section{Isolation of exosomes}

For each batch of follicular fluid, a total of $30 \mathrm{~mL}$ was thawed and centrifuged at $1000 \mathrm{xg}$ for 15 $\min$ at $4^{\circ} \mathrm{C}$ and the supernatant fraction was filtered using a $0.2 \mu \mathrm{m}$ rapid-flow Nalgene filter (Thermo Fisher Scientific, San Jose, CA, USA). The filtered material was used for follicular fluid supplementation and exosome extraction.

For exosome purification, the filtered supernatant fraction was subjected to two rounds of ultracentrifugation at $118,000 \mathrm{x}$ g for $70 \mathrm{~min}$ at $4{ }^{\circ} \mathrm{C}$ using a fixed-angle Ti-70 rotor (Beckman Coulter, Inc., Pasadena, CA, USA). The pellet, which contained exosomes, was resuspended in $200 \mu \mathrm{L}$ of sterile phosphate buffered saline (PBS) consisting of $1.06 \mathrm{mM}$ potassium phosphate monobasic; $2.97 \mathrm{mM}$ sodium phosphate dibasic and $155 \mathrm{mM} \mathrm{NaCl}, \mathrm{pH} 7.4$ and $280-315$ $\mathrm{mOsm} / \mathrm{kg})$. The resuspended pellet was stored at $-80^{\circ} \mathrm{C}$.

\section{Characterization of exosomes}

Concentration and size of exosomes in the pellet were determined by nanoparticle tracking analysis using a NanoSight NS300 (Malvern Instruments, UK) as previously described [20]. The exosomal pellet was diluted 1:1000 (v/v) in PBS before analysis.

Protein concentration was determined using the bicinchoninic acid protein assay (Thermo Fisher) after exosomes were diluted with an equal volume of radioimmunoprecipitation assay buffer (Thermo Fisher) and sonicated twice while on ice for 5-sec each. Protein in the exosomal lysate $(50 \mu \mathrm{g})$ was subjected to sodium dodecyl sulfate, polyacrylamide gel electrophoresis (SDS-PAGE) and Western blotting to identify the exosome marker flotillin-1. Procedures were as described previously (Dang et al., 2017) and the antibody was $1 \mu \mathrm{g} / \mathrm{mL}$ of rabbit polyclonal 
anti-flotillin-1 antibody (Abcam, Cambridge, MA, USA). The immunogen was a synthetic peptide corresponding to residues 1-100 of human flottilin-1 conjugated to keyhole limpet hemocyanin.

Identification of proteins in each of four preparations of exosomes was determined by mass spectrometry. For each of four samples, $50 \mu \mathrm{g}$ of total protein were separated by SDSPAGE usingprecast 4-20\% polyacrylamide gradient gels (Bio-Rad, Hercules, CA, USA). Protein bands were visualized by Coomassie labeling. The whole protein lanes were cut and transferred into $1.5 \mathrm{ml}$ conical tube. The sample were destained with $50 \mathrm{mM}$ ammonium bicarbonate and digested with $6 \mu \mathrm{g} / \mathrm{mL}$ modified trypsin (Promega, Madison, WI, USA) at $37^{\circ} \mathrm{C}$ overnight. Tryptic digests were lyophilized solid phase extraction performed to remove impurities using SOLA SPE cartridge (Thermo Fisher) according to the manufacturer's instruction.

Samples were analyzed using an Orbitrap Fusion Tribrid mass spectrometer (Thermo Fisher) equipped with a Nanospray Flex Ion Source coupled to an EASY-nLC 1200 system (Thermo Fisher). Peptides were eluted using a Acclaim Pepmap 100 precolumn $(20 \mathrm{~mm} \times 75 \mu \mathrm{m}$; $3 \mu \mathrm{m}-\mathrm{C} 18$; Thermo Fisher) and separated on a PepMap RSLC analytical column (250 $\mathrm{mm} \times 75 \mu \mathrm{m} ; 2 \mu \mathrm{m}-\mathrm{C} 18$; Thermo Fisher) at a flow rate at $300 \mathrm{~nL} / \mathrm{min}$ during a linear gradient from solvent A $[0.1 \%$ formic acid (v/v)] to $40 \%$ solvent B [0.1\% formic acid and $80 \%$ acetonitrile (v/v)] over 90 min followed by ramp up to $98 \%$ solvent B in 5 min and held for 25 min at a spray voltage of $2.0 \mathrm{kV}$. Data were acquired by MS1 analysis in the orbitrap (m/z 350 to 1800 , resolution 120,000) followed by eight data-dependent MS/MS events with high resolution product ion analysis (isolation window 1.3 Th) performed in the ETD-enabled quadrupole linear ion traps with a fixed scan cycle time of $2 \mathrm{~s}$. The form of MS/MS activation was chosen 
127 depending on the nature of the selected ions using a data-dependent decision tree (Swaney et al., 128 2008). Doubly charged ions, triply charged ions with $\mathrm{m} / \mathrm{z}$ to 650 , quadruply charged ions with $\mathrm{m} / \mathrm{z}$ to 900 , and quintuply charged ions with $\mathrm{m} / \mathrm{z}$ to 950 were triggered with either collision induced dissociation (CID) only or electron transfer dissociation (ETD) only. CID was performed at 35\% normalized collision energy (NCE), and ETD and CID were carried out with a maximum injection time of $35 \mathrm{~ms}$. A target value of 10,000 was selected for MS2 automatic gain control, and precursor ions were dynamically excluded for $30 \mathrm{~s}$.

Fisher Scientific, San Jose, CA, USA). Charge state deconvolution and deisotoping were not performed. All MS/MS samples were analyzed using Mascot (version 2.4.1; Matrix Science, London, UK). Mascot was set up to search the Uniprot Bos taurus database (downloaded on Feb. 13 2018, 32231 entries; http://www.uniprot.org/uniprot/?query=bos+taurus\&sort=score) assuming the digestion enzyme trypsin. Mascot was searched with a fragment ion mass tolerance of 1.00 Da and a parent ion tolerance of 10.0 PPM. Carbamidomethyl of cysteine was specified in Mascot as a fixed modification. Gln->pyro-Glu of the n-terminus, deamidated of asparagine and glutamine and oxidation of methionine were specified in Mascot as variable modifications. Scaffold (version 4.2.1; Proteome Software Inc., Portland, OR, USA) was used to validate MS/MS based peptide and protein identifications. Peptide identifications were accepted if they could be established at greater than $95.0 \%$ probability by the Scaffold Local FDR algorithm. Protein identifications were accepted if they could be established at greater than $95.0 \%$ probability and contained at least 1 identified peptide. Protein probabilities were assigned by the 
could not be differentiated based on MS/MS analysis alone were grouped to satisfy the principles of parsimony. Proteins sharing significant peptide evidence were grouped into clusters.

To gain insights into the biological processes that proteins found in the exosomes participate in, gene ontology analysis was performed using UniProtKB (UnitProt Consortium, 2017). A total of 71 proteins was analysed. Proteins were chosen because the spectral count was $\geq 20$ for each of the four samples analysed.

In vitro maturation, fertilization and embryo culture

Ovaries used to collect oocytes were similar to those described above. Oocytes were collected by bisecting follicles $\sim 2-8 \mathrm{~mm}$ in diameter with a scalpel and rinsing the ovaries through a solution of BoviPRO ${ }^{\mathrm{TM}}$ oocyte washing medium (MOFA Global, Verona, WI, USA). Cumulus-oocyte complexes (COC) were selected under a dissecting microscope, washed 3 times in oocyte washing medium and transferred to $50 \mu \mathrm{L}$ microdrops of oocyte maturation medium (BO IVM, IVF Biosciences, Falmouth, United Kingdom) overlaid with mineral oil (Sigma-Aldrich, St. Louis, MO, USA). The COC were matured for $22 \mathrm{~h}$ at $38.5^{\circ} \mathrm{C}$ in an atmosphere of $5 \%(\mathrm{v} / \mathrm{v}) \mathrm{CO}_{2}$ in humidified air. Other media used were prepared as described elsewhere (Ortega et al., 2017). After maturation, COC were washed 3 times in HEPES-TALP and placed in groups of up to 65 in a $35 \mathrm{~mm}$ dish of $1.7 \mathrm{~mL}$ of IVF-TALP to which $80 \mu \mathrm{L}$ of a solution of PHE $(0.5 \mathrm{mM}$ penicillamine, $0.25 \mathrm{mM}$ hypotaurine, and $25 \mu \mathrm{M}$ epinephrine) and $120 \mu \mathrm{l}$ of sperm (final concentration, $1 \times 10^{6}$ cells $/ \mathrm{mL}$ ) were placed. For each replicate, sperm were derived from straws of frozen-thawed semen from 3 individual bulls. Sperm were purified in a gradient of PureSperm (Nidacon, Mölndal, Sweden) for $10 \mathrm{~min}$ at $1000 \mathrm{x} \mathrm{g}$ and washed in HEPES-TALP for $5 \mathrm{~min}$ at 200 x g. A different assortment of bulls were used for each replicate. Gametes were co-incubated for $18 \mathrm{~h}$ at $38.5^{\circ} \mathrm{C}$ in an atmosphere of $5 \%(\mathrm{v} / \mathrm{v}) \mathrm{CO}_{2}$ in humidified air. 
Oocytes exposed to sperm were denuded of cumulus cells in a vortex with $1.4 \mathrm{U} / \mathrm{mL}$

173 hyaluronidase in $0.9 \%$ (wt/vol) $\mathrm{NaCl}$, washed 3 times in HEPES-TALP and transferred in groups of 30 to $50 \mu \mathrm{L}$ microdrops of synthetic oviduct fluid bovine embryo 2 overlaid with oil. Embryos were cultured in an atmosphere of $5 \% \mathrm{CO}_{2}, 5 \% \mathrm{O}_{2}$ and the balance $\mathrm{N}_{2}$ in humidified air. The proportion of oocytes that cleaved was determined at $3 \mathrm{~d}$ after insemination and blastocyst

177 development was determined at $7.5 \mathrm{~d}$ after insemination.

178 Experiments with heat shock

179 Three experiments were conducted to evaluate whether follicular fluid or follicular fluid exosomes would reduce detrimental effects of heat shock on COC. In the first experiment, COC were assigned randomly to one of four treatments arranged in a 2 x 2 factorial design with main effects of incubation temperature during maturation $\left(38.5 \mathrm{vs} 41^{\circ} \mathrm{C}\right)$ and concentration of follicular fluid in the maturation medium $[0$ or $10 \%,(\mathrm{v} / \mathrm{v})]$. The COC were matured at either $38.5^{\circ} \mathrm{C}$ for $22 \mathrm{~h}$ or, for the heat shock treatment, for $41^{\circ} \mathrm{C}$ for $14 \mathrm{~h}$ followed by $8 \mathrm{~h}$ at $38.5^{\circ} \mathrm{C}$. The COC were cultured in microdrops that consisted of either $50 \mu 1$ maturation medium or $45 \mu \mathrm{L}$ maturation medium and $5 \mu \mathrm{L}$ follicular fluid. Thereafter, fertilization and embryo culture proceeded as described above to determine cleavage and blastocyst development. The experiment was replicated 4 times, using a total of 210-222/oocytes per treatment. treatments were arranged in a $2 \times 3$ factorial design with main effects of temperature $(38.5$ or $41^{\circ} \mathrm{C}$ as described earlier) and with three culture media - vehicle (PBS), $10 \%$ (v/v) follicular fluid, or exosomes (final concentration of $16 \times 10^{9}$ particles $/ \mathrm{mL}$ ). A total of 4 different samples of follicular fluid and 4 preparations of exosomes were used in each experiment. The exosomes 
were prepared by adding $2.3-4.70 \mu \mathrm{L}$ exosomes to $400 \mu \mathrm{L}$ maturation medium. The vehicle control was prepared by adding a similar volume of PBS to $400 \mu \mathrm{L}$ maturation medium.

For the second experiment, expansion of COC was assessed before maturation and again at $22 \mathrm{~h}$ after maturation. Digital images of each maturation drop were obtained with an EVOS XL Core Imaging System microscope (ThermoScientific, Maltham, MA, USA; 4x magnification). Images were analysed using Image J v 1.43 software (U.S. National Institutes of Health, Bethesda, MD, USA) to determine the surface area of the COC. Separate drops of COC were evaluated before and after maturation and average surface area of COC in a drop calculated. The increase in mean surface area of COCs after maturation was determined by subtracting mean surface area before maturation from mean surface area after maturation. The experiment was replicated 5 times using a total of 119 - $122 \mathrm{COC} /$ treatment.

For the third experiment, COC were fertilized and the resultant embryos cultured as described for the first experiment to determine cleavage and blastocyst development. The experiment was replicated 6 times using 244-286 oocytes/treatment. Blastocysts from the third experiment were collected for analysis of transcript abundance by quantitative polymerase chain reaction (PCR). A total of 3 pools of 10 blastocysts/ pool were collected for each treatment. Blastocysts were treated with $0.1 \%(\mathrm{wt} / \mathrm{vol})$ proteinase from Streptococcus griseus (Roche, Nutley NJ, USA) to remove the zona pellucida. Blastocysts were then washed in Dulbecco's phosphate buffered saline (DPBS) containing 1\% (w/v) polyvinylpyrrolidone (PVP) (DPBSPVP), frozen in liquid nitrogen and stored at $-80^{\circ} \mathrm{C}$. RNA was extracted with PicoPure RNA isolation kit (ThermScientific) using the manufacturer's instructions. For PCR, samples were thawed, treated with DNase I and subjected to reverse transcription with High Capacity cDNA RT kit (Qiagen). PCR was performed using a CFX96 Real-Time PCR Detection System (Bio- 
217 Rad, Hercules, CA, USA) and the SYBR green mix. Each reaction contained $0.75 \mu \mathrm{L}$ forward

218 primer $(10 \mathrm{mM}), 0.75 \mu \mathrm{L}$ reverse primer $(10 \mathrm{mM}), 12.5 \mu \mathrm{L}$ SYBR Green Mix

219 (ThermoScientific), and $8.5 \mu \mathrm{L}$ diethyl pyrocarbonate water. The volume of $18.8 \mu \mathrm{L}$ reaction was mixed with $1.2 \mu \mathrm{L}$ of cDNA sample and samples were run in duplicate. Amplification conditions were: $95^{\circ} \mathrm{C}$ for $30 \mathrm{sec}, 40$ cycles at $95^{\circ} \mathrm{C}$ for $5 \mathrm{sec}, 60^{\circ} \mathrm{C}$ for $5 \mathrm{sec}$, and 1 cycle of melt curve analysis at $65-95^{\circ} \mathrm{C}$ in increments of $0.5^{\circ} \mathrm{C}$ every $5 \mathrm{sec}$. Primers used were described elsewhere for YWHAZ (Gooessens et al., 2005), NANOG and SOX2 (Ozawa et al., 2012) and GAPDH (Kannampuzha-Francis et al., 2017).

Uptake of exosomes by oocytes and cumulus cells

Exosomes extracted from a single preparation of follicular fluid $(20 \mu \mathrm{L})$ were incubated with $10 \mu \mathrm{M}$ BODIPY TR (Invitrogen, Waltham, MA, USA) for $20 \mathrm{~min}$ at $37^{\circ} \mathrm{C}$. The excess dye was removed by centrifugation at $750 \mathrm{x}$ g for $2 \mathrm{~min}$ in an Exosome Spin Column (Invitrogen). Labelled exosomes $\left(16 \times 10^{9}\right.$ particles $\left./ \mathrm{mL}\right)$ were added in $5 \mu \mathrm{L}$ to groups of $30 \mathrm{COC}$ in $45 \mu \mathrm{L}$ maturation medium using procedures described above. COC were then matured for up to $22 \mathrm{~h}$ at $38.5^{\circ} \mathrm{C}$ in an atmosphere of $5 \%(\mathrm{v} / \mathrm{v}) \mathrm{CO}_{2}$ in humidified air. $\mathrm{COC}$ were removed from culture after $0,0.5,1,14$ and $22 \mathrm{~h}$. Oocytes and cumulus cells were separated mechanically by pipetting in PBS-PVP and then fixed in 4\% (wt/vol) formaldehyde in PBS-PVP for 15 min and labelled with $1 \mu \mathrm{g} / \mathrm{mL}$ Hoechst 33342 in PBS-PVP for $15 \mathrm{~min}$. Specimens were evaluated for labelling using an Olympus IX2-DSU spinning disk confocal fluorescent microscope using DAPI (Ex 387/11, Em 440/40) and Texas Red (Ex 562/40, Em 624/40) filters. Z-stack images were generated by collecting a series of images at $0.75 \mu \mathrm{m}$ intervals for cumulus cells and $3 \mu \mathrm{m}$ for oocytes. A total of 5 oocytes and 5 sets of cumulus cells were examined at each time point. 
Data for percent cleavage, percent oocytes exposed to sperm that developed to the

241 blastocyst stage, percent of cleaved embryos that developed to the blastocyst stage, area of the

242 COC and gene expression were calculated for each replicate. PCR data were analysed using the

$2^{\Delta \Delta \mathrm{Ct}}$ method. Fold change was calculated relative to the value for the vehicle- $38.5^{\circ} \mathrm{C}$ group. The

value for housekeeping genes was the geometric mean of the $\mathrm{Ct}$ for GAPDH and YWHAZ. Data

were then subjected to least-squares analysis of variance using the General Linear Models procedure of SAS 9.4 (SAS Institute Inc., Cary, NC, USA). The mathematical model included effects of maturation temperature, treatment, replicate and all interactions. For experiments with 3 treatments (vehicle, follicular fluid and exosomes), orthogonal contrasts were used to partition variance for effects of treatment and the temperature $\mathrm{x}$ treatment interaction. The contrasts were 1) vehicle vs follicular fluid + exosomes and 2) follicular fluid vs exosomes. In addition, the pdiff mean separation test was used to determine effects of heat shock for each individual treatment.

\section{Results}

The effect of follicular fluid on developmental competence of oocytes

Results are shown in Fig. 1. Exposure of COC to a heat shock of $41^{\circ} \mathrm{C}$ for the first $14 \mathrm{~h}$ of maturation reduced cleavage rate $(\mathrm{P}=0.019)$ and the percent of oocytes $(\mathrm{P}=0.0015)$ and cleaved embryos $(\mathrm{P}=0.0043)$ that developed to the blastocyst stage. There was no effect of follicular fluid on cleavage rate (Fig. 1A) but addition of follicular fluid to a final concentration of $10 \%$ increased development to the blastocyst stage, whether expressed as percent oocytes becoming blastocysts (Fig. 1B; $\mathrm{P}=0.0058$ ) or percent cleaved embryos becoming blastocyst (Fig. 1C; $\mathrm{P}=0.0234)$. The temperature by heat shock interaction approached significance for percent 
263 oocytes becoming blastocysts $(\mathrm{P}=0.0788)$. The interaction resulted because the reduction in

264 development caused by heat shock was greater for oocytes cultured with vehicle than for oocytes

265 cultured with follicular fluid.

266

267

268

269

270

271

272

\section{Characterization of exosomes}

Nanoparticle tracking analysis was performed on 4 separate exosome samples using a NanoSight NS300 system. As shown for the representative analysis of a sample (Fig. 3A), the majority of particles present were less than $300 \mathrm{~nm}$ in diameter and can be classified as exosomes. The concentration of exosomes for each preparation varied between 1 and $5 \times 10^{11}$ particles $/ \mathrm{mL}$. Western blot analysis confirmed that the exosomal marker flotillin-1 was detected in each of the four exosomal preparations (Fig. 3B).

Identification of proteins in each of four preparations of exosomes was determined by mass spectrometry. The total number of proteins with at least 1 spectral count ranged from 869 to 1059. The number of proteins found in each sample with a minimum of 20 spectral counts was 77, 94, 82 and 83 for each individual sample. Information on proteins detected in each of the four samples of exosomes is presented in Supplementary File S1.

There were 71 proteins with spectral count $\geq 20$ that were present in all four samples; the identity and mean spectral count for these proteins as well as gene ontologies are listed in Supplemental File S2. The biological process ontologies containing the most proteins were cellular process and biological regulation, the cellular component ontologies containing the most proteins were extracellular region part and cell part and the molecular function containing the most proteins was binding. Many proteins found in plasma were identified including several serine proteinase inhibitors, complement proteins, fibrinogens, inter- $\alpha$-trypsin inhibitor heavy chains, and immunoglobulin proteins as well as $\alpha 2$-macroglobulin, apolipoprotein A1, albumin, 
286 serotransferrin, vitamin D binding protein and vitronectin. Three heat shock proteins were

287 present (heat shock protein $27 \mathrm{kDa}$ protein 1, heat shock cognate $71 \mathrm{kDa}$ protein and clusterin).

288 Proteins involved in cytoskeleton that were identified included several tubulin proteins and gelsolin. The trafficking molecule clathrin heavy chain was identified as was the transmembrane protein prostaglandin F2 receptor inhibitor. Proteins involved in cell adhesion included vitronectin and lactadherin.

The effect of follicular fluid exosomes on cumulus cell expansion of bovine oocytes exposed to heat-shocked

Exposure of COC to heat shock reduced $(\mathrm{P}=0.001)$ cumulus cell expansion (Fig. 3). Addition of either follicular fluid or exosomes increased cumulus cell expansion compared to vehicle $(\mathrm{P}=0.053)$. There was, however, no interaction between temperature and treatment.

The effect of follicular fluid and follicular fluid exosomes to reduce effects of heat shock on developmental competence of oocytes

As shown in Fig. 4A, cleavage rate was reduced by heat shock $(\mathrm{P}=0.0149)$ and was higher for oocytes cultured with either follicular fluid or exosomes than for oocytes cultured with vehicle (vehicle vs follicular fluid + exosomes, $\mathrm{P}=0.063$ ). Moreover, the effect of heat shock was reduced by both follicular fluid and exosomes (temperature $\mathrm{x}$ vehicle vs follicular fluid + exosomes, $\mathrm{P}=0.0098)$.

Heat shock also reduced development to the blastocyst stage, whether expressed as percent of oocytes becoming blastocysts (Fig. 4B; $\mathrm{P}=0.048$ ) or percent of cleaved oocytes (Fig. $4 \mathrm{C} ; \mathrm{P}=0.062)$. Overall, development of oocytes $(\mathrm{P}=0.019)$ or cleaved oocytes $(\mathrm{P}=0.052)$ to the blastocyst stage was higher for oocytes treated with follicular fluid or exosomes than oocytes treated with vehicle. Interactions between temperature and treatment were not significant but 
analysis of differences between individual means using pdiff indicated that heat shock reduced the percent of oocytes becoming blastocysts for oocytes treated with vehicle $(\mathrm{P}=0.0068)$ and follicular fluid ( $\mathrm{P}=0.080)$ but not for oocytes treated with exosomes (Fig. 4B). Similar results were found for percent of cleaved embryos becoming blastocysts. Heat shock reduced development for oocytes treated with vehicle $(\mathrm{P}=0.014)$ but not for oocytes treated with follicular fluid or exosomes.

Expression of NANOG and SOX2 in blastocysts derived from oocytes of each treatment was examined to determine effects of temperature and treatment on selected genes important for pluripotency of the blastocyst. Overall, there was no effect of temperature or treatment on transcript abundance of NANOG (Fig. 5A). There was, however, an interaction between temperature and the comparison of vehicle vs follicular fluid + exosomes $(\mathrm{P}=0.058)$. This interaction resulted because heat shock reduced $N A N O G$ expression for blastocysts from oocytes treated with exosomes only $(\mathrm{P}=0.060)$. There were no effects of temperature or treatment on expression of SOX2 (Fig. 5B).

\section{Exosome uptake}

Cumulus-oocytes complexes were incubated with labelled exosomes for up to $22 \mathrm{~h}$ during oocyte maturation to determine whether cumulus cells or oocytes take up exosomes (Fig. 6). There was no specific labelling of cumulus cells with exosomes after $0.5 \mathrm{~h}$ of incubation (note the nonspecific red fluorescence in panel A than it similar in intensity to fluorescence in cumulus cells incubated without labelled exosomes in panel E). Thereafter, however, labelled spherical structures were associated with cumulus cells, at $1 \mathrm{~h}$ (Fig. 6B), $14 \mathrm{~h}$ (Fig. 6C) and $22 \mathrm{~h}$ (Fig. 6D). In contrast, there was no association of labelled exosomes with oocytes at any time (Fig. 6F). Further analysis of labelling of individual cumulus cell by tracing labelling through Z-stack 
332 sections indicated that labelled exosomes could be identified inside the cell including adjacent to 333 the nucleus (Fig. 7).

\section{Discussion}

335 Communication between cellular constituents of the ovarian follicle and between the follicle and other organs, is essential for the follicle to achieve its twin goals of steroid hormone secretion and production of an oocyte capable of fertilization and supporting subsequent embryonic development (Monniaux, 2016; Russell et al., 2016; LaVoie, 2017). It has been shown previously that addition of follicular fluid to oocyte maturation medium can increase cumulus cell expansion, reduce cumulus cell apoptosis, increase competence of the oocytes to be fertilized and develop to the blastocyst stage, and protect the oocyte from heat shock (Rodrigues et al., 2015; Grupen and Armstrong, 2010; Somfai et al., 2012). Similar effects of follicular fluid were observed in present study. Moreover, it is likely that this property of follicular fluid resides, at least in part, in the exosomal fraction of the fluid. In particular, exosomes isolated from follicular fluid from small follicles acted on the COC during oocyte maturation to enhance cumulus cell expansion and increase competence of the oocyte to cleave after fertilization and to support development to the blastocyst stage. Moreover, exosomes could reduce consequences of exposure of the COC to heat shock with respect to effects on cleavage rate and development of embryos to the blastocyst stage. Taken together, results support the idea that exosomes in follicular fluid play important roles during oocyte maturation to enhance oocyte function and protect it from stress. One practical implication is that exosomes may prove useful in enhancing outcomes of embryo production systems in vitro.

It is likely that exosomes affect oocyte function not by acting directly on the oocyte but rather by affecting function of associated cumulus cells. Indeed, as has been reported previously 
355 (Hung et al., 2015), cumulus cells but not oocytes took up labelled exosomes derived from

356 follicular fluid. The uptake of exosomes is performed by endocytosis or membrane fusion

357 (Mulcahy et al., 2014) and the endocytic capacity of the oocyte is reduced after zona pellucida formation (Fair et al., 1997). Additional evidence that exosomes were acting on cumulus cells was the finding that exosomes increased cumulus cell expansion during maturation. Similar effects of follicular-fluid derived exosomes on cumulus cell expansion have been reported in cattle (Hung et al., 2015) and pigs (Matsuno et al., 2017).

It is likely that the effects of exosomes on oocyte competence are not due directly to the effect on cumulus expansion. In mice, genetic models in which cumulus expansion is compromised is associated with normal fertilization and embryonic development (Ploutarchou et al., 2015; Bertolin et al., 2017). Other reported effects of exosomes on cumulus cell function during maturation include alterations in gene expression (Hung et al., 2015) and it is possible that regulation of cumulus gene expression by exosomes results in downstream improvements in oocyte function.

In addition to improving cumulus cell expansion and oocyte competence for fertilization, treatment with exosomes increased the resistance of the COC to heat shock. In particular, the negative effects of heat shock on cleavage rate and development to the blastocyst stage, although not cumulus cell expansion, were reduced in COC cultured with either follicular fluid or exosomes. Such a result points to a physiological role for exosomes in follicular fluid to protect the oocyte during maturation from disruption by elevated body temperature (Putney et al., 1988). The cytoprotective effects of follicular fluid exosomes are probably not limited to heat shock but extend to other stresses as well. This conclusion is based on recent results regarding oxidative stress (Guay and Regazzi, 2017). In particular, bovine granulosa cells exposed to 
hydrogen peroxide released exosomes into the culture medium that were enriched for mRNA encoding for genes involved in antioxidant defense such as NRF2, CAT and TXN1. Incubation of granulosa cells with exosomes secreted from cells subjected to oxidative stress resulted in uptake of the exosomes, increased transcript abundance for NRF2, PRDX1, CAT and TXN1, and reduced effects of hydrogen peroxide on reactive oxygen species content, mitochondrial activity, cell cycle and cell proliferation.

Exosomes have been implicated in communication between organs through secretion into blood (Guay and Regazzi, 2017; Fleshner and Crane, 2017) and some follicular fluid exosomes are probably produced outside the follicle. However, the composition of exosomes in follicular fluid differs from exosomes in blood in women (Santonocito et al., 2014) and local sources of exosomes include granulosa cells (Saeed-Zidane et al., 2017; Vashisht et al., 2018). The oocyte has also been reported to produce exosomes (Barraud-Lange et al., 2012; Benammar et al., 2017) although it is not known whether oocyte-derived exosomes cross the zona pellucida. The molecular pathways by which exosomes affect $\mathrm{COC}$ to improve oocyte competence and thermotolerance remain to be determined. Exosomes can transport mRNA, microRNA, long non-coding RNAs, mitochondrial DNA, proteins and phospholipids (Choi et al., 2013; DiPietro, 2016), any of which could conceivably affect cumulus cell function. There is evidence for exosome-mediated delivery of microRNA (Sohel et al., 2013) and mRNA (Guay and Regazzi, 2017) to bovine granulosa cells and evidence that exosome-delivered microRNA can change abundance of mRNA targeted by the microRNA (Sohel et al., 2013). Exosome-derived microRNA are also involved in mediating regulation of granulosa cell proliferation (Hung et al., 2017). Among the proteins present in exosomes were two heat shock proteins that confer 
400 thermotolerance - heat shock protein 27 (carper et al., 1997; Doerwald et al., 2003; Shi et al., 4012011 ) and heat shock cognate $71 \mathrm{kDa}$ protein (Ciavarra et al., 1994). Overall, the protein composition of the exosomes isolated from bovine follicular fluid for

403

404

405

406

407

408

409

410

411

412

413

414

415

416

417 the current experiments was comparable to that of exosomes isolated from fluid of dominant follicles from the mare (da Silveira et al., 2012). Most similar was a predominance of proteins characteristic of plasma and other extracellular fluids. In addition, several intracellular or membrane proteins found in exosomes from other fluids were identified in follicular fluid exosomes. These included clathrin heavy chain, heat shock cognate $71 \mathrm{kDa}$, gelsolin, lactadherin, and several tubulin proteins (Hegmans et al., 2004; Conde-Vancells et al., 2008; da Silveira et al., 2012; Dang et al., 2017).

The expression of NANOG and SOX2 in blastocysts was measured to ascertain whether blastocyst characteristics were altered by treatment of the oocytes from which they were derived. There were no consistent effects of follicular fluid, exosomes or heat shock on expression of either of these two pluripotency genes. The lack of effect of oocyte heat shock on gene expression of the resultant blastocysts is consistent with studies showing no difference in blastocyst cell number between blastocysts derived from control or heat-shocked oocytes (Roth and Hansen, 2004ab; Lima et al., 2017; Ascari et al., 2017) although there is at least one report that cell number of blastocysts is reduced by oocyte heat shock (Rodrigues et al., 2016). The current experiments were performed using follicular fluid from small follicles. However, the events studied here occur during oocyte maturation when the COC is enclosed in a large preovulatory follicle. It is possible that the exosomes exerting effects seen here are absent or present in reduced amounts in follicular fluid from large preovulatory follicles. Indeed, concentration of exosomes in follicular fluid of the cow decreases as follicles increase in size and 
423 there are concomitant changes in the exosomal microRNA content (Navakanitworakul et al.,

424 2016). Moreover, exosomes from small follicles are taken up more readily by granulosa cells

425 than exosomes from large follicles (Hung et al., 2017).

\section{Acknowledgements}

427 The authors thank Florida Beef Inc., Wauchula, Florida, for donating ovaries; Eddie Cummings,

428 for collection of ovaries; and Dra. Flávia R. de Oliveira Barros, for initial discussions leading to

429 these experiments.

\section{Conflict of Interest}

431 The authors declare no conflicts of interest.

432 


\section{References}

Ascari, I.J., Alves, N.G., Jasmin, J., Lima, R.R., Quintão, C.C.R., Oberlender, G., Moraes, E.A., and Camargo, L.S.A. (2017). Addition of insulin-like growth factor I to the maturation medium of bovine oocytes subjected to heat shock: effects on the production of reactive oxygen species, mitochondrial activity and oocyte competence. Domest. Anim. Endocrinol. 60, $50-60$.

Barraud-Lange, V., Chalas Boissonnas, C., Serres, C., Auer, J., Schmitt, A., Lefèvre, B., Wolf, J.P., and Ziyyat, A. (2012). Membrane transfer from oocyte to sperm occurs in two CD9-independent ways that do not supply the fertilising ability of CD9-deleted oocytes. Reproduction 144, 53-66.

Benammar, A., Ziyyat, A., Lefèvre, B., and Wolf, J.P. (2017). Tetraspanins and mouse oocyte microvilli related to fertilizing ability. Reprod. Sci. 24, 1062-1069.

Bertolin, K., Meinsohn, M.C., Suzuki, J., Gossen, J., Schoonjans, K., Duggavathi, R., and Murphy, B.D. (2017). Ovary-specific depletion of the nuclear receptor Nr5a2 compromises expansion of the cumulus oophorus but not fertilization by intracytoplasmic sperm injection. Biol. Reprod. 96, 1231-1243.

Carper, S.W., Rocheleau, T.A., Cimino, D., and Storm, F.K. (1997). Heat shock protein 27 stimulates recovery of RNA and protein synthesis following a heat shock. J. Cell Biochem. 66, $153-164$.

Ciavarra, R.P., Goldman, C., Wen, K.K., Tedeschi, B., and Castora, F.J. (1994). Heat stress induces hsc70/nuclear topoisomerase I complex formation in vivo: evidence for hsc70mediated, ATP-independent reactivation in vitro. Proc. Natl. Acad. Sci. USA 91, 1751-1755. 
Choi, D.S., Kim, D.K., Kim, Y.K., and Gho, Y.S. (2013). Proteomics, transcriptomics and lipidomics of exosomes and ectosomes. Proteomics 13, 1554-1571. comprehensive proteome profiling of exosomes secreted by hepatocytes. J. Proteome Res 7, 5157-5166.

da Silveira, J.C., Andrade, G.M., Del Collado, M., Sampaio, R.V., Sangalli, J.R., Silva, L.A., Pinaffi, F.V.L., Jardim, I.B., Cesar, M.C., Nogueira, M.F.G., Cesar, A.S.M., Coutinho, L.L., Pereira, R.W., Perecin, F., and Meirelles, F.V. (2017). Supplementation with smallextracellular vesicles from ovarian follicular fluid during in vitro production modulates bovine embryo development. PLoS One 12, e 0179451.

da Silveira, J.C., Veeramachaneni, D.N., Winger, Q.A., Carnevale, E.M., and Bouma, G.J. 2012. Cell-secreted vesicles in equine ovarian follicular fluid contain miRNAs and proteins: a possible new form of cell communication within the ovarian follicle. Biol. Reprod. 86, 71. Dalenezi, F.M., and Ferreira, J.C.P. (2016). Gene expression of in vitro maturated oocytes can be modulated by follicle exosomes from cows kept under thermo-neutral or heat- stress condition. Vet Zootech 23, 54 (abstr.). and proteomic analysis of exosomes from mouse cortical collecting duct cells. FASEB J. 31, 5399-5408. 
de Castro E Paula, L.A., and Hansen, P.J. (2007). Interactions between oxygen tension and glucose concentration that modulate actions of heat shock on bovine oocytes during in vitro maturation. Theriogenology 68, 763-770.

Di Pietro, C. (2016). Exosome-mediated communication in the ovarian follicle. J. Assist. Reprod. Genet. 33, 303-311.

Doerwald, L., Onnekink, C., van Genesen, S.T., de Jong, W.W., and Lubsen, N.H. (2003). Translational thermotolerance provided by small heat shock proteins is limited to capdependent initiation and inhibited by 2-aminopurine. J. Biol. Chem. 278, 49743-49750.

Fair, T., Hulshof, S.C., Hyttel, P., Greve, T., and Boland, M. (1997). Oocyte ultrastructure in bovine primordial to early tertiary follicles. Anat. Embryol. (Berl.) 195, 327-336.

Flamenbaum, I., and Galon, N. (2010). Management of heat stress to improve fertility in dairy cows in Israel. J. Reprod. Dev. 56 Suppl, S36-41.

Fleshner, M., and Crane, C.R. (2017). Exosomes, DAMPs and miRNA: Features of stress physiology and immune homeostasis. Trends Immunol. 38, 768-776.

Goossens, K., Van Poucke, M., Van Soom, A., Vandesompele, J., Van Zeveren, A., and Peelman, L.J. (2005). Selection of reference genes for quantitative real-time PCR in bovine preimplantation embryos. BMC Dev. Biol. 5, 27.

Grupen, C.G., and Armstrong, D.T. (2010). Relationship between cumulus cell apoptosis, progesterone production and porcine oocyte developmental competence: temporal effects of follicular fluid during IVM. Reprod. Fertil. Dev. 22, 1100-1109. 
Guay, C., and Regazzi, R. (2017). Exosomes as new players in metabolic organ cross-talk. Diabetes Obes. Metab. 19 Suppl 1, 137-146.

Hansen, P.J. (2009). Effects of heat stress on mammalian reproduction. Philos. Trans. R. Soc. Lond. B Biol. Sci. 364, 3341-3350.

Hegmans, J.P., Bard, M.P., Hemmes, A., Luider, T.M., Kleijmeer, M.J., Prins, J.B., Zitvogel, L., Burgers, S.A., Hoogsteden, H.C., and Lambrecht, B.N. (2004). Proteomic analysis of exosomes secreted by human mesothelioma cells. Am. J. Pathol. 164, 1807-1815.

Hung, W.T., Hong, X., Christenson, L.K., and McGinnis, L.K. (2015). Extracellular vesicles from bovine follicular fluid support cumulus expansion. Biol. Reprod. 93, 117.

Hung, W.T., Navakanitworakul, R., Khan, T., Davis, J.S, McGinnis, L.K., and Christenson, L.K. (2017). Stage-specific follicular extracellular vesicle uptake and regulation of bovine granulosa cell proliferation. Biol. Reprod. 97, 644-655.

Ispada, J., Rodrigues, T.A., Risolia, P.H.B., Lima, R.S., Gonçalves, D.R., Rettori, D., Nichi, M., Feitosa, W.B., and Paula-Lopes, F.F. (2018). Astaxanthin counteracts the effects of heat shock on the maturation of bovine oocytes. Reprod. Fertil. Dev. 2018; in press.

$$
\text { Jella, K.K., Yu, L., Yue, Q., Friedman, D., Duke, B.J., and Alli, A.A. (2016). Exosomal }
$$
GAPDH from proximal tubule cells regulate ENaC activity. PLoS One 11, e0165763. Kannampuzha-Francis, J., Tribulo, P., and Hansen, P.J. (2017). Actions of activin A, connective tissue growth factor, hepatocyte growth factor and teratocarcinoma-derived growth factor 1 on the development of the bovine preimplantation embryo. Reprod. Fertil. Dev. 29, 1329-1339. 
516 LaVoie, H.A. (2017). Transcriptional control of genes mediating ovarian follicular growth,

517 differentiation, and steroidogenesis in pigs. Mol. Reprod. Dev. 84, 788-801.

518 Lima, R.S., Risolia, P.H., Ispada, J., Assumpção, M.E., Visintin, J.A., Orlandi, C., Paula-

519 Lopes, F.F. (2017). Role of insulin-like growth factor 1 on cross-bred Bos indicus cattle

520 germinal vesicle oocytes exposed to heat shock. Reprod. Fertil. Dev. 29, 1405-1414.

521 Matsuno, Y., Onuma, A., Fujioka, Y.A., Yasuhara, K., Fujii, W., Naito, K., and Sugiura, K.

522 (2017). Effects of exosome-like vesicles on cumulus expansion in pigs in vitro. J. Reprod.

523 Dev. 63, 51-58.

Mehlmann, L.M. (2005). Stops and starts in mammalian oocytes: recent advances in understanding the regulation of meiotic arrest and oocyte maturation. Reproduction 130, 791799.

Monniaux, D. (2016). Driving folliculogenesis by the oocyte-somatic cell dialog: Lessons from genetic models. Theriogenology 86, 41-53.

Mulcahy, L.A., Pink, R.C., and Carter, D.R. (2014). Routes and mechanisms of extracellular vesicle uptake. J. Extracell. Vesicles 4, 3.

Nabenishi, H., Ohta, H., Nishimoto, T., Morita, T., Ashizawa, K., and Tsuzuki, Y. (2012). The effects of cysteine addition during in vitro maturation on the developmental competence, ROS, GSH and apoptosis level of bovine oocytes exposed to heat stress. Zygote 20, 249-259. in follicular fluid of developing bovine antral follicles. Sci. Rep. 6, 25486. 
537 Nesvizhskii, A.I., Keller, A., Kolker, E., and Aebersold, R. (2003). A statistical model for 538 identifying proteins by tandem mass spectrometry. Anal. Chem. 75, 4646-4658. M.V., and Hansen, P.J. (2017). A single nucleotide polymorphism in COQ9 affects mitochondrial and ovarian function and fertility in Holstein cows. Biol. Reprod. 96, 652-663. (2012). Importance of culture conditions during the morula-to-blastocyst period on capacity of inner cell-mass cells of bovine blastocysts for establishment of self-renewing pluripotent cells. Theriogenology 78, 1243-1251.

Ploutarchou, P., Melo, P., Day, A.J., Milner, C.M., and Williams, S.A. (2015). Molecular analysis of the cumulus matrix: insights from mice with O-glycan-deficient oocytes. Reproduction 149, 533-543.

Putney, D.J., Drost, M., and Thatcher, W.W. (1988).Embryonic development in superovulated dairy cattle exposed to elevated ambient temperatures between the onset of estrus and insemination. Theriogenology 30,195-209. Visintin, J.A., and Paula-Lopes, F.F. (2016). Thermoprotective effect of insulin-like growth factor 1 on in vitro matured bovine oocyte exposed to heat shock. Theriogenology 86, 20282039.

Rodrigues, T.A., Orlandi, C.M.B., Gonçalves, D.R., Silva, D.F., and Paula-Lopes, F.F. (2015). Follicular fluid thermoprotective role during in vitro maturation of bovine oocytes subjected to heat shock. Anim. Reprod. 12, 776 (abstr.). 
Roth, Z., and Hansen, P.J. (2005). Disruption of nuclear maturation and rearrangement of

560 cytoskeletal elements in bovine oocytes exposed to heat shock during maturation.

561 Reproduction $129,235-244$.

Roth, Z., and Hansen, P.J. (2004a). Involvement of apoptosis in disruption of developmental competence of bovine oocytes by heat shock during maturation. Biol. Reprod. 71, 18981906.

Roth, Z., and Hansen, P.J. (2004b). Sphingosine 1-phosphate protects bovine oocytes from heat shock during maturation. Biol. Reprod. 71, 2072-2078.

Russell, D.L., Gilchrist, R.B., Brown, H.M., and Thompson, J.G. (2016). Bidirectional communication between cumulus cells and the oocyte: Old hands and new players? Theriogenology 86, 62-68.

Saeed-Zidane, M., Linden, L., Salilew-Wondim, D., Held, E., Neuhoff, C., Tholen, E., Hoelker, M., Schellander, K., and Tesfaye, D. (2017). Cellular and exosome mediated molecular defense mechanism in bovine granulosa cells exposed to oxidative stress. PLoS One 12, e0187569.

Santonocito, M., Vento, M., Guglielmino, M.R., Battaglia, R., Wahlgren, J., Ragusa, M., Barbagallo, D., Borzì, P., Rizzari, S., Maugeri, M., Scollo, P., Tatone, C., Valadi, H., Purrello, M., and Di Pietro, C. (2014). Molecular characterization of exosomes and their microRNA cargo in human follicular fluid: bioinformatic analysis reveals that exosomal 1761. 
Shi, Y., Nishida, K., Campigli Di Giammartino, D., and Manley, J.L. (2011). Heat shockinduced SRSF10 dephosphorylation displays thermotolerance mediated by Hsp27. Mol. Cell Biol. 31, 458-465.

Sohel, M.M., Hoelker, M., Noferesti, S.S., Salilew-Wondim, D., Tholen, E., Looft, C., Rings, F., Uddin, M.J., Spencer, T.E., Schellander, K., and Tesfaye, D. (2013). Exosomal and nonexosomal transport of extra-cellular microRNAs in follicular fluid: Implications for bovine oocyte developmental competence. PLoS One 8, e78505. supplementation during in vitro maturation promotes sperm penetration in bovine oocytes by enhancing cumulus expansion and increasing mitochondrial activity in oocytes. Reprod. Fertil. Dev. 24, 743-752. spectrometry for shotgun proteomics. Nature Meth. 5, 959-964. Torres-Júnior, J.R. de S.., Pires, M. de F.A., de Sá. W.F., Ferreira A. de M., Viana, J.H.M., Camargo, L.S., Ramos, A.A., Folhadella, I.M., Polisseni, J., de Freitas, C., Clemente, C.A., de Sá Filho, M.F., Paula-Lopes, F.F., and Baruselli, P.S. (2008). Effect of maternal heatstress on follicular growth and oocyte competence in Bos indicus cattle. Theriogenology $\mathbf{6 9}$, 155-166. 
600 Urbanelli, L., Magini, A., Buratta, S., Brozzi, A., Sagini, K., Polchi, A., Tancini, B., and 601 Emiliani, C. (2013). Signaling pathways in exosomes biogenesis, secretion and fate. Genes $602 \quad$ (Basel) 4, 152-170.

603 Vashisht, M., Rani, P., Sunita, Onteru, S.K., and Singh, D. (2018). Curcumin primed 604 exosomes reverses LPS-induced pro-inflammatory gene expression in buffalo granulosa $605 \quad$ cells. J. Cell Biochem. 119, 1488-1500.

606 
607

608 Fig. 1. The effect of follicular fluid on developmental competence of oocytes matured at 38.5

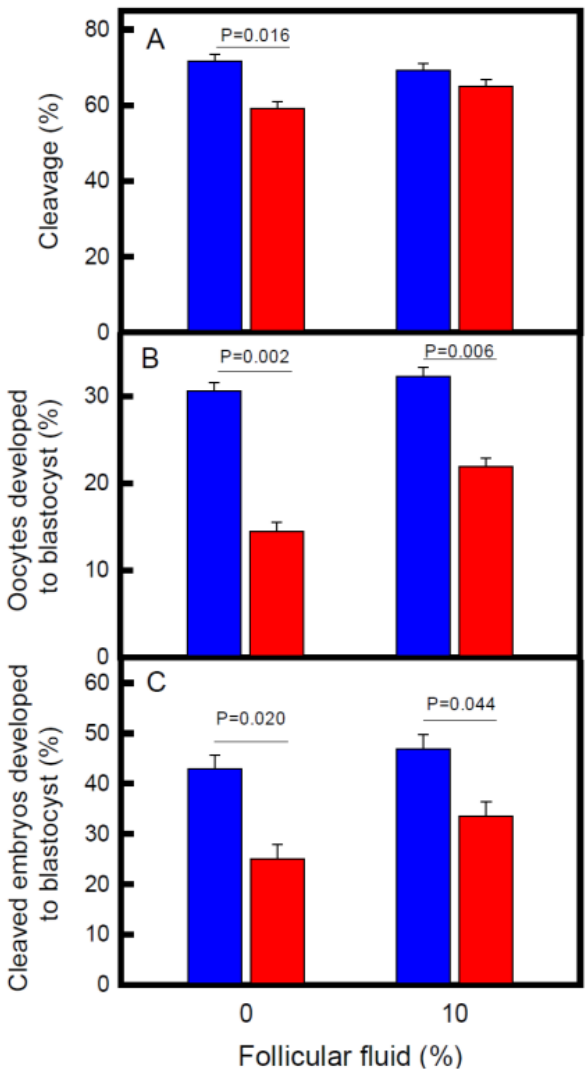

609 (blue) or $41^{\circ} \mathrm{C}$ (red). After maturation, oocytes were fertilized and allowed to develop until day

6107.5 after insemination. Results are least-squares means \pm SEM of 4 replicates using 210-222

611 oocytes/treatment. Lines over pairs of bars represent effects of heat shock for an individual

612 treatment - temperature combination. In addition, analysis of variance indicated that maturation

613 at $41^{\circ} \mathrm{C}$ reduced cleavage rate (panel $\mathrm{A} ; \mathrm{P}=0.019$ ) and the percent of oocytes (panel $\mathrm{B}$;

$614 \mathrm{P}=0.0015$ ) and cleaved embryos (panel $\mathrm{C} ; \mathrm{P}=0.0043$ ) that developed to the blastocyst stage.

615 Addition of $10 \%$ follicular fluid increased development to the blastocyst stage, whether

616 expressed as percent oocytes becoming blastocysts (panel $\mathrm{B} ; \mathrm{P}=0.0058$ ) or percent cleaved

617 embryos becoming blastocyst (Fig. $1 \mathrm{C} ; \mathrm{P}=0.0234$ ). The temperature by heat shock interaction

618 approached significance for percent oocytes becoming blastocysts $(\mathrm{P}=0.0788)$. There was a temperature effect $(\mathrm{P}<0.05)$ on the percentage of embryos cleaved. 
A

E11

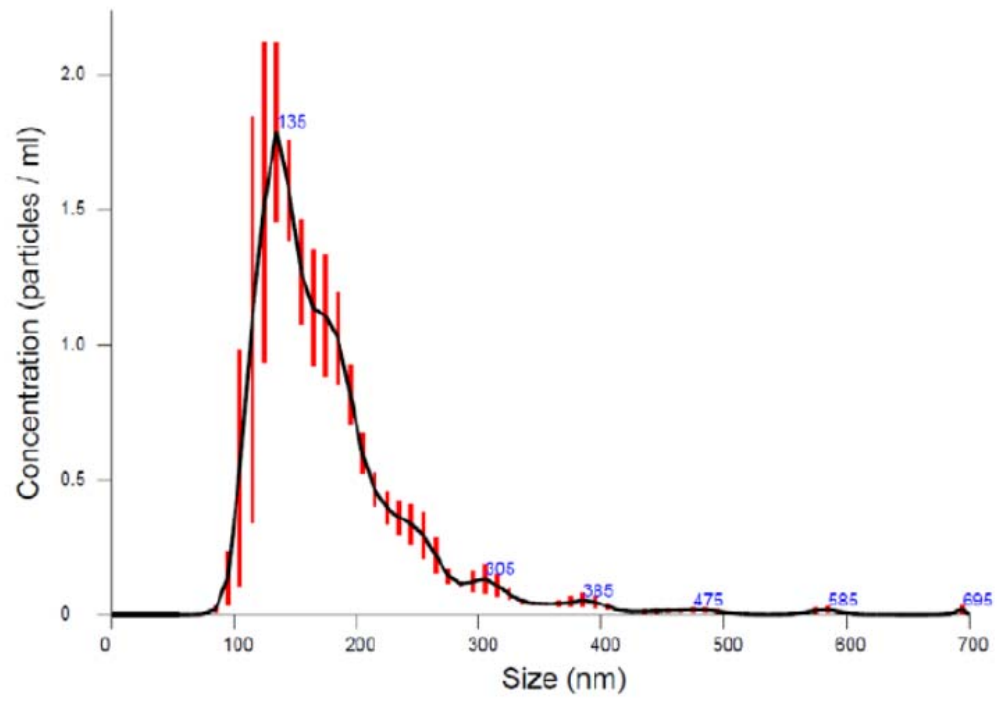

B

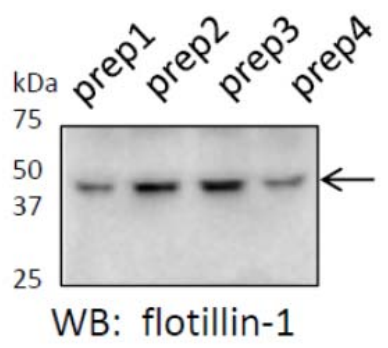

620

621

622 Fig. 2. Characterization of follicular fluid exosomes. A. Representative analysis of an exosomal 623 preparations by Nanosight $(n=4)$ showing the concentration of follicular fluid exosomes in 624 particles per $\mathrm{mL}$ and the diameter of the exosomes in nanometers $(\mathrm{nm})$. The sample was 625 analyzed in triplicate and red lines are standard error bars. Peaks are indicated by blue numbers.

626 B. Western blot analysis of the four exosome preparations (prep1-prep4) used in the 627 experiments. 


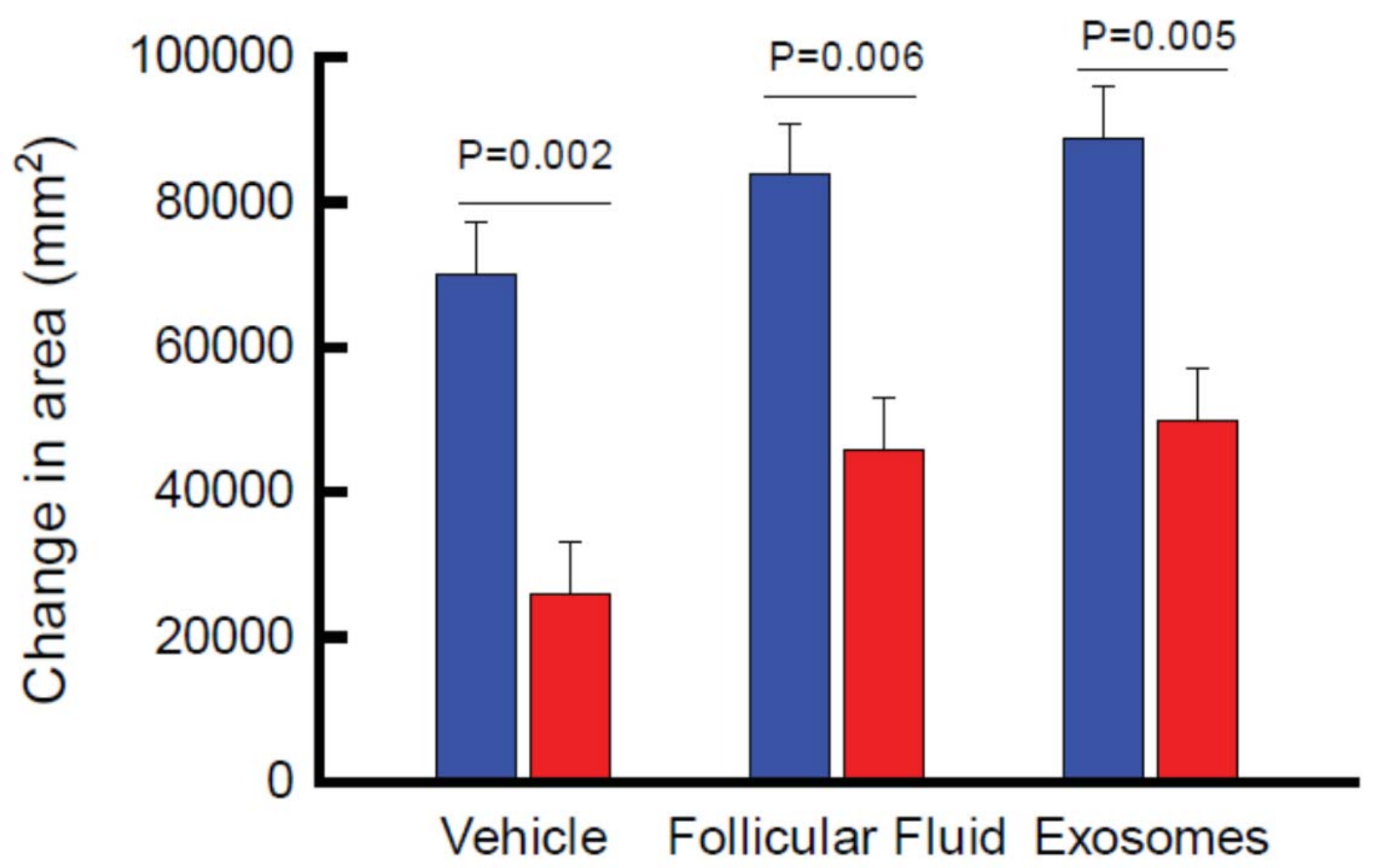

629

630 Fig. 3. The effect of follicular fluid and exosomes added during maturation on cumulus

631 expansion in cumulus-oocyte complexes (COC) matured at 38.5 (blue) or $41^{\circ} \mathrm{C}$ (red). The

632 increase in mean surface area of COCs after maturation was determined by subtracting mean

633 surface area before maturation from mean surface area after maturation. The experiment was

634 replicated 5 times using a total of 119 - 122 cumulus-oocyte complexes/treatment. Results are

635 least-squares means \pm SEM. Lines over pairs of bars represent effects of heat shock for an

636 individual treatment - temperature combination. In addition, analysis of variance indicated that

637 maturation at $41^{\circ} \mathrm{C}$ reduced $(\mathrm{P}=0.001)$ cumulus cell expansion. Addition of either follicular fluid

638 or exosomes increased cumulus cell expansion compared to vehicle $(\mathrm{P}=0.053)$. There was,

639 however, no interaction between temperature and treatment. 


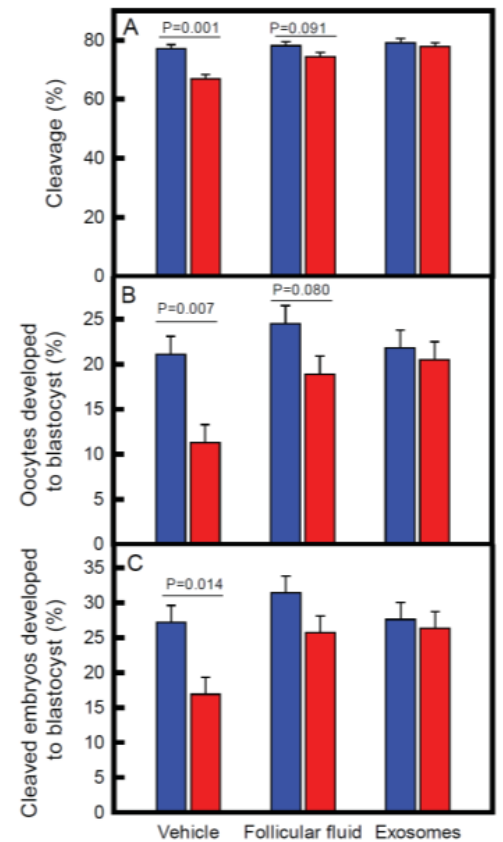

642 Fig. 4. The effect of follicular fluid and exosomes on developmental competence of oocytes 643 matured at 38.5 (blue) or $41{ }^{\circ} \mathrm{C}$ (red). After maturation, oocytes were fertilized and allowed to 644 develop until day 7.5 after insemination. Results are least-squares means \pm SEM of 6 replicates using 244-286 oocytes/treatment. Lines over pairs of bars represent effects of heat shock for an individual treatment - temperature combination. In addition, analysis of variance indicated the following effects. Cleavage rate (A) was reduced by maturation at $41^{\circ} \mathrm{C}(\mathrm{P}=0.0149)$, was higher for oocytes cultured with either follicular fluid or exosomes than for oocytes cultured with vehicle (vehicle vs follicular fluid + exosomes, $\mathrm{P}=0.063$ ) and there was an interaction between temperature and the vehicle vs follicular fluid + exosomes comparison $(\mathrm{P}=0.0098)$. The percent of oocytes that developed to the blastocyst stage (B) was affected by maturation temperature $(\mathrm{P}=0.0048)$ and the comparison of vehicle vs follicular fluid + exosomes $(\mathrm{P}=0.019)$. The percent of cleaved embryos that developed to the blastocyst stage was affected by maturation temperature $(\mathrm{P}=0.062)$ and the comparison of vehicle vs follicular fluid + exosomes $((\mathrm{P}=0.052)$. 


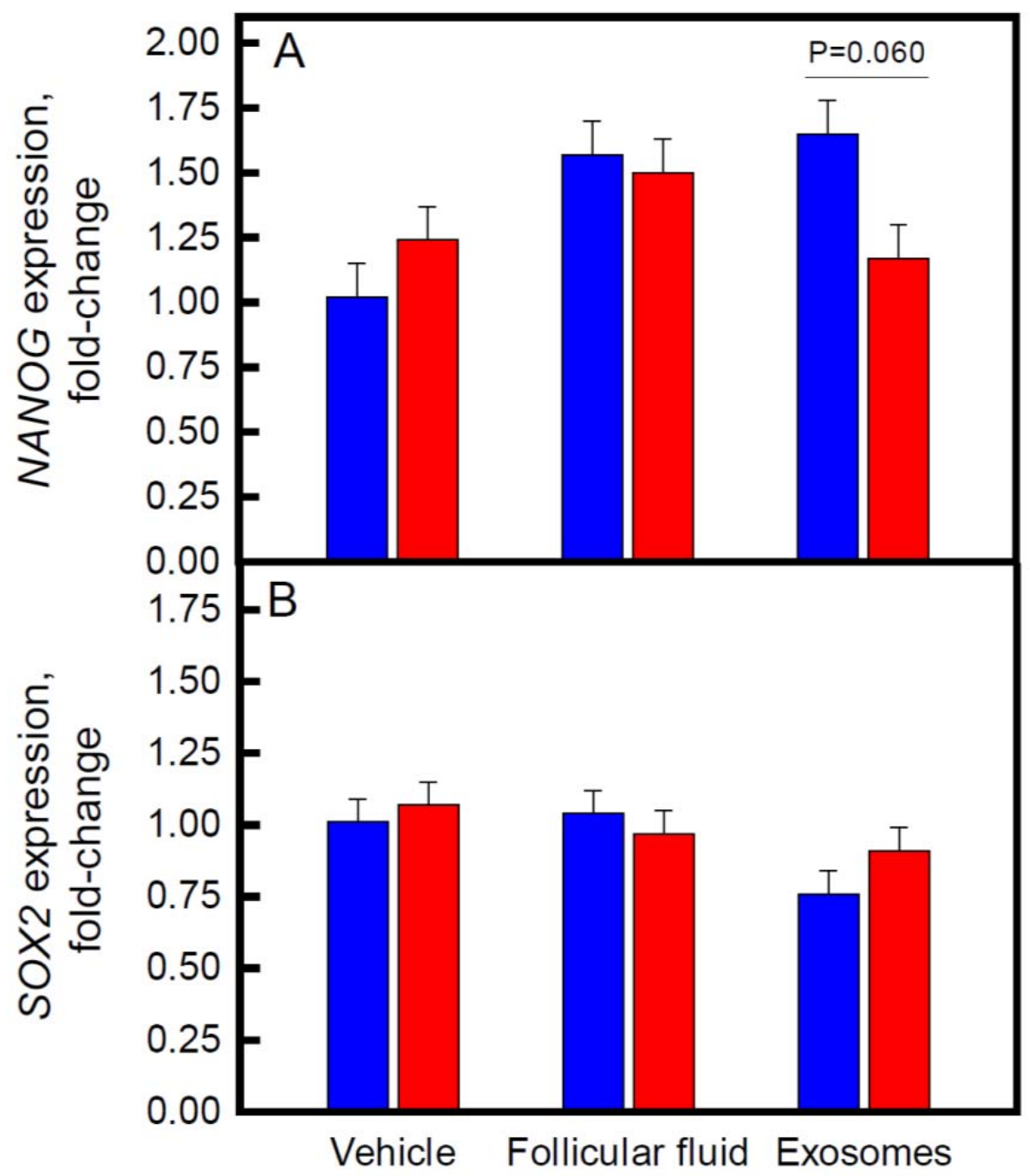

656

657 Fig. 5. Blastocyst expression of NANOG (A) and SOX2 (B) for blastocysts derived from oocytes 658 treated with follicular fluid and exosomes during oocytes maturation at 38.5 (blue) or $41^{\circ} \mathrm{C}$ (red).

659 Results are least-squares means \pm SEM of results from a total of 3 pools of 10 blastocysts/pool 660 for each treatment. The lines over one pair of bars represent effects of heat shock for the 661 follicular fluid treated group. In addition, analysis of variance indicated that NANOG expression 662 was affected by the interaction between temperature and the comparison of vehicle vs follicular 663 fluid + exosomes ( $\mathrm{P}=0.058)$. There were no significant effects of expression of SOX2. 


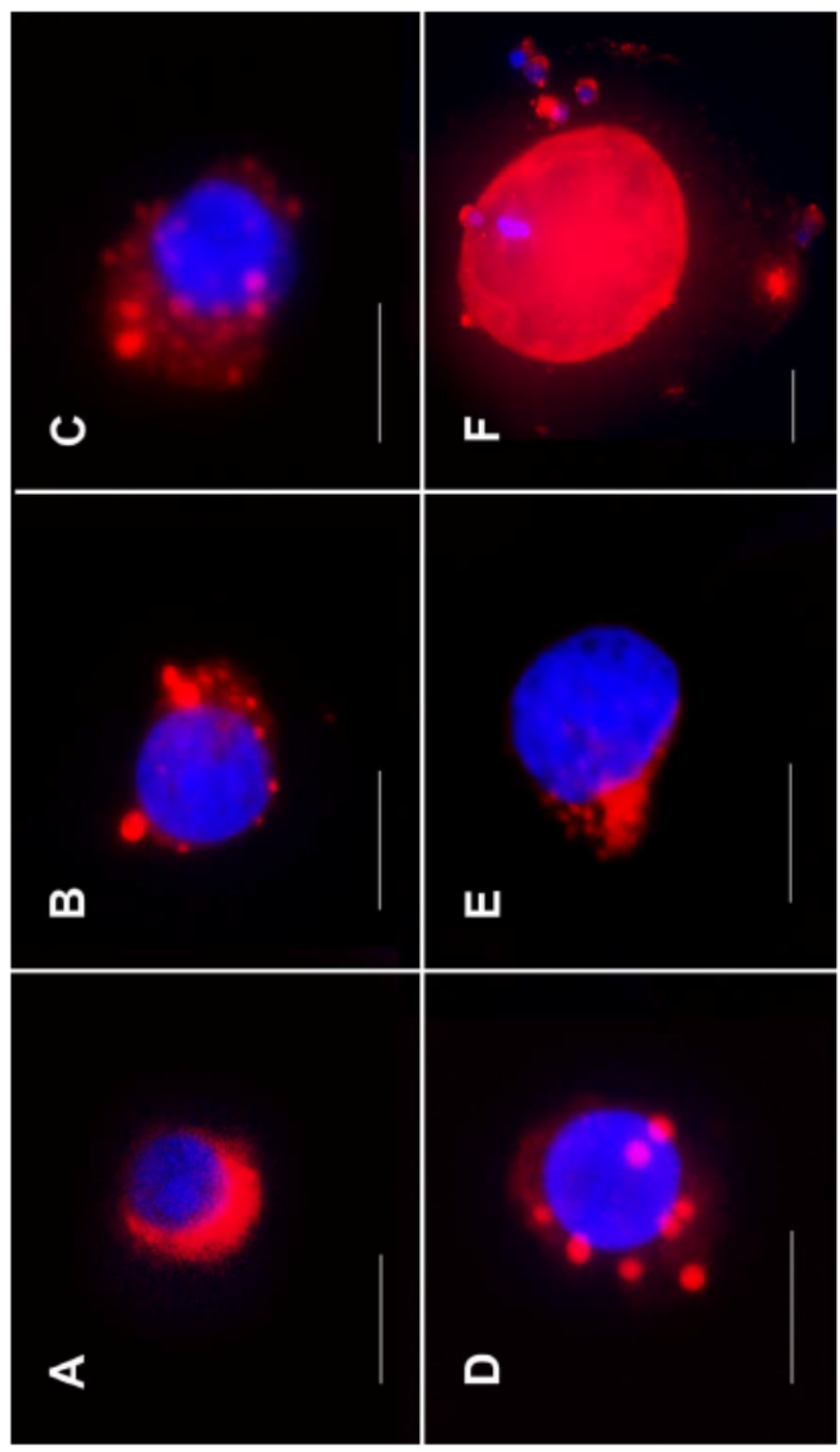

665

666 Fig. 6. Representative examples of labeling of individual cumulus cells (A-E) and the oocyte (F)

667 after incubation with exosomes labeled with BODIPY TR (red). DNA was also labeled with

668 Hoechst 33342 (blue). Images of cumulus cells were obtained after incubation for 0.5 (A), 1 (B),

66914 (C) and $22 \mathrm{~h}$ (D). Panel E represents a cumulus cell that was incubated without exosomes.

670 The oocyte in panel $\mathrm{F}$ was incubated with exosomes for $22 \mathrm{~h}$. White bars represent $10 \mu \mathrm{M}$. 
672

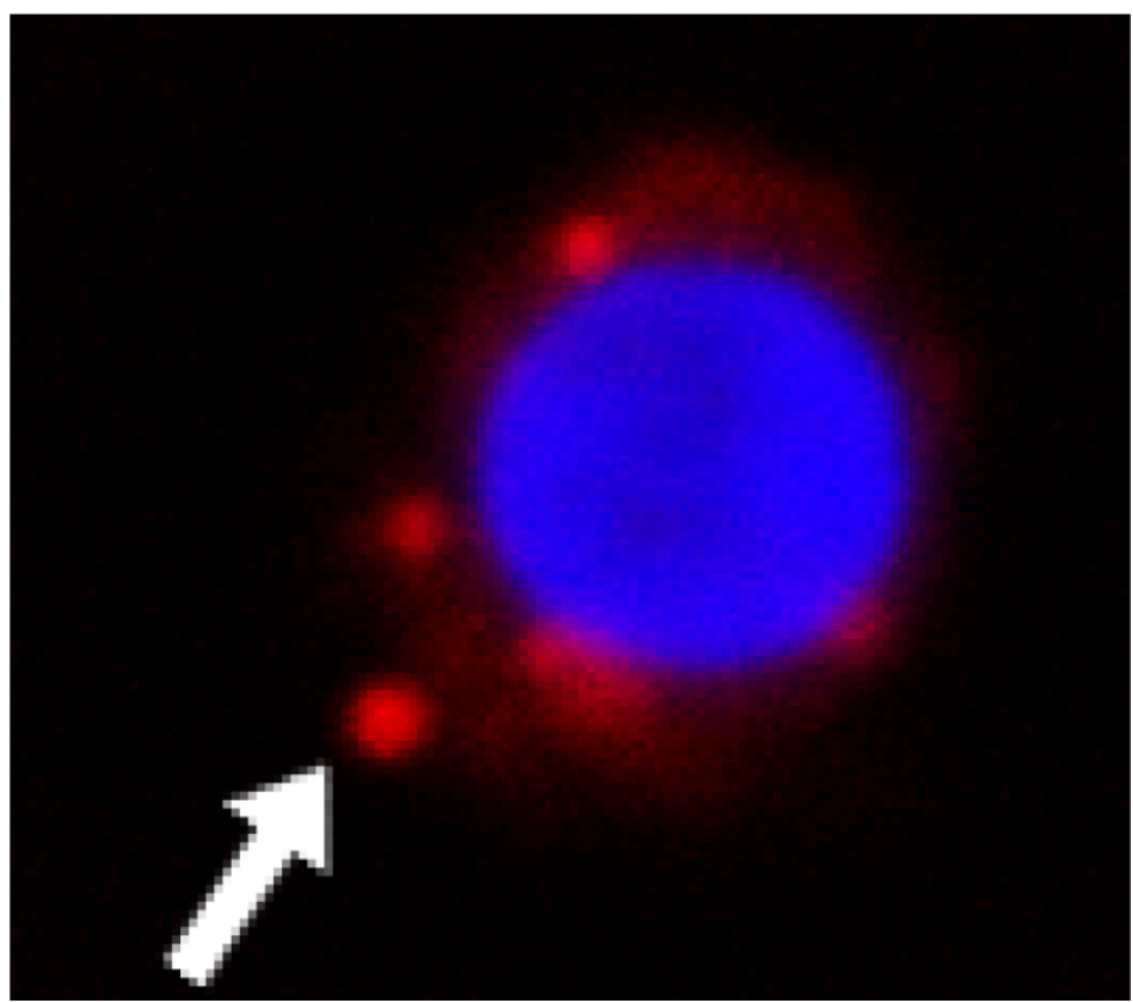

673

674 Fig. 7. Cross sections of a Z-stacked image $(0.75 \mu \mathrm{m})$ of a single cumulus cell incubated for 22

$675 \mathrm{~h}$ with exosomes labeled with BODIPY TR (red). DNA was also labeled with Hoechst 33342

676 (blue). Arrows indicate individual exosomes. White bars represent $10 \mu \mathrm{M}$.

677 
678 Supplemental File S1. Spectral counts for individual peptides and proteins identified in four 679 samples of exosomes from follicular fluid.

680 Supplemental File S2. List of most abundant proteins in exosomes isolated from follicular fluid 681 (tab 1) and their classification by gene ontology terms (tab 2). 